\title{
Examining the efficacy of parent -child interaction therapy with high -functioning autism
}

Joshua J. Masse

West Virginia University

Follow this and additional works at: https://researchrepository.wvu.edu/etd

\section{Recommended Citation}

Masse, Joshua J., "Examining the efficacy of parent -child interaction therapy with high -functioning autism" (2009). Graduate Theses, Dissertations, and Problem Reports. 2853.

https://researchrepository.wvu.edu/etd/2853

This Dissertation is protected by copyright and/or related rights. It has been brought to you by the The Research Repository @ WVU with permission from the rights-holder(s). You are free to use this Dissertation in any way that is permitted by the copyright and related rights legislation that applies to your use. For other uses you must obtain permission from the rights-holder(s) directly, unless additional rights are indicated by a Creative Commons license in the record and/ or on the work itself. This Dissertation has been accepted for inclusion in WVU Graduate Theses, Dissertations, and Problem Reports collection by an authorized administrator of The Research Repository @ WVU.

For more information, please contact researchrepository@mail.wvu.edu. 
Examining the Efficacy of Parent-Child Interaction Therapy with High-Functioning Autism

\author{
Joshua J. Masse \\ Dissertation submitted to the \\ Eberly College of Arts and Sciences \\ at West Virginia University \\ in partial fulfillment of the requirements \\ for the degree of \\ Doctor of Philosophy \\ in \\ Psychology \\ Cheryl B. McNeil, Ph.D., Chair \\ Martin L. Boone, Ph.D. \\ Steven A. Branstetter, Ph.D. \\ Tracy L. Morris, Ph.D. \\ Claire St. Peter-Pipkin, Ph.D. \\ Department of Psychology
}

Morgantown, West Virginia 2009

Keywords: Parent-Child Interaction Therapy, High-Functioning Autism, Externalizing Behaviors, Empirically-Supported Treatments. 


\begin{abstract}
Examining the Efficacy of Parent-Child Interaction Therapy with High-Functioning Autism
\end{abstract}

\author{
Joshua J. Masse
}

Externalizing behaviors are a common component of the clinical presentation of autism spectrum disorders (ASD) and are typically the initial focus of treatment for children within this population. Although a number of therapies targeting behaviors characteristic of ASD exist, most do not offer a short-term, manual-based approach aimed at increasing child compliance.

Although traditionally used with typically-developing children, Parent-Child Interaction Therapy (PCIT) is one behaviorally-based, short-term ( $\sim 14$ sessions) parent training program that has demonstrated success in increasing child compliance, reducing problem behavior, and improving parent-child communication. The study examined the efficacy of PCIT as a first-line treatment for children with high-functioning autism by employing a single subject, non-concurrent multiple baseline design across three subjects. Primary findings revealed significant increases in child compliance, reductions in child disruptive behavior and improved parenting skills across participants. In addition, each caregiver reported high levels of satisfaction with the intervention. Results suggested that PCIT may be a viable first-line treatment for children on the high end of the autism spectrum with co-occurring behavioral difficulties. Study findings serve as a foundation for future research in this area. Limitations, clinical implications and future directions are discussed. 


\section{Acknowledgement}

This project would never have been realized without the dedication and hard work of a number of people.

First, I would like to thank my committee chair and advisor, Dr. Cheryl McNeil. Her supervision and guidance throughout this project and my graduate career has been absolutely invaluable and much appreciated. She has consistently demonstrated that success in this field comes from both the head and the heart and I am truly grateful to have worked with her over the past five years.

I would like to acknowledge the valuable input and expertise provided by each of my committee members. A heartfelt thank you is extended to Dr. Martin Boone, Dr. Steven Branstetter, Dr. Tracy Morris, and Dr. Claire St. Peter-Pipkin.

Although this study was small in sample size, it was not short on time commitment, devotion, or work. I would like to recognize Stephanie Wagner for serving as co-therapist on the study and selflessly making this project a priority without a single protest. For that, I am very grateful. I also thank Paul Shawler and Ashley Tempel for giving up their time to extend a helping hand on the project.

I would like to acknowledge each of the families who participated in the study. To the parents, you welcomed us into your homes and worked tirelessly out of dedication and love for your children. Thanks for being great parents.

Lastly and most lovingly, I would like to thank my family and friends for providing perpetual motivation and encouragement. To Lisa, who supported me throughout the project and endured many hours of me "thinking out loud," I am truly appreciative. Finally, I would like to thank my parents, two people who made incredible 
sacrifices in their life so one day I could better my own. I am blessed to have had a mother who instilled in me the importance of a quality education and a father who passed on the work ethic needed to attain it. Because of their unending love and commitment, I dedicate this manuscript to them. 


\section{Table of Contents}

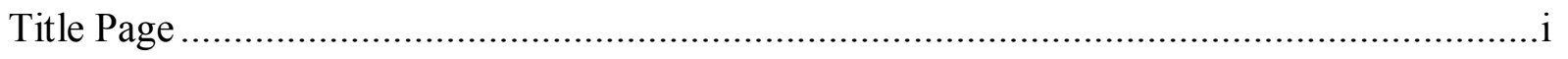

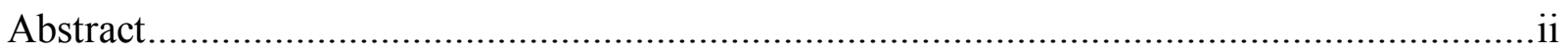

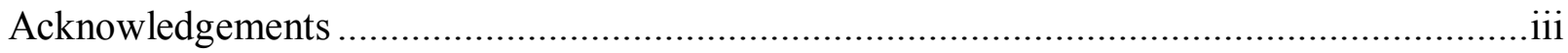

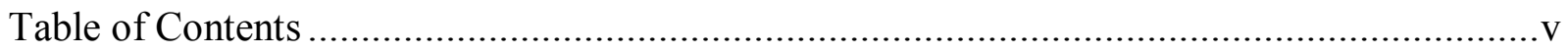

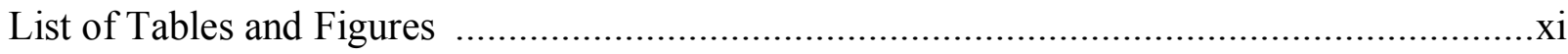

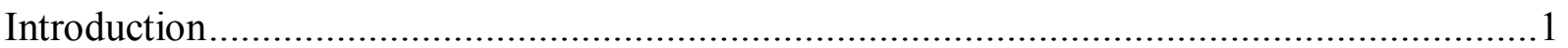

Overview of Established Treatments for Autism ..................................................

Applied Behavior Analysis ....................................................................

Functional Analysis of Problem Behavior ..............................................4

The UCLA Young Autism Project ..................................................... 5

Pivotal Response Training ........................................................... 7

Positive Behavior Support ......................................................... 9

TEACCH Method................................................................................ 11

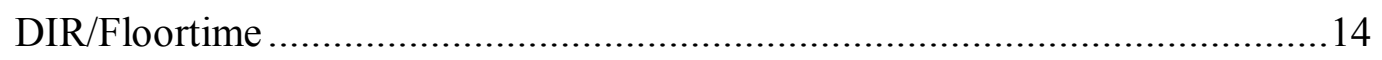

Parent-Child Interaction Therapy ................................................................. 16

Timeout Component ...........................................................................20

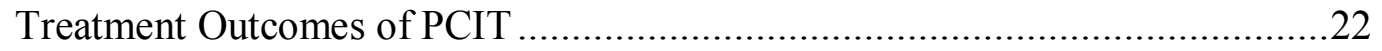

PCIT and Specialized Populations .......................................................23

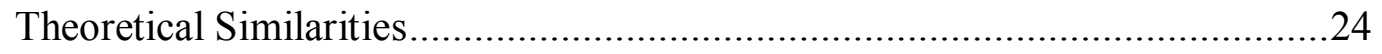

Utility of PCIT with High Functioning Autism ..........................................25

Study Rationale and Hypotheses.....................................................................27

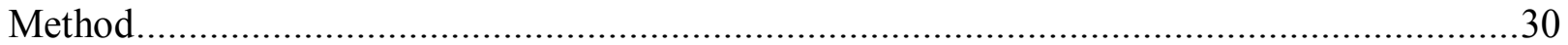




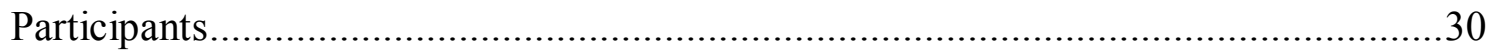

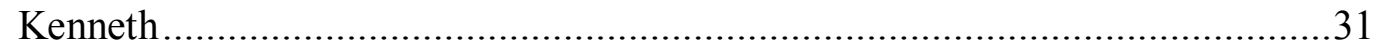

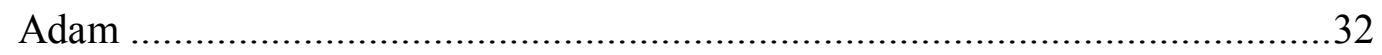

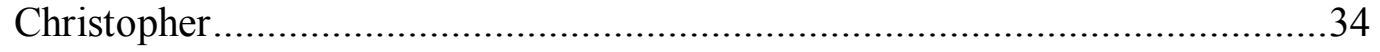

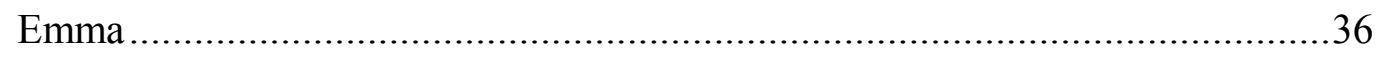

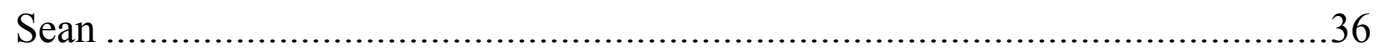

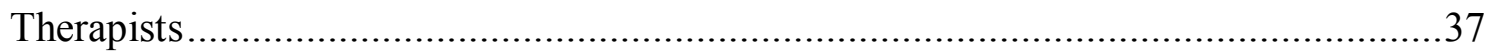

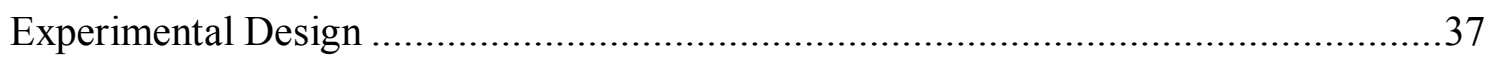

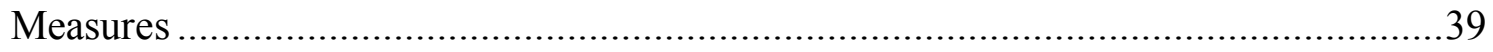

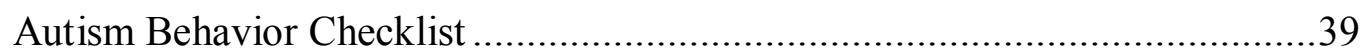

Childhood Autism Rating Scale .....................................................................41

Child Behavior Checklist .......................................................................42

The Compliance Probability Checklist ..............................................................42

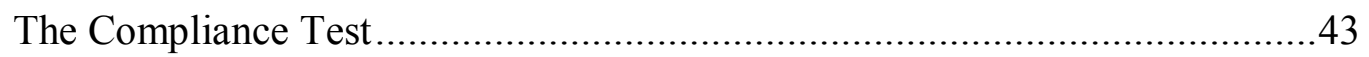

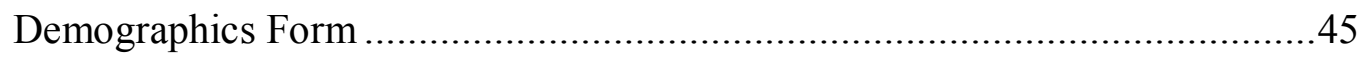

Dyadic Parent-Child Interaction Coding System-III ........................................46

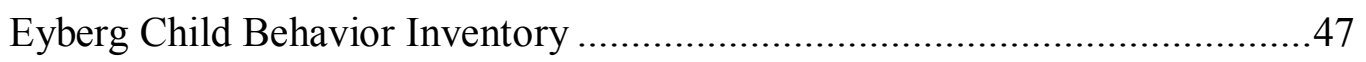

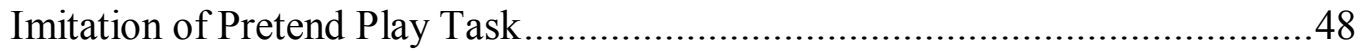

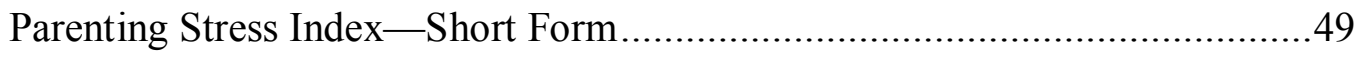

Peabody Picture Vocabulary Test—Third Edition............................................5

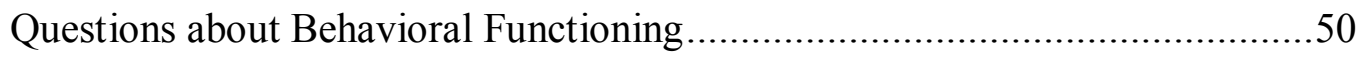

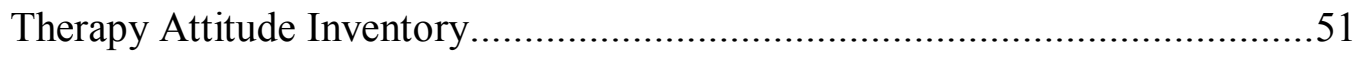


Vineland Adaptive Behavior Scales-Interview Edition................................52

Wechsler Preschool and Primary Scale of Intelligence-Third Edition..............52

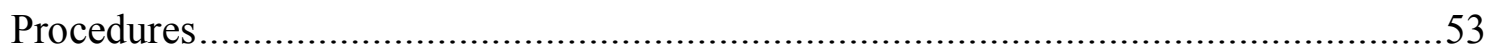

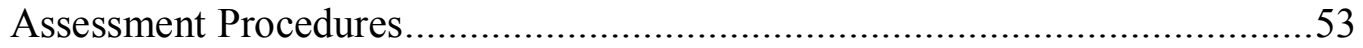

Treatment Procedures ....................................................................53

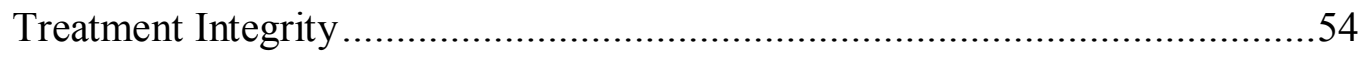

Reliability of the Observational Measures ........................................................5

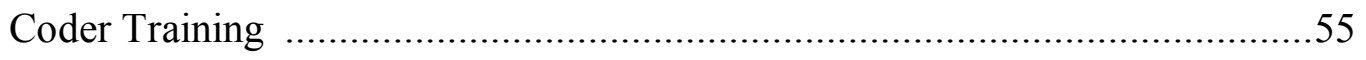

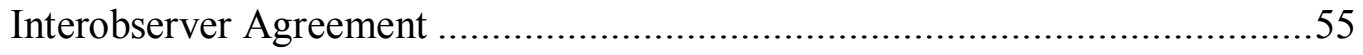

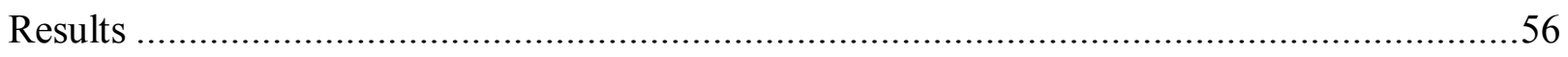

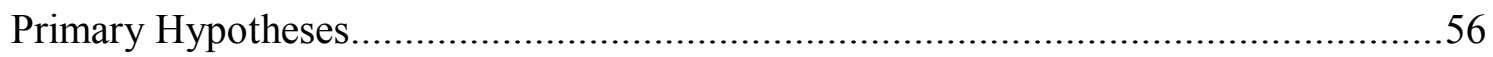

Child Compliance for Kenneth .......................................................56

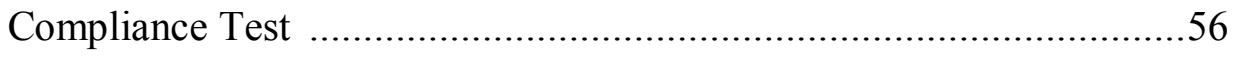

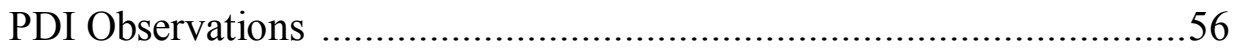

Clean Up Observations .........................................................57

Compliance Probability Checklist ............................................57

Child Compliance for Adam ..................................................................57

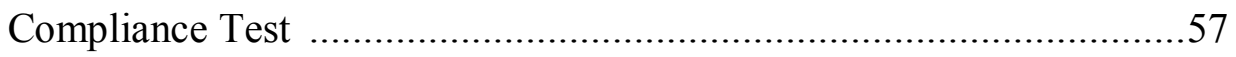

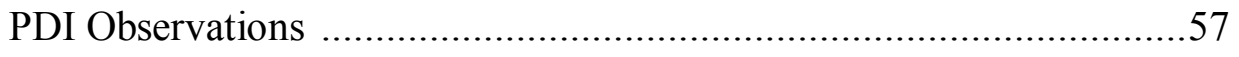

Clean Up Observations ......................................................58

Compliance Probability Checklist ..........................................58

Child Compliance for Christopher .................................................5

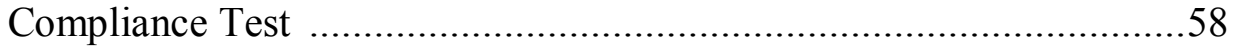


Clean Up Observations .........................................................59

Compliance Probability Checklist ...........................................59

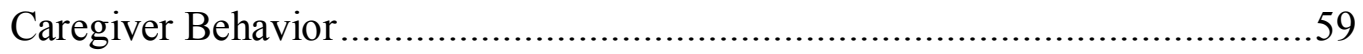

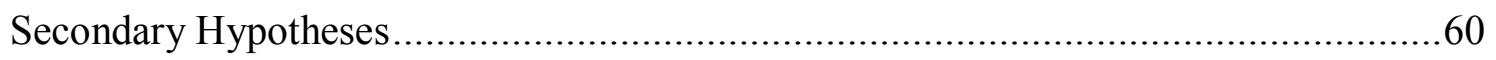

Parent Report of Child Behavior ....................................................6 60

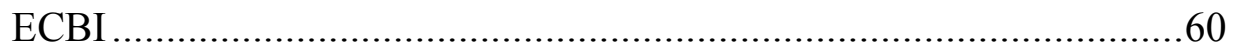

Child Behavior Checklist........................................................62

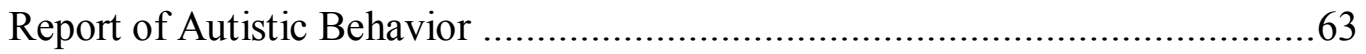

Autism Behavior Checklist ........................................................63

Childhood Autism Rating Scale ................................................64

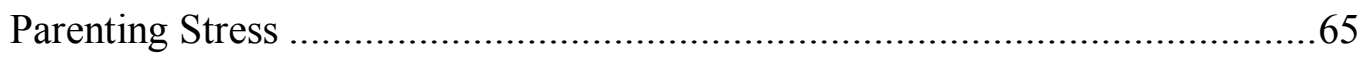

Parenting Stress Index .....................................................65

Receptive Language .........................................................................6 66

Peabody Picture Vocabulary Test ..............................................66

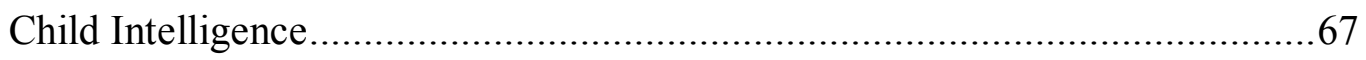

WPPSI-III ......................................................................6 67

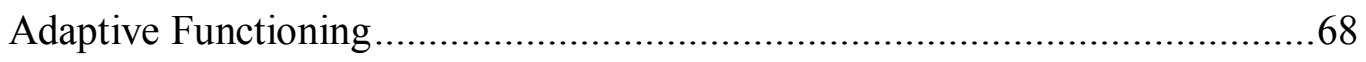

Vineland Adaptive Behavior Scales-Interview Edition......................68

Imitation

Parent Report of Behavior Function .....................................................69

Questions about Behavioral Functioning ......................................69

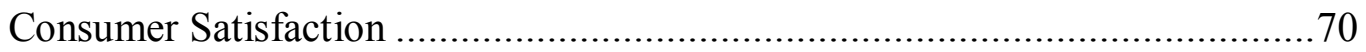


Treatment Attitude Inventory .................................................... 70

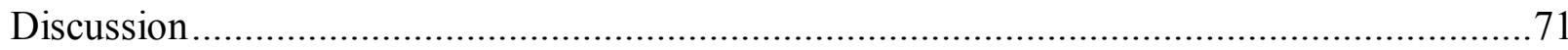

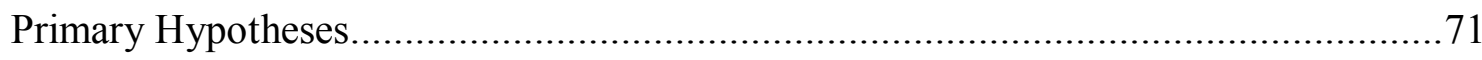

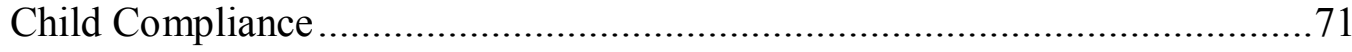

Caregiver Behavior ..................................................................... 75

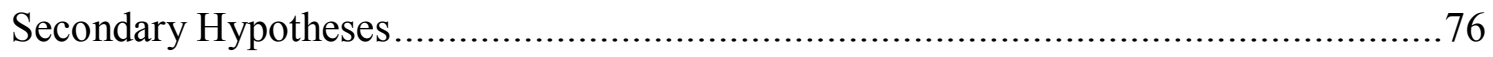

Parent Report of Child Behavior ........................................................ 76

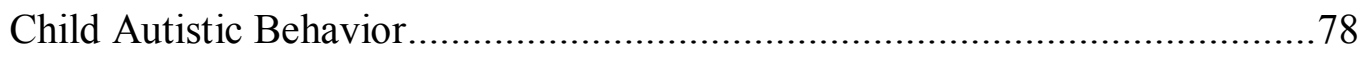

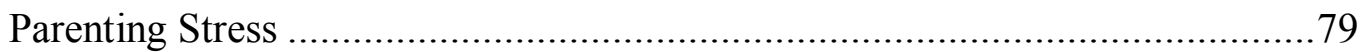

Receptive Language Capabilities ........................................................ 81

Child Intelligence/Child Adaptive Functioning..................................... 82

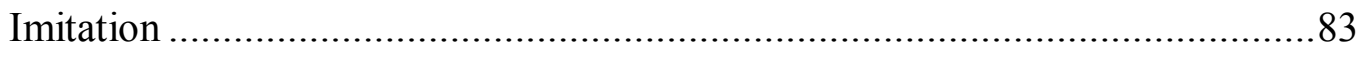

Parent Report of Behavior Function ................................................. 84

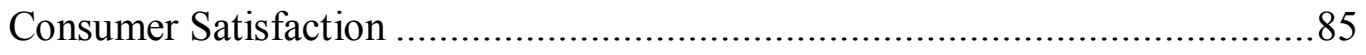

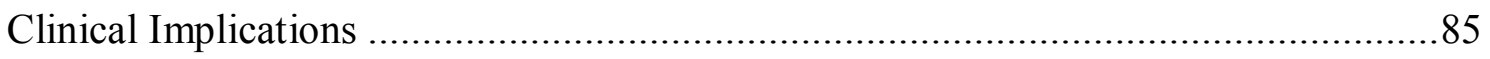

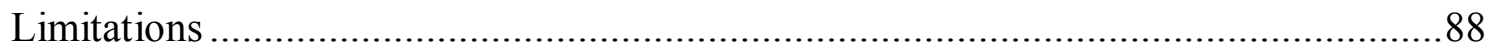

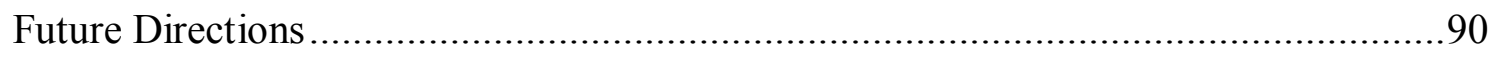

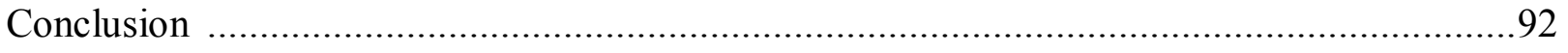

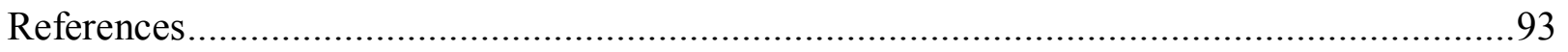

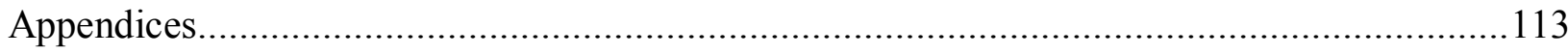

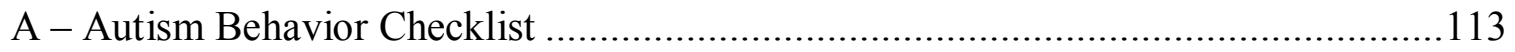

B - Childhood Autism Rating Scale ......................................................... 114

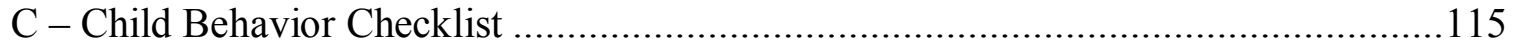




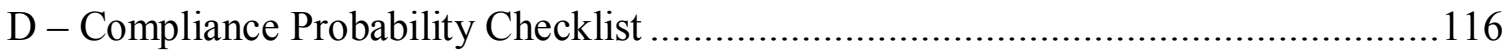

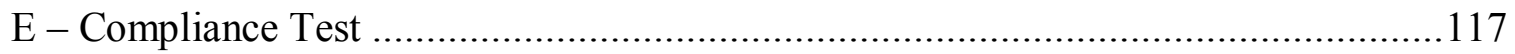

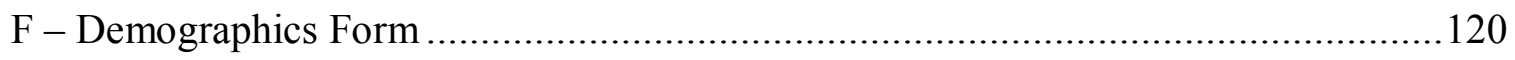

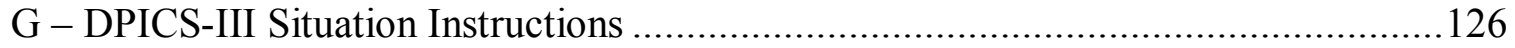

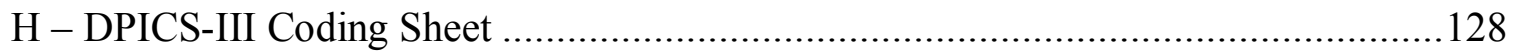

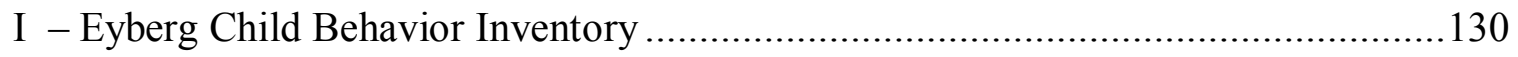

J - Imitation of Pretend Play Task Coding/Instruction Sheet .......................................131

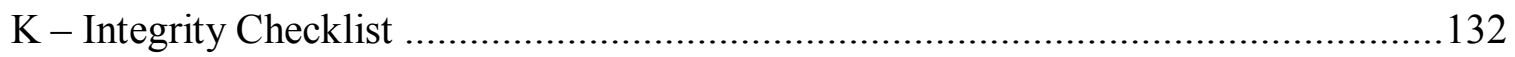

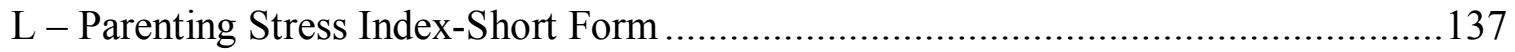

M - Peabody Picture Vocabulary Test —Third Edition ............................................138

$\mathrm{N}$ - Questions about Behavioral Functioning ..............................................................139

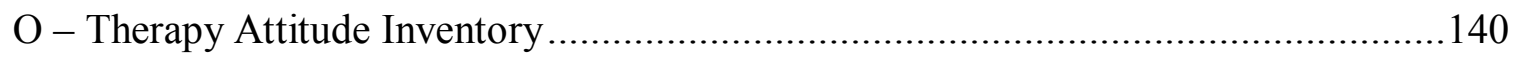

P - Vineland Adaptive Behavior Scales-Interview Edition........................................142

Q - Wechsler Preschool and Primary Scale of Intelligence-Third Edition .....................143 


\section{List of Tables and Figures}

Table 1. Dependent Variables, Measures, and Assessment Points

Table 2. Definitions of DPICS-III Codes

Table 3. Assessment Procedures.

Table 4. Comparison of child compliance rates to previous PCIT and ABA studies

Figure 1. Compliance Test percentage exhibited by participants with horizontal lines indicating phase mean.

Figure 2. PDI compliance percentage exhibited by participants with horizontal lines indicating phase mean

Figure 3. Clean-up task compliance percentage across participants

Figure 4. Parent report of percentage of measures items participants would "usually" or

"almost always" comply with.

Figure 5. Positive parenting behaviors exhibited by caregivers with horizontal lines

indicating phase mean

Figure 6. ECBI intensity scores reported by caregivers with horizontal lines indicating

phase mean and dashed horizontal line indicating clinical cutoff.

Figure 7. ECBI problem scores reported by caregivers with horizontal lines indicating phase mean and dashed horizontal line indicating clinical cutoff.

Figure 8. CBCL total score and subscale scores reported by caregivers with horizontal

line indicating clinical cutoff.

Figure 9. Autism Behavior Checklist total score reported by caregivers with horizontal

line indicating clinical cutoff...... 164

Figure 10. Childhood Autism Rating Scale total score across participants with horizontal 
line indicating clinical cutoff score

Figure 11. PSI total score and subscale scores reported by caregivers with horizontal line

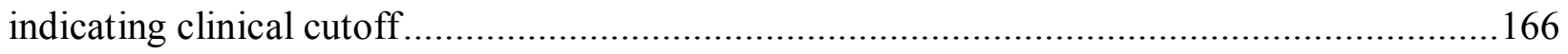

Figure 12. Peabody Picture Vocabulary Test score across participants ...............................167

Figure 13. WPPSI overall score and subscale scores across participants. .............................168

Figure 14. Vineland Adaptive Behavior Scale composite score across participants. ...............169

Figure 15. Imitation Task score across participants. ..................................................... 170 
Examining the Efficacy of Parent-Child Interaction Therapy with High-Functioning Autism

Autism spectrum disorders (ASD) are childhood psychiatric conditions characterized by a deficit in social interaction skills, communication abilities, and behavioral patterns marked with repetitive, idiosyncratic behaviors that typically function to serve as self-stimulatory actions. Due to the overlap of behavior seen in more than one diagnosis on the autism spectrum (e.g., Autistic Disorder \& Asperger's Disorder), it is sometimes difficult to differentiate between developmental disorders, particularly when the clinical presentation of problem behavior is more sophisticated and falls on the higher end of the autism spectrum. Although a discussion on how to discriminate diagnostically between developmental disorders goes beyond the scope of this study, it is worth noting that some researchers contend that children with Asperger's Disorder typically develop secondary psychiatric conditions in the form of externalizing behaviors (Polirstok \& Houghteling, 2006). Though the literature suggests that a formal diagnosis of a behavioral disorder may be more unique to Asperger's Syndrome, the presence of behavioral difficulties (i.e., oppositionality, aggressiveness, limited attention span) in children with ASD is widely cited and recognized. In fact, some research has demonstrated that most children who fall on the autism spectrum present to clinics with problem behavior as the primary focus of treatment (Mandell, Walrath, Manteuffel, Sgro, \& Pinto-Martin, 2005). As any child with excessive problem behavior has difficulty entering or staying enrolled in a structured classroom, it is understandable that parents, in order to increase their child's school readiness, oftentimes seek treatment to target these behaviors. 
As disruptive behavior is typically the primary presenting problem for children with ASD, clinicians oftentimes take a behavioral approach to treatment. Although traditionally used with typically-developing children, one intervention that has demonstrated success in improving parent-child relationships, reducing problem behavior, and increasing child compliance is Parent-Child Interaction Therapy (PCIT: Hembree-Kigin \& McNeil, 1995). PCIT is an empirically-based, short-term parent training program for young children ages 2-7 who engage in disruptive problem behavior. Clinically, due to the prevalent behavioral component of developmental disorders, many children with autism spectrum disorders have been referred for PCIT in the last several years. Although the impact of PCIT has not been tested empirically with this population, the increase of referrals has raised the question of whether PCIT may be an effective gateway therapy to enhance children's readiness for more comprehensive treatments that target behavioral concerns specifically associated with autism (e.g., social skills). Clinical descriptions indicate that PCIT has been a successful first-line treatment in that children become more compliant and less aggressive, thereby increasing their cooperation with more intensive and focused therapy (Stevens, Thompson, Masse, Burrell, Conley, \& McNeil, 2005). In addition, parents tend to be more optimistic about undertaking additional services once their child's behavior is under better control. Although PCIT has shown some clinical success with case studies of children with high-functioning Asperger's/Autism, it is important to note that not all children with ASD are expected to benefit from PCIT. For example, children with poor receptive language skills $(<24$ months) who do not understand simple instructions likely would not benefit from PCIT. PCIT may only be indicated for children who would be described as falling on the 
higher-functioning end of the autism spectrum as defined in this study by receptive language skills above 24 months.

This introduction gives an overview of the prominent behavioral and educational treatments for autism spectrum disorders demonstrating a number of ways in which researchers and clinicians have conceptualized and treated these diagnoses. Next, an overview of the components of PCIT is outlined, followed by a conceptualization as to how PCIT could possibly serve as an effective adjunct to current interventions for highfunctioning autism.

Overview of Established Treatments for Autism

\section{Applied Behavior Analysis}

Applied Behavior Analysis (ABA) is a paradigm that seeks to increase socially appropriate repertoires while decreasing challenging behaviors for children diagnosed with ASD (Green, 1996). ABA uses an empirically-validated and principle-based approach to treat problem behavior, with an emphasis on functional assessment and building skills. The goal is to help the individual to develop skills that will allow that person access to the widest possible range of reinforcers. Behaviorists conceptualize autism as a disorder characterized by both behavioral deficits (e.g., communication, social skills) and excesses (e.g., ritualistic behavior, tantrums; [Green]). To modify behavior, ABA focuses on teaching specific, well-defined behaviors in a systematic manner in the context of repeated trials. For instance, behavior analysts may work on improving speech by targeting a specific skill or behavior such as labeling objects. After an appropriate response or attempt to respond, a positive reinforcer is administered. On the contrary, negative behaviors (e.g., self-injurious behavior) are not reinforced and 
incompatible tasks are introduced in order to reduce problematic behaviors (Green). Although teaching specific skills has resulted in improvements in specific targeted areas, these skills have often not been found to generalize to other environments and situations without additional training. For instance, studies have shown that teaching language skills to children does not result in increased social interaction unless the children also learn specific peer interaction skills (Lovaas \& Smith, 2003).

Overall, ABA has been modifying its treatment procedures for over 50 years and the approach continues to be refined as new research develops. As a result, there are a number of popular and effective treatment approaches from within the ABA framework that are designed to treat problems associated with autism and several of these are outlined below.

Functional Analysis of Behavior

A functional assessment of behavior is a methodology focused on the individual and seeks to understand difficult behaviors by observing and identifying environmental antecedents and contingencies that maintain behavior (Skinner, 1953). A functional analysis involves initially observing a behavior under a control condition, then manipulating a variable in the environment, followed by observing the effect the environmental change had on the behavior (Hanley, Iwata, \& McCord, 2003). This technique is commonly used and widely prevalent in the literature. As of 2003, 277 empirical evaluations of functional analyses had been published with the majority focused on children with developmental disabilities exhibiting aggressive or selfinjurious behavior (Hanley et al.). Functional analysis has been effective in guiding the implementation of function-based interventions and managing a variety problem 
behaviors of children with developmental delays including self-injurious behaviors (Iwata, Pace, Kalsher, \& Cowdery, 1990), aggression (Adelinis, Piazza, \& Goh, 2001; Kahng, Abt, \& Schonbachler, 2001) and rumination (Lyons, Rue, Luiselli, DiGennaro, 2007).

Although functional assessment has repeatedly shown to be an effective assessment tool guiding the implementation of treatment, a couple of limitations are noted. First, some researchers contend that functional analysis does not account for biological factors that may influence behavior such as physical illness or physiological effects of drugs (Carr, 1994). Also, Repp (1994) noted the importance of a more detailed account of behavioral antecedents before the analysis is conducted (i.e., setting events) as opposed to those immediately preceding the behavior.

\section{The UCLA Young Autism Project}

In order to address the difficultly with behavior generalization, Lovaas (1987) devised a more broad-based treatment targeting all of a child's developmental and behavioral problems across settings. This intervention, often referred to as the UCLA Young Autism Project, employs several therapists providing intensive (i.e., 40 hours per week) one-on-one treatment at home, school and the community with the goal of increasing desirable behavior (e.g., language, social behavior) and reducing disruptive behavior (e.g., aggression, tantrums).

In addition to clinician-delivered services, the treatment also contains a parentbased approach in which parents are taught useful skills that can be implemented in the home setting (Lovaas, 1987). While learning the skills, parents work directly with a therapist helping implement treatment (Lovaas \& Smith, 2003). This technique enables 
the therapists to observe the parents and provide helpful feedback so that parents can become effective "therapists" for their children.

Typically, this approach is implemented early in the child's life and treatment is continued until the child begins elementary school. Treatment progresses through several stages, each of which contains different goals that are built upon as the treatment advances (Lovaas \& Smith, 2003). For instance, the initial stage uses discrete trial training (DTT) to establish a teaching relationship with the goal of teaching a child to comply with one-step directions (e.g., "come here"). Next, DTT is employed to teach a variety of foundational skills, such as identifying objects, playing with toys, matching, and dressing. In the third stage, therapists use DTT and incidental teaching to target communication skills including imitating speech sounds and labeling objects. The next stage focuses on communication and peer interaction at which point the therapist uses DTT, incidental teaching, and dyads with peers to teach skills such as recognizing emotion and pretend play. Lastly, treatment targets skills that assist children who are beginning school including language concepts (e.g., pronouns, past tense, and prepositions), how to converse with others, and how to understand the perspective of others.

The UCLA Young Autism Project is empirically-supported and has been replicated several times. To study the treatment's efficacy, Lovaas (1987) compared three groups of children with autism: a group of children who received 40 hours per week of this intensive intervention, a group of children who received 10 hours or less per week of behavioral treatment, and a special education class. At post-treatment, results revealed that $47 \%$ of the children in the 40 hours per week condition achieved average IQs and 
performed at a satisfactory level in school compared to $3 \%$ of the children in the control condition. Replications of this study have found similar improvements (although sometimes not as large) in areas such as IQ and school performance for groups receiving a similar intensive intervention as compared to controls (e.g., Sallows \& Graupner, 2005; Smith, 1999; Smith, Groen, \& Wynn, 2000). Moreover, research has demonstrated that this approach is effective in community settings as well (Cohen, Amerine-Dickens, \& Smith, 2006). Yet, findings about the overall effectiveness of the UCLA program are not conclusive; as it is difficult to replicate this work given the great many resources and personnel demands that are required to duplicate the study methods.

\section{Pivotal Response Training}

Pivotal response training (PRT), a data-driven approach for treating children with autism, is based on applied behavioral analytic principles and is used to treat the language, social, behavioral, and play deficits that characterize children with autism (Koegel, O’Dell, \& Koegel, 1987). In contrast to other ABA early intervention approaches, PRT attempts to improve broad areas of functioning that then generalize to many other domains (e.g., Koegel \& Koegel, 1995). These modifications were made to the traditional ABA approach for the purpose of attempting to improve the efficiency and make the treatment more cost-effective (Koegel, Koegel, Harrower, \& Carter, 1999).

PRT strives to develop independence and improve self-education in children with autism by targeting motivation and self-initiation, the critical pivotal domains (Koegel et al., 1999). Specifically, PRT is based on the belief that improving child motivation and self-initiation will lead to increases in responsiveness and inquisitiveness in their natural environment. Particular target behaviors are modified based on the idiographic need 
specific to each child. Although behaviors of interest tend to be individualized to each child, communication and social skills are typically taught in the child's environment (e.g., home, playroom, playground) through the use of natural stimuli (e.g., toys as opposed to flash card drills) (Koegel, Koegel, \& Brookman, 2003). In order to enhance child motivation, PRT employs an array of techniques including the use of toys and activities the child prefers as well as allowing the child to be an active participant in choosing an activity (Koegel, et al., 1987). Other critical components of the intervention include gradually introducing new tasks with tasks that the child has already mastered, using natural reinforcement when possible, and reinforcing response efforts as opposed to only reinforcing correct responses (Koegel et al., 1987). For instance, children learn selfinitiation by receiving prompts to actively ask questions which are then proceeded by attaining positive reinforcement for their question. For example, children are prompted to ask, "What's that?" when they are interested in an object (Koegel et al., 2003).

Similar to other educational and behavioral interventions for autism disorder, PRT holds that parental involvement in the treatment is critical for behavior change. Therefore, parents often play an active role in learning skills and implementing treatment techniques (Koegel et al., 2003). In the context of educational classes, parents work with their child and receive feedback from a therapist on how to improve their child's pivotal responses. Specifically, parents learn techniques to increase their child's motivation and self-initiation through teaching communication and academic skills (Koegel et al., 2003).

Numerous research studies examining PRT have found positive results across a wide variety of domains including child social-emotional behavior, self-initiation, and communication. In addition, studies have shown a decrease in parental reports of stress, 
depression, and an improvement in the quality of the parent-child interaction (see Koegel et al., 2003 for review). Research has examined both individual components of PRT and the complete treatment each demonstrating positive results (e.g., Koegel, Bimbela, \& Schreibman, 1996; Koegel, Camarata, Koegel, Ben-Tall, \& Smith, 1998). Lastly, results have been attained by employing a number of methodologically-sound research designs including multiple baseline designs and random controlled trials (e.g., Koegel, Bimbela, et al., 1996; Koegel, Camarata, Koegel, 1998; Koegel, Camarata, Valdez-Mechaca, \& Koegel, 1998).

\section{Positive Behavior Support}

Positive behavior support (PBS) is a common intervention model used to treat children with autism spectrum disorders (Carr et al., 2002; Koegel, Koegel, \& Dunlap, 1996). The principal goal of PBS is to establish a better quality of life by creating environmental circumstances that help not only children with autism, but also others in the environment as well (e.g., teachers, parents, and friends). Secondary to this goal, PBS attempts to reduce negative behaviors in a non-aversive and more socially acceptable manner (Carr et al., 2002). From a conceptual perspective, PBS was developed from three primary sources: ABA, the normalization/inclusion movement, and person-centered values. Due to its eclectic theoretical underpinnings, positive behavior support employs a combination of numerous procedures and intervention, demonstrating techniques commonly seen with behavioral family intervention, systems change models, ABA treatment strategies, and the family support movement (Newsom \& Hovanitz, 2006). Although a detailed description of procedures used in PBS is beyond the scope of this overview (see Lucyshyn, Horner, Dunlap, Albin, \& Ben, 2002 for a more thorough 
description), the fundamental components include conducting a functional assessment, developing and continually assessing hypotheses regarding the functions of negative and positive behaviors in a specific context, and designing and implementing an appropriate behavior support plan geared toward enhancing the overall quality of life for both the child and others in his/her environment.

A number of studies examining PBS have shown it to be an effective treatment for children with autism spectrum disorders. For example, Durand and Carr (1992) conducted a study comparing children with developmental disabilities who received functional communication training - an important aspect of PBS - to a control group who received time out from positive reinforcement. Although both groups demonstrated a decrease in negative behavior, the PBS group exhibited (a) an increase in unprompted communication, and (b) generalization and maintenance of treatment gains across different contexts and over time (i.e., after the intervention was completed). Dunlap and Fox (1999) employed PBS with six young children with autism and found significant reductions in problem behavior and decreased occurrence of autistic behavior as measured by the Autism Behavior Checklist (Krug, Arick, \& Almond, 1980). Furthermore, families reported being more comfortable taking their children to public venues. Similar results were found by Koegel, Stiebel, and Koegel (1998) who used PBS with three preschool-aged children with autism and demonstrated significant reductions in overall rates of aggression toward their siblings, increases in both the parents' and child's levels of happiness, and increases in strangers' levels of comfort in interacting with the family. 
Reviews of the literature (Carr et al., 1999) show that over 100 studies conducted between 1985-1996 demonstrated the effectiveness of PBS in reducing problem behaviors in a number of clinical diagnoses including children with mental retardation, mental retardation with other diagnoses, and children with autism - some investigations finding reductions in negative behavior to upwards of $80 \%$. Treatment gains found in single-subject studies of children with autism have been even larger in recent years; with average percentage of behavior reductions remaining within $15 \%$ of initial behavior reduction levels (see Horner, Carr, Strain, Todd, \& Reed, 2002).

Despite extensive support for the PBS paradigm, concerns have been raised as to whether positive behavior support is actually a novel treatment approach (Mulick \& Butter, 2005). Also, some researchers have called into question whether the sole use of non-aversive techniques is truly effective for optimal child development (Newsom \& Kroeger, 2005). Further, researchers have expressed concern that accommodation alone may be effective in reducing behavioral problems primarily because of the reduction in new demands. While placing fewer demands on the child reduces opportunities for the child to experience oppositionality, providing fewer challenges and expectations could slow the child's maturation.

\section{TEACCH Method}

Another treatment approach within the behavioral paradigm is the TEACCH Model (Treatment and Education of Autistic and Related Communication Handicapped Children; Mesibov, 1994; Schopler, 1994; Schopler \& Reichler, 1971), an approach which stresses structure in teaching new behaviors, targeting specific skills, and defining conditions and consequences of behaviors through shaping. Like the PBS approach, the 
TEACCH model takes a comprehensive and broad-based perspective of autism treatment. The TEACCH model is devised on the assumption that comprehensive services are necessary across the lifespan (Mesibov, 1983) and must be individualized and tailored to meet the unique needs of the individual, their personal environment, skills deficits, and specific family situations (Mesibov, 1994). In addition to key members in the child's like (e.g., teachers), parents are seen as an essential component in the TEACCH method and are critical to the success of the treatment. Four areas of communication serve as the foundation for this model. The first is functionality, where goals are selected based on their usefulness in daily living, with a focus on making communication more meaningful and rewarding for the child. The second is incidental learning in which children are taught new language skills after naturally occurring, child-initiated behaviors lead to a situation where a child may learn or improve their communication skills (e.g., asking for a soda from the vending machine). Another aspect of the model involves assisting the child in learning alternative forms of communication (i.e., non-verbal) when difficulties with language or speech production exist. Finally, the TEACCH method has been strongly influenced by the psycholinguistic literature, which has assisted with assessment, improving communication skills, and helping further define and devise communication strategies.

From a theoretical perspective, the TEACCH approach focuses on tolerance, compromise, acceptance, and personal enhancement rather than normalization or inclusion (Mesibov, 1994). The program recognizes the distinctions between people with autism and the general population, yet it stresses that these differences do not suggest 
inferiority. The focus is on the individual and working with a person's strengths to assist them in reaching personal goals.

Investigations examining the effectiveness of the TEACCH model demonstrated improvements in child learning and positive behavior following the introduction of a structured learning environment in classrooms (Schopler, Brehm, Kinsbourne, \& Reichler, 1971). In addition, research on the home-based model has shown that the TEACHH model has been effective in reducing noncompliance and enhancing parenting skills (Marcus, Lansing, Andrews, \& Schopler, 1978). Similarly, Short (1984) compared the home-based program to wait-list controls and found improvements in positive child behavior, communication skills, and improved parent-child interaction. Lastly, Schopler, Mesibov \& Baker (1982) conducted a consumer satisfaction study with 348 parents of children in the TEACCH program and found high levels of treatment acceptability, with many parents reporting maintenance of intervention effects following completion of treatment.

While preliminary studies of the TEACHH model showed promising results, many failed to include an appropriate control group making it difficult to attribute the change solely to the treatment as opposed to extraneous variables (i.e., developmental maturation). In order to remedy this methodological shortcoming, Ozonoff and Cathcart (1998) conducted a study of 22 children with autism and compared the effects of homebased TEACCH services with a control group who did not receive the TEACCH model. All children were attending day treatment programs in the community. Following four months of services, children in the TEACCH group showed significantly more improvement than children in the control group across a variety of do mains including 
fine motor skills, imitation, gross motor skills, and cognitive performance, as well as overall scores on the Psychoeducational Profile-Revised (PEP-R; Schopler, Reichler, Bashford, Lansing, \& Marcus, 1990).

\section{DIR/Floortime}

Developed by Stanley Greenspan, the "Developmental, Individual-difference, Relationship-based model" (DIR; Greenspan, 1992; Greenspan \& Wieder, 1999; Wieder \& Greenspan, 2006) is a developmentally sensitive, functionally-based approach that strives to help children "climb the developmental ladder" and achieve critical developmental milestones. The model presents six major functional milestones that are necessary for normal emotional and cognitive development: 1) self-regulation and interest in the world, 2) engaging and relating to others, 3) intentionality and two-way communication, 4) social problem-solving, mood regulation, and formation of a sense of self, 5) creating symbols and using words and ideas, and 6) emotional thinking, logic, and a sense of reality. In addition to the six primary stages, three advanced stages characterize ongoing development throughout adolescence and adulthood: 1) multicausal and triangular thinking, 2) gray-area and emotionally differentiated thinking, and 3) a growing sense of self/reflection on an internal standard (Greenspan \& Wieder, 2006). The treatment is devised to allow children to progress through the developmental stages while continually identifying strengths and weaknesses, assisting with the development of new skill sets, and establishing learning relationships that are adapted and suited to a child's specific needs.

The DIR model is an intensive intervention that requires a great deal of parental involvement. For example, parents are asked to frequently interact with their children (up 
to 8 times a day) for twenty minutes per interaction. Also, the intervention requires parents to conduct interactions across a variety of settings. An essential component of the DIR model is Floortime, a specific technique where the caregiver interacts with their child on the floor for at least twenty minutes or more in child-led play. A primary objective throughout Floortime and DIR is to maintain focus on the child, following their lead and creating rewarding and enriching interactions between child and caregiver. In turn, this process encourages the child to increase their social capabilities and emotional warmth, with the assumption being that the parent-child relationship will improve as the caregiver demonstrates more interest in the child. The components of Floortime include observing the child's behavior, opening and enhancing circles of communication by recognizing the child's emotional tone and gestures, consistently allowing the child to lead the play activity and validating their thoughts and ideas, increasing play repertoires through supportive and genuine comments and strategic, empathic questioning, and permitting the child to close the circles of communication (i.e., responding in a manner that completes or compliments the activity at hand) established during the Floortime activities.

Greenspan and Wieder (1997) investigated the DIR/Floortime treatment outcome literature (200 children with a variety of impairments) and found that $58 \%$ of children who received the intervention over two or more years exhibited significant gains in various domains including social problem solving, cognitive and motor tasks, and academic performance. Also, the children showed a significant decrease in behaviors indicative of autism spectrum disorders including self-absorption, avoidance, selfstimulation, and perseveration (Greenspan \& Wieder, 2006). In addition, scores on the 
Childhood Autism Rating Scale (CARS) were no longer in the clinical range. Of the 200 children examined, $25 \%$ showed moderate gains across most areas of development while $17 \%$ showed very slow gains from the treatment (Greenspan \& Wieder, 2006). Although research on this approach has been promising, the authors assert that the majority of the families who showed significant gains were highly invested in their children's treatment, possibly confounding the study results. A follow-up study conducted 10-15 years after treatment (Greenspan \& Wieder, 2006) on 16 of the children who showed "good to outstanding" improvements showed that treatment gains maintained over time with this group of children still exhibiting little or none of the behaviors commonly seen with Autism Spectrum Disorders. While long-term studies have indicated that DIR/Floortime may be an effective treatment for children on the autism spectrum, many of the investigations have not contained a control group, bringing the validity of the results under some question.

\section{Parent-Child Interaction Therapy}

Parent-Child Interaction Therapy is based on Hanf's (1969) two-stage treatment model, social learning theory, and attachment theory. Similar to other behavior parenting training programs based on Hanf's model, PCIT consists of two phases, a relationship enhancement phase (Child Directed Interaction [CDI]) and a discipline phase (Parent Directed Interaction [PDI]). However, PCIT is unlike many other parent training programs as the treatment involves both parents and children in the sessions as well as live coaching. Another feature that distinguishes PCIT from other parent training programs is that treatment progress is data-driven and therefore individualized for each family. Specifically, families only progress to PDI when parents demonstrate mastery of 
the CDI skills. Likewise, mastery of the PDI skills is a pre-requisite to therapy completion.

The two phases of PCIT are conducted in weekly 1-hour sessions and both contain didactic and experiential components. Each phase of treatment begins with a didactic, in which the therapist teaches, models, and role plays the skills with the parents alone. The subsequent sessions begin with a brief check-in with the parents, in which a therapist discusses the homework from the previous week and also reviews learned skills. After the check-in, the therapist coaches the parent to help improve their skills using a bug-in-the-ear microphone device from an observation room while the parent and child play together. During the coaching, the therapist helps the parents master the skills by providing support, reinforcement, and corrective feedback.

CDI, the first phase of PCIT, is similar to play therapy because the child leads the play as the parents provide support in an effort to enhance the parent-child relationship. During CDI, parents learn communication skills for creating or strengthening their bond with their child, increasing their positive parenting, and improving their child's social skills. Specifically, the therapist teaches parents to follow the child's lead in play by using the PRIDE skills: Praising the child for a specific behavior (labeled praise), Reflecting the child's statements, Imitating the child's play, Describing their child's behavior, and using Enthusiasm throughout the play. They also learn to avoid asking questions, criticizing, and giving their child commands because these behaviors prevent the child from leading the play and create an unpleasant environment. After the therapist teaches the parent these skills, the parent practices both in clinic sessions (while being coached) and at home for five minutes daily. With regard to behavior management, 
parents learn to use selective attention by responding to appropriate behaviors with the PRIDE skills while ignoring negative behaviors. In order to move onto the next phase of treatment, parents must demonstrate mastery of these skills. Specifically, they have to provide 10 descriptions of child behavior, 10 labeled praises, and 10 reflections, while providing 3 or less commands, questions, and criticisms in a 5-minute play situation without the assistance of the therapist.

After the parents have mastered the skills taught in CDI, they progress to PDI, the second phase of PCIT. In this phase, parents continue to use the skills taught in CDI but also learn skills to increase child compliance and pro-social behaviors and decrease inappropriate behaviors. The therapist teaches the parents how to give effective instructions and consistently provide different consequences for child compliance and noncompliance. Additionally, parents learn strategies for enforcing house rules and controlling their child's behavior in public settings.

The first skill that the parents learn in PDI is how to give effective, developmentally-appropriate commands or instructions. Parents learn to give clear, direct commands that let the child know exactly what is expected. In order to increase the child's understanding of the direction, instructions typically involve a visual cue such as pointing or imitating the desired action in addition to the verbal direction. Also, parents are taught to give commands they are certain the child comprehends and is able to perform. For example, at the outset of therapy, children's developmental capabilities are assessed in terms of ability to differentiate colors, identify toys, and perform the appropriate motor actions (e.g., please put the crayon in my hand). Next, parents learn specific steps to follow based on the child's response to the commands. They learn to use 
these steps every time they give a command so that discipline becomes consistent and predictable. For instance, if the child complies with the command, they learn to give an enthusiastic labeled praise. However, if the child does not comply, they learn to wait five seconds and then issue a warning. If the child still does not comply with the initial command, parents place the child in a timeout chair. In instances when the child does not stay on the timeout chair, a back-up consequence is used to teach the child to stay in timeout (e.g., back-up timeout room). Parents must also master PDI skills, including giving effective commands and following the timeout procedure. In order to master PDI, parents' commands must be effective (i.e., direct, clear), and followed through correctly (i.e., labeled praise for compliance, warning then timeout for noncompliance) at least $75 \%$ of the time, and the child must exhibit a compliance rate of at least $75 \%$.

PDI is similar to CDI in that the parents practice these skills in session while a therapist coaches them to ensure that they are following the procedure correctly. Additionally, like CDI, parents practice PDI outside of treatment sessions by giving their child commands during daily compliance exercises that are conducted at home. As skills in PDI progress and parents begin using these skills throughout the day, they are taught to use PDI only when it is important that the child complies and when they are able to follow through with a timeout, if necessary.

Another feature of PDI is that the therapist individualizes the program based on the parent's goals for the child. Specifically, PDI can be used to increase desired behaviors. For instance, if the parents want to increase child eye contact, the therapist could have the parents issue a command directing the child to look at the parent. Then, if the child complies, the parents would follow through with a labeled praise. For instance, 
they might say, "Thank you so much for looking at me. Now I know you are ready to listen."

\section{Timeout Component}

As PCIT includes a timeout component, a discussion of the use of punishment procedures with children on the high-functioning end of the autism spectrum is warranted. For over 40 years, researchers have debated the appropriateness of the use of aversive procedures in children with developmental disabilities creating a division within the ASD research community. This debate has generated a number of arguments including the definition of aversive: a term that could potentially have a number of meanings ranging from physical pain to temporary mild irritation. In an effort to grant a more precise definition of the term, Turnbull (1986), while delivering his presidential address at the American Association on Mental Deficiency (AAMD), stated that "not every intervention that is unwelcomed by the client or that may cause unpleasant consequences should be regarded as presumptively questionable. To take that approach would be to exclude, for example, timeout, seclusion, medications, or modest repetitions of skill building tasks" (p. 266). Currently, researchers contend there remains ambiguity about a valid definition of this term but recognize that some use of punishment may be necessary for childhood learning and development (Newsom \& Kroeger, 2005). Going further, some researchers propose that a solely-positive approach may not be as effective as one that employs a combination of positive methods and punishment, recognizing that punishment is a necessary first step in establishing an environment where positive consequences can become reinforcing (Sidman, 1989). 
Employing a timeout procedure for difficult behaviors is a technique that is widely accepted and used in behavioral parent training programs. In order to insure a safe and accurate implementation of the timeout procedure, PCIT requires clinicians to dedicate a session solely to teaching and practicing the timeout sequence with parents. In addition, parents receive in-vivo coaching during each timeout sequence and are coached to a mastery level (see description of PCIT). Overall, PCIT has been widely accepted within the clinical and research community and has been used with a variety of clinical problems including parents referred for child abuse (Chaffin et al., 2004).

Based on Baumrind's (1971) research, it has long been recognized that an authoritative parenting style (one that is characterized not only by warmth and praise, but also consistent limit setting) enhances the likelihood of more positive child outcomes. Further, as aversive contingencies (e.g., restricted privilege) are commonly used to modify behavior in the natural environment (e.g. workplace, classroom), a solely positive approach may not be comprehensive enough for helping children with high-functioning autism to cope with societal demands (Newsom and Kroeger, 2005).

To summarize, PCIT incorporates both positive parenting skills and limit setting and it has been successful in reducing difficult behaviors with typically-developing children (see the "treatment outcomes of PCIT" section of this proposal for a list of treatment outcome studies). PCIT has been shown to have clinical efficacy with a high degree of caregiver acceptability. Yet, in families of children with ASD, there exists need for further empirical research to examine if this treatment is a beneficial gateway intervention. It is possible that PCIT opens the gateway for children to be better able to benefit from more comprehensive and multi-component treatments. In other words, PCIT 
is expected to improve compliance and social responsivity, two fundamental skills that provide a gateway for treatment that addresses a variety of adaptive behaviors (e.g., social skills training). If children with ASD do not learn at an early age to attend and comply, they remain distracted by stereotypical interests and behaviors that prevent them progressing with treatments addressing higher-order concerns such as empathy and social reciprocity.

\section{Treatment Outcomes of PCIT}

PCIT is an empirically-supported treatment for treating young children with disruptive behaviors. Research examining the efficacy of clinic-based PCIT has shown significant decreases in child externalizing behaviors in the clinic, home and school environment as assessed by teacher report, parent report and behavior observations (Eisenstadt, Eyberg, McNeil, Newcomb, \& Funderburk, 1993; McNeil, Eyberg, Eisenstadt, Newcomb, \& Funderburk, 1991; Schuhmann et al., 1998). In addition, research has also shown that PCIT leads to improvements in positive parenting behavior (e.g., labeled praise) and reductions in negative verbalizations (e.g., sarcastic statements) (Eisenstadt et al.; Schuhmann et al.). PCIT researchers have compared PCIT to waitlist controls (McNeil, Capage, Bahl, \& Blanc, 1999; Querido \& Eyberg, 2001; Schuhmann et al.), and classroom controls (McNeil et al., 1991) and have found significant reductions in disruptive behavior in the PCIT group. Also, evidence shows the effects of PCIT generalize to untreated siblings (Brestan, Eyberg, Boggs, \& Algina, 1997; Eyberg \& Robinson, 1982) and to other settings, such as school (McNeil et al., 1991). Last, PCIT has been shown to be associated with more positive outcomes for parents in terms of stress level reduction, increased self-perception, and improved psychological functioning 
(Eyberg, Boggs, \& Algina, 1995; Eyberg \& Robinson).

Research demonstrates that treatment gains are maintained over time. For example, a number of researchers (e.g., Eisenstadt et al., 1993; Nixon, Sweeney, Erickson \& Touyz, 2003; Querido \& Eyberg, 2001) demonstrated that parents continued to use positive parenting skills over the short-term ( $<12$ months) while child compliance continued to remain at low levels. Similar behaviors were found 1-2 years after treatment completion (Eyberg et al, 2001). Lastly, 3-to-6 year follow up studies have shown that parent report of child oppositionality maintained over time (Hood \& Eyberg, 2003).

\section{PCIT and Specialized Populations}

Although PCIT was devised for families of children with oppositional behaviors, several investigations have examined its usefulness with diverse populations and clinical disorders and have found preliminary success. For example, PCIT has been disseminated to children with developmental disorders and mental retardation (Bagner \& Eyberg, 2007; Eyberg \& Matarazzo, 1980), chronic illness (Bagner, Fernandez, \& Eyberg, 2004; Miller \& Eyberg, 1991), internalizing disorders (Pincus, Choate, Eyberg, \& Barlow, 2005), and child maltreatment populations (Urquiza \& McNeil, 1996). Also, PCIT has been researched with a variety of cultural groups including Puerto Rican families (Matos, Torres, Santiago, Jurado, \& Rodriquez, 2006), Mexican-American families (McCabe, Yeh, Garland, Lau, Chavez, 2005), Spanish speaking families (Borrego, Anhalt, Terao, Vargas, \& Urquiza, 2006), and African American families (Fernandez, Butler, \& Eyberg, 2006; Capage, Bennett, \& McNeil, 2001).

Over the past few years, several research projects examining the effectiveness of PCIT with abusive populations have been conducted (Chaffin et al., 2004; Timmer, 
Urquiza, Zebell, \& McGrath, 2005). Specifically, Chaffin et al. (2004) investigated the effects of PCIT on recidivism rates in a sample of maltreating families and found that $19 \%$ of participants in the PCIT condition had a re-report compared to $36 \%$ in the Enhanced PCIT group (traditional PCIT + individual services) and $49 \%$ in the community-based group. Individual services were tailored to each participant and included interventions focused on parental depression, substance abuse, family dysfunction, marital problems, and domestic violence. The community-based group was uniform across participants and consisted of a group psychoeducational parent training program. Overall, the study demonstrated that the enhanced version of PCIT produced poorer outcomes (as defined by negative parent behaviors) than the traditional version meaning added services may not be necessary to realize improvements in parent behavior.

\section{Theoretical Similarities}

PCIT is unique in that it contains a blend of therapeutic techniques seen in a number of therapies devised for children with ASD. For example, PCIT, like Floortime and TEACCH, recognizes the importance of consistent, one-on-one parent-child interaction and stresses that the quality of a parent-child bond is important to demonstrate acceptance and support for the child's behaviors and verbalizations. In addition, PCIT is similar to pivotal response training in that it emphasizes the importance of using familiar play objects in an environment that is comfortable for the child in an effort to promote generalization. Indeed, families in PCIT are instructed to use their parenting skills at home on a consistent basis with familiar activities and stimuli that encourage parent-child interaction. A common theme inherent within many interventions for children with ASD 
is to take a comprehensive approach by allowing parents to play an integral part in therapy. By increasing parental involvement, skills learned within a clinic are then generalized to other settings such as the home and public environments. Likewise, PCIT views the parent as the agent of change in a child's life and therefore trains parents to a mastery level in each component of treatment. In having stringent mastery criteria, requiring consistent practice and providing ample live feedback to parents, PCIT places a great deal of emphasis on treatment fidelity, generalization across environments and maintenance over time. Lastly, PCIT not only stresses the importance of relationshipbuilding through enriching and rewarding parent-child interactions, but also contains an intensive compliance training component (i.e., command-consequence sequence) similar to the discrete trials seen in ABA protocols.

Overall, due to its overlap with current specialized treatments, PCIT presents a number of components that may prove to be helpful for children with ASD. More specifically, PCIT may serve to prepare a child for more intensive therapy by serving as a necessary primer that enhances the parent-child relationship and increases child compliance, thereby setting the stage for greater success across a variety of treatment modalities (e.g. social skills training, academic tutoring).

\section{The Utility of PCIT with High-Functioning Autism}

Overall, PCIT strives to increase school-readiness skills by using techniques designed to enhance the parent-child relationship, improve language and social skill capabilities, increase attention span, expand the play repertoire with age-appropriate tasks (as opposed to self-stimulatory behaviors), increase compliance rate, and decrease oppositional and aggressive behaviors. Although there has been some initial clinical 
success in accomplishing these goals (Stevens, Thompson, Masse, Burrell, Conley, \& McNeil, 2005), it is important to note that PCIT may not be an effective treatment for all children with ASD in that it relies on social reinforcement as a way to modify behavior. Prior studies examining the relation between social reinforcement and behavior of children with autism have demonstrated that attention is reinforcing though it may influence behavior differently. Fisher, Ninness, Piazza, \& Owen-DeSchryver (1996) showed that adult attention in the form of a reprimand ("Don't do that") maintained destructive behaviors in a young boy with autism more so than verbal attention not related to the behavior ("It's a sunny day outside"). In addition, Piazza et al., (1999), employing a concurrent schedule of reinforcement, demonstrated that reprimands were a stronger reinforcer for inappropriate behavior than praise was for appropriate behavior though praise was reinforcing when it was the only option available. Gena (2006) revealed that children on the autism spectrum increased spontaneous social initiations and responses to social bids when the behaviors were followed by verbal ("you're doing a great job talking") or physical (pat on the back) encouragement. Thus, although research has shown that attention can be reinforcing in maintaining or increasing behavior with children on the autism spectrum, studies have shown that it is important to consider the form of attention and how each may have a varying effect on behavior (Piazza et al.) One advantage of PCIT is that each session is essentially a continuous functional assessment as therapists are coaching parents through systematic manipulations of antecedents and consequences and monitoring the changes in the child's behavior. For example, it is common for a therapist to coach a parent to turn away from the child and ignore a disruptive behavior (e.g., screaming) and then to assess whether social attention was 
reinforcing that behavior by determining whether the behavior increased or decreased over time and with repeated trials. As noted, children with Asperger's or high-functioning autism (HFA) are likely to display a range of behaviors that are reinforced by social attention. On the other hand, it is recognized that some children with ASD are less responsive to social contingencies. Given that PCIT is based in large part on social reinforcers (e.g., labeled praise, reflection of speech, imitation) the approach may only be effective and appropriate for the portion of children with ASD who can easily be taught to consistently respond to social contingencies. Therefore, PCIT may be limited for a specific portion of the ASD population.

\section{Study Rationale and Hypotheses}

Historically, cases of ASD have been excluded from participation in PCIT as it was assumed that the treatment would not be effective with this population because of PCIT's reliance on social contingencies. Yet, as noted, many children with ASD who are in the high-functioning range (e.g., those with the diagnosis of Asperger's) are reinforced by social attention. Thus, over the past several years, there has been an increase in the number of children with ASD referred to PCIT clinics. As externalizing behaviors are very common in a clinical presentation of ASD, many parents desire to initially treat their child's noncompliance and aggression before treating other behaviors. Thus, the question has been raised as to whether PCIT should be more readily available as a gateway intervention for preschool children with high-functioning autism who display cooccurring problems with noncompliance/defiance and aggression. Research is greatly needed in this area to assist community providers in determining the appropriateness of PCIT as a component of an intensive, multifaceted treatment protocol with children on 
the autism spectrum. The proposed project examined the efficacy of Parent-Child Interaction Therapy with high-functioning autism by employing a non-concurrent multiple baseline design across participants. The aim of the study was to assess whether PCIT is a viable, short-term, first-line treatment option for families with children on the high end of the autism spectrum continuum who demonstrate co-occurring behavioral difficulties. The study tested the following hypotheses:

Primary Hypotheses

1.) Child Compliance: It was hypothesized that child compliance rates would increase during the PDI phase of the intervention and changes would maintain at follow-up visit. Behavior observations (Compliance Test, DPICS-III PDI and cleanup situations) and parent report (Compliance Probability Checklist) was used to measure this variable. 2.) Caregiver Behavior: It was hypothesized that the implementation of PCIT would result in observable changes in parenting behavior.

(a) Caregiver use of positive parenting behavior (PPB as defined by labeled praise, behavior description, reflection) would increase during the CDI phase of therapy and skills maintain or improve throughout PDI and at the follow-up visit. (b) Caregiver use of negative parenting behavior (NPB as defined by questions, commands, negative talk) would decrease during the CDI phase of therapy and skills would maintain or improve throughout PDI and at the follow-up visit.

Secondary Hypotheses

3.) Parent Report of Child Behavior: It was hypothesized that there would be reductions in child externalizing behaviors at post-treatment and at the follow-up visit as measured by the Child Behavior Checklist and Eyberg Child Behavior Inventory. 
4.) Child Autistic Behavior: It was hypothesized that behaviors indicative of autism would decrease at post-treatment and follow-up as measured by Autism Behavior Checklist and Childhood Autism Rating Scale.

5.) Parenting Stress: It was hypothesized that there would be reductions in reported stress at post-treatment and follow-up as measured by Parenting Stress Index-Short Form. 6.) Receptive Language Capabilities. It was hypothesized that child receptive language skills would improve at post-treatment and maintain at follow-up visit as measured by Peabody Picture Vocabulary Test-Third Edition.

7.) Child Intelligence: It was hypothesized that child intelligence scores would increase at post-treatment and maintain at follow-up visit as compliance with testing instructions would increase. Child intelligence was measured by Wechsler Preschool and Primary Scale of Intelligence-Third Edition.

8.) Child Adaptive Functioning: It was hypothesized that child adaptive functioning would improve at follow up and maintain at follow-up visit as measured by Vineland Adaptive Behavior Scales-Interview Edition.

9.) Child Imitation: It was hypothesized that child imitation rates would increase between pre-treatment and post-treatment and maintain at follow-up visit as measured by Imitation of Pretend Play Task.

10.) Consumer Satisfaction: It was hypothesized that PCIT would be deemed as an acceptable and efficacious intervention for reducing noncompliance in children with autism at post-treatment and follow up as measured by Treatment Attitude Inventory. 
Method

\section{Participants}

Participants were recruited from community referrals (e.g., schools, clinicians, health care professionals) in Morgantown, WV. Inclusion criteria for the study were as follows: (a) child was between the ages of 2 and 7 (due to PCIT requirements), (b) participating caregiver was the primary caregiver and legal guardian of the child, (c) caregiver agreed to the constraints of the research design (i.e., time needed to complete assessment questionnaires, home-based assessment and treatment), (d) child was previously diagnosed with autism spectrum disorder and was identified by a teacher or mental health professional as having significant compliance issues, (e) pre-treatment behavioral observations (i.e., a minimum of three consecutive baseline sessions) demonstrating child compliance rates equal to or lower than an average of $60 \%$, and (f) child had receptive language skills greater than 24 months (as assessed by the Peabody Picture Vocabulary Test-III). Referred families were excluded from participation if (a) there was a known history of psychosis or organic brain damage for the caregiver or child, (b) the caregiver-child dyad was non-English-speaking, or (c) scores on the Childhood Autism Rating Scale (CARS; Schopler, Reichler, \& Renner, 1988) or the Autism Behavior Checklist (ABC; Krug, Arick, \& Almond, 1993) were below clinical cutoff. As participants met selection criteria, they were admitted into the study. Participants were offered remuneration for their completion of assessment measures (i.e., $\$ 75$ for pre-treatment assessment, $\$ 75$ for post-treatment assessment and $\$ 100$ for follow up). When more than one caregiver was interested in participating in the treatment, he/she was given the option of observing treatment sessions and receiving coaching after 
primary caregiver, but did not participate in weekly assessments. A total of 5 families were recruited for the study with 3 families completing treatment and 2 families excluded at pre-treatment for not meeting study criteria. The following is a description of each child and family. Names have been changed to protect client confidentiality.

\section{Treatment Completers}

Kenneth. Kenneth was a 3-year-old Caucasian male who participated in the study with his 38-year-old father. Kenneth was recruited for the study from a local clinic specializing in developmental disabilities. Developmentally, Kenneth was born pre-term at 32 weeks weighing 9 pds., 4 ounces. He reached developmental milestones within normal limits but regressed at 18 months. At this time, he was diagnosed with Autistic Disorder at a nationally-recognized center for the assessment and treatment of pervasive developmental disorders. Since the diagnosis, Kenneth received speech, occupational, and physical therapy which continued throughout the study. Medically, Kenneth was lactose intolerant thus requiring a specialized diet. He was taking omega-3 fish oils throughout the study.

Family medical history was significant for diabetes (maternal grandfather) and high blood pressure on both paternal and maternal side of family. No family psychiatric history reported. With respect to social history, Kenneth lived at home with his biological parents. His mother has a bachelor's degree and worked as a nurse and father has bachelor degree and works as a training specialist. Family annual income was rated at $\$ 60,000$ or above.

Kenneth's father reported several behavioral concerns including physical aggression (e.g., hitting, kicking, biting), noncompliance at home and school, inattention, 
and hyperactivity. At intake, there was concern that Kenneth was going to be expelled from daycare as a result of aggressive behavior toward other children. In addition, Kenneth's father raised concerns about Kenneth's social functioning namely with establishing relationships and connectedness with others.

Kenneth and his father completed 3 baseline sessions, 2 CDI didactic sessions, 4 CDI coaching sessions, 2 PDI didactic sessions, 8 PDI coaching sessions, a posttreatment session, and a 3 month follow-up session. Kenneth's father completed homework consistently and stated he used the skills on a daily basis between sessions.

Adam. Adam was a 4-year-old Caucasian male who participated in the study with his 39-year-old biological mother. Adam was recruited from a specialized education program at a local elementary school. In terms of developmental history, Adam was born via cesarean section after 41 weeks gestation with no postnatal complications. He was described as a "socially aloof" infant often becoming rigid when held by parents. He walked at 9 months but showed significant delays in communication with limited language development until approximately 2 years of age. He was diagnosed with autism at 19 months by a clinical psychologist and received speech therapy, occupational therapy, and physical therapy at that time. His expressive and receptive language capabilities improved considerably after receiving speech services. At intake, Adam no longer received these services. Adam had fine motor difficulties and had difficulty appropriately holding writing implements. At time of intake, he had recently been placed in a specialized education classroom for children with developmental delays and was awaiting an IEP meeting to establish accommodations and services. He was not receiving additional therapeutic services outside of the specialized classroom. 
In terms of medical history, Adam was on a gluten and dairy-free diet due to food allergies. In addition, he also experienced digestive difficulties including Gastrointestinal Esophageal Reflux Disorder (GERD) and poor appetite control (i.e., overeating) sometimes resulting in vomiting. Also, he had some sleep difficulties in that he would fall asleep for an extended length of time (e.g., 3-5 hours) in the afternoon and would subsequently have difficulty falling asleep at bedtime. He received Melatonin nightly to help manage sleep problems. On several occasions, therapy sessions were cancelled as Adam was asleep and his caretaker was not comfortable awakening him. During the study, Adam was hospitalized briefly for Croup and experienced episodes of respiratory difficulties. Family medical history was significant for heart disease (paternal grandfather), and hypothyroidism (mother, maternal grandmother). Family psychological history was positive for panic disorder (maternal grandmother, maternal aunt, mother), obsessive-compulsive disorder (maternal grandmother), depression (mother), attentiondeficit hyperactivity disorder (cousin), Pervasive Developmental Disorder-Not Otherwise Specified (sister), and Asperger's Disorder (brother). Adam's mother was receiving combined therapy and psychopharmacologic treatment for her depression at the time of the study.

In respect of social history, Adam lived with his biological mother, 7-year-old biological sister and 11-year-old biological brother. Several months prior to the study, Adam's parents separated and filed for divorce with an ensuing custody dispute for the children. Adam's father lived out of state and saw Adam and his siblings approximately two weekends per month. As an additional stressor, Adam's family was in the process of selling their home during the study. Adam's mother has a bachelor's degree and was 
unemployed at the time of the study. His father has a master's degree and worked as a chemical engineer. The household combined annual income was rated as $\$ 60,000$ or above.

At intake, Adam was having behavioral difficulties at both home and school. He was often noncompliant and with his mother and school staff. He exhibited frequent tantrums typically when his needs were not met or when a limit was set. In addition, he engaged in risky behaviors such as running away from adults in public settings (e.g., playground, parking lots, stores).

Adam and his mother completed 5 baseline sessions, 2 CDI didactic sessions, 6 CDI coaching sessions, two PDI didactic sessions, 11 PDI coaching sessions, posttreatment session one week following final PDI coaching, and a follow-up session 10 weeks following post-treatment session. PDI coding began at PDI session 7 as Adam's mother demonstrated initial apprehension to giving her son a timeout and required additional coaching to ensure a safe and effective implementation of the timeout sequence. Homework assignments were initially completed on a daily basis but began to wane as therapy progressed and the stress of the divorce and selling the home intensified.

Christopher. Christopher was a 4-year-old Caucasian male who participated in the study with his 25-year-old biological mother. Christopher was recruited from a specialized educational program at a community school. Developmentally, prenatal complications were remarkable for pre-eclampsia resulting in induced labor at 35 weeks gestation. Christopher's mother also acknowledged that she used cigarettes during the pregnancy as she was not aware of the pregnancy until the second trimester. In terms milestones, Christopher began talking at 12 months but his language entirely regressed at 
18 months. He began walking independently at 18 months. Christopher was diagnosed at 18 months with autism by a clinical psychologist at a nationally recognized center for developmental disabilities. At the time of study, he was receiving in-home occupational and physical therapy which continued throughout treatment. He exhibited significant expressive language delays, immediate echolalia, and several self-stimulatory behaviors (e.g., rocking, hand flapping).

Family medical history was significant for diabetes, heart disease high blood pressure, Down's Syndrome on the maternal side and heart disease and obesity on the paternal side. Psychiatric history was remarkable for bipolar disorder (maternal grandmother), learning disability (mother and father), mood disorder (mother), and developmental delays (sister). Christopher's mother disclosed she was receiving individual counseling during the study.

Christopher lived in an apartment with his biological parents and 1-year-old sister. He attended a specialized program for children with developmental delays and had difficulty making friends. His mother had a high school degree and volunteered at a local school and his father had a bachelor's degree and worked as a correctional officer. Family combined income was reported in the $\$ 30,000-\$ 40,000$ range. In regards to familial stressors, Christopher's 18-month-old sister also demonstrated significant developmental delays (entirely nonverbal, pica) and required continuous supervision. Christopher's father worked nights placing the burden of caring for the children solely on his mother. Behaviorally, Christopher's mother reported that he was defiant and often would not comply with demands at both home and school. In addition, he frequently had tantrums and would become physically aggressive with parents. 
Christopher and his mother completed 6 baseline sessions, 2 CDI didactic sessions, 5 CDI coaching sessions, 2 PDI didactic sessions, and 8 PDI coaching sessions with PDI coding beginning at session 4, post-treatment session approximately one week following final PDI coaching session, and a 3 month follow-up session. Christopher's mother completed homework assignments consistently although periodically presented as tearful or irritable for sessions without providing more than a vague explanation of mood.

\section{Treatment Non-Completers}

Emma. Emma was a 7-year-old Caucasian female referred by a community school psychologist. Emma was diagnosed with PDD-NOS in July, 2007 and exhibited aggressive and disruptive behaviors at home and school. Emma was having frequent and severe tantrums in both settings. Per mother's report, Emma's behavior was typically "unpredictable" with prolonged episodes of irritability, aggression and rigid behavior. Emma's pretreatment ECBI intensity (132) and problem (22) as well as her Autism Behavior Checklist scores (66) were above clinical cutoff. Also, PPVT standard score was 93 with an age equivalence of 6 years, 6 months. Emma was excluded from the study as the Compliance Test was not sensitive to her behavioral difficulties and likely incongruent with her developmental abilities (i.e., under demanding). The average compliance rates across the initial three baseline sessions were $95.33 \%$ thus not allowing for behavioral improvement as measured by the study assessment.

Sean. Sean was a 3-year-old Caucasian male referred from a local outpatient facility specializing in pervasive developmental disorders. Sean's language development regressed at 15 months to a level of severe impairment. Sean was diagnosed with Autism Disorder at the age of 2 at a local agency specializing in the assessment and treatment of 
autism. He demonstrated frequent self-stimulatory behavior and was generally non-verbal with the exception of few words. Pre-treatment ECBI scores were in the clinical range on both the intensity (155) and problem (23) scales. Autism Behavior Checklist score (97) was also above clinical cutoff. Sean was excluded from the study as he was unable to complete the Compliance Test (attempted on 3 separate occasions) due to receptive language and attention difficulties. Specifically, the Compliance Test was discontinued at each administration after Sean was not able to stay on-task or accurately identify the materials of the test (e.g., basket, dinosaur, chair).

\section{Therapists}

Two graduate students from the Clinical Child Psychology Program at West Virginia University served as clinicians for the study. Both therapists had prior clinical and research experience with Parent-Child Interaction Therapy and were provided with a treatment manual with detailed outlines of the procedures for each session. Both therapists received weekly 1 -hour supervision throughout the study from a licensed clinical psychologist and nationally-recognized expert in PCIT.

\section{Experimental Design}

A non-concurrent (i.e., families did not need to begin therapy contemporaneously) multiple staggered baseline design across subjects was used to measure caregiver behavior and child compliance. Treatment commenced after the baseline criteria were met. Prior to the study, a minimum number of baseline sessions (i.e., either 3, 4, or 5 sessions) were randomly assigned to family \#1, family \#2, and family \#3. Assigned baseline number for families excluded from the study were re-entered for random assignment. Kenneth and his family was assigned a minimum of 3 baseline sessions, 
Adam and his family was assigned 5 baseline sessions, and Christopher and his family was assigned 4 baseline sessions. Baseline data were collected for each dyad prior to the initial phase of treatment (i.e., CDI). Baseline data were obtained using the Compliance Test with the data point representing percentage rate of compliance. Prior to treatment, data demonstrated either a downward or even trend. Data were collected no more than once a day and an effort was made to collect data no fewer than once per week. If an appointment was missed or cancelled, another appointment was scheduled as soon as possible. Follow-up data was collected at one point for each dyad following the postsession. Time between post-treatment and follow-up session ranged from 10 to 12 weeks. The baseline criterion for progressing to the CDI phase of treatment was three data points demonstrating a neutral or downward trend in child compliance percentage. There were two criteria for switching from the CDI phase to the PDI phase. First, parents demonstrated mastery of the CDI skills. CDI mastery criteria were coded during the 5minute Dyadic Parent-Child Interaction Coding System-III (DPICS-III; Eyberg, Nelson, Duke \& Boggs, 2005). CDI observation and are defined as the caregiver's use of the following skills: (a) 10 labeled praises, 10 reflections, and 10 behavioral descriptions; (b) no more than 3 questions, commands, or criticisms/smart talk (coded as Negative Talk); and (c) ignoring of non-harmful inappropriate behaviors. Second, as PDI targets child compliance, the researcher needed to be insured that the introduction of PDI, rather than extraneous variables (e.g., maturation), had an effect on child behavior. Therefore, percentage of child compliance had to remain stable or show a downward trend over three consecutive CDI sessions before PDI was introduced. Caregiver behavior was obtained during the 5-minute CDI observation period. Child compliance data was 
gathered during the administration of the Compliance Test. If a dyad met CDI mastery criteria, but failed to meet the criterion of a stable or downward trend in percentage of child compliance, then baseline data continued to be collected until the criteria were met.

The proposed study investigated ten dependent variables during various phases of the study (i.e., pre-treatment, each session, post-treatment, follow up; Table 1). The caregiver behavior variable was coded during the 5-minute DPICS-III CDI observations before each CDI session. Caregiver positive behavior was assessed by examining the number of labeled praises, reflections, and behavioral descriptions. Caregiver negative behavior was calculated by adding the number of questions, criticisms/smart talk, and commands. In addition, the child compliance variable was assessed at every session during the study (i.e. pre-treatment through follow up). This variable was obtained at the outset of each treatment session using the Compliance Test. Next, the child imitation variable was obtained at pre-treatment, post-treatment and follow up. The other dependent variables include the Eyberg Child Behavior Inventory, Parenting Stress Index- Short Form, Therapy Attitude Inventory, Childhood Autism Rating Scale, Compliance Probability Checklist, Autism Behavior Checklist, Peabody Picture Vocabulary Test, Questions About Behavioral Functioning, Vineland Adaptive Behavior Scales, and the Wechsler Primary and Preschool Scale of Intelligence. Each of these listed dependent variables were measured at pre-treatment, post-treatment and follow up. Measures

Autism Behavior Checklist (ABC; Krug, Arick, \& Almond, 1980). The ABC is a 57-item assessment devised to measure behaviors indicative of autism spectrum disorders (see Appendix A). The ABC is designed to be completed independently by a parent or a 
teacher familiar with the child. The respondent answers each item in a "yes/no" format in terms of presence of the behavior. Each item on the assessment is given a weight (1-4) based on the degree to which it is indicative of Autism Spectrum Disorders. For example, "frequently does not attend to social/environmental cues" received four points and "cannot point to five named objects" receives one point. The $\mathrm{ABC}$ has 57 questions divided into five categories: (1) sensory, (2) relating, (3) body and object use, (4) language, and (5) social and self-help. The total score, or the sum of the weights, is used to assess the presence of autism.

Although the cutoff score was originally established by Krug et al. (1980) at 53, additional research (Wadden, Bryson, \& Rodger, 1991) has demonstrated that a lower cutoff score of 44 demonstrated stronger construct validity. More specifically, the study examined 123 children with developmental delays and correctly classified $87 \%$ of children with Autism and 96\% of non-autistic children. Other research has shown adequate psychometric properties for the ABC. For example, Krug et al. (1980) demonstrated split-half reliabilities of .87 for the total score, whereas Volkmar et al. (1988) reported split-half reliability index of .70 for the total score. In addition, Krug et al. (1980) found $95 \%$ inter-rater reliability across 42 independent raters. The internal consistency of items has been studied extensively (Sturmey, Matson, \& Sevin, 1992) with the majority of investigations showing moderate support for analyzing individual subscales. The study used the overall cutoff score of 44 devised by Wadden et al. and individual subscale scores when analyzing the results of the measure. The $\mathrm{ABC}$ was completed by the parent at pre-treatment, post-treatment, and follow up. 
Childhood Autism Rating Scale (CARS; Schopler, Reichler, \& Renner, 1988).

The CARS is a 15 -item behavior rating scale based on direct behavior observation or interview (see Appendix B). The CARS was designed to identify children two years and older with autism and to distinguish them from developmentally-handicapped children who are not autistic. Observers rate child behavior on 14 general dimensions indicative of Autism Disorder (e.g., verbal communication, adaptation to change, etc.) plus an overall "impression of autism" dimension. Each dimension is rated on a 4-point Likert scale. Total score distinguishes level of autism on a continuum ranging from non-autistic to severely autistic with higher scores indicating higher levels of autism. A total score of 29 or less is indicative of "non-autism;" scores between 30 and 36 signify "mild-moderate autism;" and scores 36 and above indicate "severe autism." Research has shown adequate reliability and validity indexes for the CARS. More specifically, Eaves and Milner (1993) examined the relationship between the Autism Behavior Checklist and the CARS and found a validity coefficient of .67. Also, the researchers concluded that both assessments were sensitive in accurately detecting children diagnosed with autism. Next, the authors of the measure found a one year test-retest correlation of .88 and criterion-related validity correlation of .84 indicating the assessment is stable over time and has high validity when compared to criterion ratings (e.g., clinical ratings). The CARS was administered at pretreatment, post-treatment and two-month follow-up.

For the proposed project, the Childhood Autism Rating Scale was administered through behavioral observations conducted by trained graduate students and an undergraduate student. Prior to the study, the observers underwent a training in which they were tested on definitions for all 15 constructs included on the measure. Each 
observer obtained at a score of $80 \%$ on the quizzes. Next, raters observed 30 -minute videotaped segments of a child with autism and coded the behavior using the assessment. Scores based on the observation were within four points or one standard deviation (Perry, Condillac, Freeman, Dunn-Geier, \& Belair, 2005) on three consecutive observations.

Observer scores were within six points or one and a half standard deviations (Perry et al.) of each other at each assessment point of the study.

Child Behavior Checklist (CBCL; Achenbach \& Edelbrock, 1981; Achenbach \& Rescorla, 2001, 2002). The CBCL is a well-recognized parent assessment used to measure child psychopathology. The preschool (ages $1 \frac{1}{2}$ to 5) forms were used for the proposed study (see Appendix C). When filling out the form, parents rate on a 3-point scale the degree to which each item characterizes their child's behavior within the past 2 months. Results include a Total Problems score, two broadband scores (Internalizing Problems, Externalizing Problems) and narrowband subscale scores (e.g., Aggressive Behaviors). The $\mathrm{CBCL}$ is recognized as one of the best validated measures for assessing behavioral problems in children. Psychometric properties of the CBCL have been widely cited in the literature (e.g., see Achenbach \& Rescorla, 2000, 2001 for reviews). Also, the CBCL has shown to distinguish referred, clinical samples from non-referred samples (Achenbach, 1981). Norms are age-based and gender-based. The CBCL was administered to parents at pre-treatment, post-treatment and follow up.

The Compliance Probability Checklist (Ducharme, Popynick, Pontes, \& Steele, 1996). The Compliance Probability Checklist is an assessment comprised of 122 requests targeting general areas of compliance such as dressing, hygiene, playtime, academic skills, cleanup, and mealtime (see Appendix D). For each request, parents rate the 
likelihood of child compliance based on the percentage of time they would expect their child to comply with the particular item. Parents select from "almost always" (76\%100\%), "usually" (51\%-75\%), "occasionally" (26\%-50\%), and "rarely" (0\%-25\%). Currently, little empirical data exists on the psychometric properties of the measure although the assessment has been used in several investigations (e.g., Ducharme, Spencer, Davidson, \& Rushford, 2002; Ducharme, Atkinson, \& Poulton, 2000). The proposed project used this assessment as a clinical guideline measuring change in general compliance over time. The measure was distributed to parents at pre-treatment, posttreatment, and follow up.

The Compliance Test (Roberts \& Powers, 1988). The Compliance Test is designed to assess child compliance rate to parental demands. Typically, therapists coach parents through a one-way mirror using a bug-in-the-ear device. However, as the proposed project took place in the home environment, therapists conducted in-room coaching with the parent by sitting behind the parent and discretely providing direction. When administering the assessment, therapists gave the parent a series of cards, one at a time, which contained a specific script. For example, for each command administered, the parent was given a single card that read, "say please pick up this cow." In addition, the therapist manipulated the play area after each command in order that the play situation was naturalistic and the assessment can continue without interruption. Brumfield and Roberts (1998) analyzed each study using the Compliance Test between 1981 and 1998 and provided an overview of the psychometric properties of the assessment. The authors assert that the measure has consistently shown strong inter-rater reliability coefficients (97\% average across studies) and high internal consistency (Kuder Richardson $20=.99$ ). 
Also, the measure has shown sensitivity to intervention effects (Roberts \& Powers, 1988). Lastly, Brumfield and Roberts (1998) state that the test is clinically useful in that it minimizes false positives by correctly identifying noncompliance across repeated administrations. Roberts and Powers (1998) found that each child who met criteria for noncompliance $(<60 \%$ compliance) remained noncompliant at the subsequent testing prior to the introduction of treatment. Overall, the Compliance Test has consistently demonstrated strong reliability and validity indices.

When administering the test, a parent was coached to administer 10 two-step motor tasks to pick up particular toys and place them in specific containers. The verbal directions were accompanied by a physical gesture (i.e., pointing to the specific object). The sequence of the directions as well as the particular toys and containers used in the assessment were standardized across administrations. The first command instructed the child to pick up the toy with the second step directing the child to place the toy in a particular container. For example, the parent directed the child to "please pick up this red block" followed by "please put the red block into the school bus." The parent waited 5 seconds for compliance and then was coached to give another command regardless of child compliance. Compliance was coded if the child initiated a continuous motor movement within 5 seconds that terminated in grasping the object or complying with the command. Noncompliance was coded if the child failed to initiate within 5 seconds or if the child initiated, but discontinued after 5-seconds without grasping the object or completing the command. If the child does not comply with the first command, the command is combined with the second (i.e, "please pick up the red block and put it into the Lego box"). Compliance rate (\%) is determined by the number of compliant 
responses divided by the number of instructions given (i.e. frequency of compliance/30).

For the project, the Compliance Test was modified in a several ways. First, in an effort to prevent ceiling effects that may occur due to the potential ease of the play commands, the test included 10 items from the Compliance Probability Questionnaire-Academic Version (Ducharme \& DiAdamo, 2005). Second, the test items was modified to make the tasks more developmentally appropriate and logistically feasible. For example, the item, "please put the beads in the laundry basket" has been changed to, "please put the red block in the Lego box." See Appendix E for measure with modifications and scoring key.

The Compliance Test was used in determining baseline criteria and as one of the dependent variables in the study. If a child's compliance rate was equal to or above an average of $60 \%$ across 3 consecutive baseline sessions, then the child was excluded from the study based on ceiling effects. In other words, a child who was consistently demonstrating high compliance rates prior to treatment introduction was likely not a good candidate for the study (Emma).

The Compliance Test was administrated at the outset of each baseline and treatment session. The Compliance Test was videotaped at pre-treatment, post-treatment, and follow up. Behavior observations and coding was conducted in-vivo with inter-rater reliability being attained for $57 \%$ of the observations.

Demographics Form. A demographics form was devised specifically for the proposed study (See Appendix F). This form included the following information: (a) child age, (b) child gender, (c) child ethnicity, (d) diagnosis child has received, (e) date child received assessment/diagnosis, (f) agency where child obtained diagnosis, (g) types of services child has received or is currently receiving, (h) medications your child has 
taken or is currently taking, (i) developmental history, (j) specialized dietary

considerations (k) caregiver age, (l) caregiver gender, (m) caregiver ethnicity, (n) number and ages of siblings in the home, (o) marital status, (p) employment status, (q) occupation, (r) caregiver education level, and (s) family income.

Dyadic Parent-Child Interaction Coding System-III (DPICS-III; Eyberg, Nelson, Duke \& Boggs, 2005). The Dyadic Parent-Child Interaction Coding System (DPICS) is a behavioral observation system designed to assess particular features of parent-child social interactions (see Table 2). The coding system was devised to code caregiver and child overt physical and verbal behaviors during one-on-one interaction. During these interactions, the level of parental control differs (Hembree-Kigin \& McNeil, 1995) and the therapist gives the parent specific instructions to convey to the child prior to each interaction. The first is the DPICS-III Child Directed Interaction (CDI) observation where the caregiver is told to let the child lead the play and follow the child's lead. The second situation is the DPICS-III Parent Directed Interaction (PDI) observation in which the caregiver tells the child it is the caregiver's turn to choose the activity and lead the play. The third situation is the DPICS-III cleanup situation in which the caregiver instructs the child to clean up the toys in the play area (See Appendix G for coding instructions). The psychometric properties of the DPICS has been studied extensively (see Eyberg, Nelson, Duke \& Boggs [2005] for an overview) and normative data are available (Eyberg et al., 1994). Reliability and validity studies of the DPICS during live coding situations have demonstrated adequate results (Bessmer \& Eyberg, 1993). The definitions for the codes are displayed in Table 2. 
Observations using the DPICS-III CDI interaction and PDI interaction was conducted at the start of each session in order to determine parent mastery criterion. Coders used a standardized form to record all observational data (see Appendix H). All DPICS-III coding was conducted live for dependent variables that are critical to phase switch criteria or treatment completion (i.e., Labeled Praise, Behavioral Description, Reflection, Questions, Negative Talk, Direct Command, Indirect Command, Child Compliance, Child Noncompliance, No Opportunity to Comply). Inter-rater reliability was attained on $55 \%$ of interactions over the course of the study. Pre-treatment, posttreatment, and follow up sessions were videotaped for further analysis.

Eyberg Child Behavior Inventory (ECBI; Eyberg \& Pincus, 1999; Eyberg \& Ross, 1978). The ECBI is a parent-report assessment that examines disruptive behaviors of children between the ages of 2 and 16 (See Appendix I). The measure is made up of 36 items that have shown to be specific problem behaviors for children with externalizing behavior disorders. Parents rate the frequency of behavior on a scale of 1 (never) to 7 (always), producing an Intensity Score. In addition, parents report whether the behavior is a problem (i.e., yes or no), yielding a Problem Score. The clinical cutoff scores are 131 for the Intensity Score and 15 for the Problem Score (Eyberg \& Pincus, 1999). Per PCIT treatment guidelines, criterion for treatment completion was intensity score of below or equal to 113. Several studies have shown the ECBI to be a reliable and valid measure in assessing problem behavior and also sensitive to behavior change at post-treatment (e.g., Boggs, Eyberg, \& Reynolds, 1990; Eyberg \& Ross). The ECBI was completed at pretreatment, weekly throughout the CDI and PDI portions of treatment, post-treatment, and follow up. 
Imitation of Pretend Play Task. A number of research studies have found that children with autism demonstrate deficits in imitation abilities (see Smith \& Bryson, 1994 for a review). Several authors have put forth theories in an effort to explain this phenomenon typically basing their hypotheses on cognitive deficit models (e.g., working memory; Rogers, Bennetto, McEvoy, \& Pennington, 1996). Study findings have been mixed in determining whether children with autism have more deficits in imitating simple actions than mental-aged matched children without developmental delays (Ingersoll, Schreibman, \& Tran, 2003). In order to examine imitation of pretend play, the proposed project adapted a method employed by Ingersoll and colleagues (see Ingersoll, Schreibman, \& Tran for overall procedure). First, the parent modeled a particular action three times while overtly describing the behavior (i.e., "I am feeding the baby"). Before initiation of each act, the child was verbally encouraged to watch the parent (i.e., "watch me"). The child had an identical toy placed in front of him/her prior to the first trial. If the child did not respond within the first ten seconds following the parent's third trial, the child was asked "What can you do with this?" The child then had 20 seconds to respond followed by the presentation of the next action. Scoring for the imitation task was based on guidelines suggested by Stone, Ousley, \& Littleford, (1997). Raters scored the task on a 0-2 scale with " 0 " representing a failure to imitate, " 1 " representing an emerging, but inaccurate, response (i.e., the child made an effort to engage in imitation but failed to reproduce the exact action), and " 2 " indicating an exact imitation (see Appendix $\mathrm{J}$ for instruction/coding sheet).

In order to standardize test administration, parents were given specific wording for each imitation activity and practiced assessment administration with the therapist 
prior to the session. Therapists were given the wording via a single note card until all imitations activities were completed. Therapists manipulated the play area between imitation activities to ensure that the assessment had minimal interruptions. Each prompt was given in the same order for every administration across parent child dyads. In addition, therapists tracked the time between trials and will indicate to the parent via note card when a prompt (i.e., "what can you do with this?") may be necessary. Imitation of pretend play was measured by examining individual differences in total score at each phase of the study. Ten imitation prompts were administered at pre-treatment, posttreatment, and at follow up.

Parenting Stress Index-Short Form (PSI-SF); Abidin, 1995). The PSI-SF is a 36item parent self-report condensed deigned to measure stress within the parent-child relationship (See Appendix L). In filling out the form, parents are asked to endorse items using a Likert scale ranging from strongly agree to strongly disagree. All subscales (e.g., Parental Stress, Difficult Child, etc.) were examined. The PSI-SF is a widely used measure and several studies have shown adequate reliability and validity for the measure (see Abidin, 1995 for review). More specifically, the PSI-SF has demonstrated concurrent validity $(r=.94)$ with the long form version (Abidin) and factor analysis revealed two separate and internally consistent subscales (Parental Distress and Dysfunctional ParentChild Interactions; Haskett, Ahern, Ward, \& Allaire, 2006). In addition, studies have been conducted with more varied populations (e.g., minorities, single parents) and have shown the PSI-SF to be a reliable and valid assessment tool supporting the use of the measure with an array of populations (Bhavnagri, 1999; Reitman, Currier, \& Stickle, 2002). Lastly, Eisenstadt et al. (1993) showed that scores on the full-scale PSI are 
sensitive to PCIT treatment effects. The PSI-SF was administered at pre-treatment, posttreatment, and follow up.

Peabody Picture Vocabulary Test-Third Edition (PPVT-III; Dunn \& Dunn, 1997). The PPVT-III is an interviewer-based vocabulary test assessing receptive language skills (See Appendix M). In administering the test, a child is read a vocabulary word, shown a series of four pictures, and then asked to point to the picture that best depicts the vocabulary word (e.g., "Can you show me the ball?”). Based on the responses, a raw score is calculated and then converted into a standard score equivalent and mental age equivalent. The test is separated into beginning points for various age groups and is completed when a child gets a certain number of questions incorrect within a particular age group. The PPVT-III is has been used extensively in clinical and research settings and has shown strong psychometric properties. More specifically, Dunn and Dunn (1997) have shown high internal consistency (Cronbach's Alpha ranging from .92. to .98 ; split half reliability ranging form .86 to .97 ) and solid test-retest coefficients ranging from .91 to .94. Lastly, the authors assert that the PPVT-III shows strong convergent validity with WISC-III verbal intelligence quotient. The PPVT-III was administered at pre-treatment, post-treatment, and follow up. At pre-treatment, the assessment was used as a screening measure at which time children will need to attain a score of $>24$ months to qualify for the study.

Questions about Behavioral Functioning (QABF; Mattson \& Vollmer, 1995). The QABF is a 25-item parent report measure devised for the purposes of identifying behavioral functions of abnormal behavior (See Appendix N). The measure was completed by rating frequency of specified target behavior (i.e., noncompliance) on a 
Likert scale ranging from " $0 /$ Never" to " $3 / \mathrm{Often."} \mathrm{In} \mathrm{addition,} \mathrm{the} \mathrm{caregiver} \mathrm{was} \mathrm{given}$ the option to rate "does not apply" for each item. The assessment is scored by tallying total number of items endorsed for each subscale and frequency of each of behavior (i.e., total score of subscale). The measure is divided into the following five categories of behavioral functioning: attention, escape, non-social, physical, and tangible. Freeman, Walker \& Kaufman (2007) investigated the psychometric properties of the QABF with a child sample and found adequate internal consistency (Nonsocial [.80], Physical [.88], and Tangible [.88]; the Attention [.79], and Escape [.79]). In addition, results demonstrated strong convergent validity with the Motivation Assessment Scale (Durand \& Crimmins, 1988) with correlations with similar subscales ranging from .66 to .76. The QABF attention subscale was primarily used in this study.

Therapy Attitude Inventory (TAI; Eyberg, 1974). The TAI was first developed by Eyberg and Johnson (1974) as a post-treatment measure to assess parental satisfaction following the completion of behavioral parent training programs (See Appendix O). Eyberg (1974) revised the questionnaire to make it more applicable to PCIT. The TAI is a ten-question measure containing items on a 5-point Likert scale. Higher score represent higher levels of caregiver satisfaction. Specific items ask parents to rate various components of the treatment including change in child problem behavior, confidence in implementing intervention components and general impressions of the treatment. Studies have shown strong validity and reliability for the TAI (Eisenstadt et al., 1993; Eyberg \& Matarazzo, 1980). Specifically, the TAI demonstrated high internal consistency $($ Cronbach's Alpha $=.91)$ and test-retest coefficient $(r=.85)$ (Brestan, Jacobs, Rayfield, \& Eyberg, 1999). The TAI was administered at post-treatment and follow up. 
Vineland Adaptive Behavior Scales-Interview Edition (Sparrow, Balla, \& Cicchetti, 1984). The Vineland Adaptive Functioning Scale is a 463-Item assessment measuring a number of domains (e.g., socialization, motor skills, communication, etc.) pertinent to daily functioning for individuals up to the age of 18 years, 11 months (See Appendix P). The interviewer asks the child's caregiver to respond to each item using a 5-point Likert scale ranging from "Don't know" to "Yes, usually." The caregiver begins the assessment at the appropriate age-designated item. Each domain question set is discontinued after seven consecutive scores of 0 . The Vineland has been widely used with a variety of clinical populations and has shown adequate psychometric properties. The authors of the measure demonstrated split half correlations ranging form .83 to .90 for the subscales and .94 for the composite score; test-retest reliability ranging from .81 to .86 for the subscales and .88 for the composite; and inter-rater reliability ranging from .62 to .78 for the subscales and .74 for the composite. The Vineland Adaptive Functioning Scale was administered at pre-treatment, post-treatment, and follow up.

Wechsler Preschool and Primary Scale of Intelligence-Third Edition (WPPSI-III; Wechsler, 2002). The WPPSI-III is an interview-based series of 12 individual subtests (e.g. block design, picture concepts, word reasoning, etc) designed to assess the cognitive ability of young children ages 2 years, 6 months to 7 years, 3 months (See Appendix Q). The WPPSI-III provides a general index of verbal and performance ability as well as an overall index of intelligence. The WPPSI-III has been standardized and normed on large samples and contains adequate psychometric properties (see Wechsler, 2002 for a more detailed description). The core subtests of the WPPSI-III were administered at pretreatment, post-treatment, and follow up. 


\section{Procedures}

Assessment procedure. Table 3 presents an overview of the assessment procedures. Prior to the study, all children were diagnosed with Autism Disorder by a psychologist or medical doctor through a full diagnostic intake and also identified as having compliance difficulties. In addition to the diagnostic report, the principal investigator gathered all documentation regarding the participant's individualized educational plan, previous testing results, etc. Pre-treatment assessment began by obtaining written informed consent to participate in the study. Inclusion criteria was measured using the Compliance Test for child compliance ( $<60 \%$ compliance rate), PPVT-III (>24 months) for receptive language capabilities, and ABC and CARS for autistic behavior. The pre-treatment assessment was conducted over a number of visits depending on the age and developmental level of the child. If the dyad met criteria (as assessed by the Compliance Test, PPVT-III, ABC \& CARS) and remained interested in participating in the study, they were enrolled into the study. Baseline sessions began following the completion of pre-treatment assessments. Post-treatment assessments were conducted on the session following the family's completion of treatment and measurements were administered in the same order as pre-treatment. At follow up, the post-treatment assessment were replicated.

Treatment procedure. Treatment was conducted in participant's homes. Treatment followed the standard clinic-based PCIT protocol with the exception that the sessions took place in the home setting. Due to the change in setting, a number of adaptations from the clinic-based protocol were necessary to properly implement the treatment. For instance, when PCIT was conducted in a laboratory or clinic setting, therapists employed 
a bug-in-the-ear device to coach parents from behind a one-way mirror. As this device is not accessible in the home setting, therapists coached parents in an "in-room" format. Therefore, during coaching sessions, the therapist sat behind the caregiver and quietly provided feedback to the parent. In addition, children were instructed to ignore the therapists while the therapists will not give attention to a child's advances. Preliminary research suggests that in-room coaching is an effective substitute to the traditional bugin-the-ear method (Rayfield \& Sobel, 2000). Also, Ware, McNeil, Masse, and Stevens (2008) found that PCIT in the home was as effective as the clinic-based model.

A detailed session-by-session protocol was administered to therapists in a manual modified for home-based PCIT. At the session after baseline criteria were met, the graduate student therapist(s) taught, modeled, and practiced the CDI skills with the parents. CDI coaching then began and proceeded until the caregiver met CDI mastery criteria. When the parent met CDI mastery criteria and compliance percentage rates were stable or decreasing over three consecutive sessions, the PDI didactic was conducted. Following the PDI didactic, PDI coaching sessions took place until ECBI scores were below 114 and the caregiver met mastery criteria (parents' commands must be effective and followed through correctly at least $75 \%$ of the time, and the child must exhibit a compliance rate of at least $75 \%$ ). The following week, post-treatment assessments were administered. A follow up session took place between 10 to 12 weeks following posttreatment.

Treatment integrity. Treatment integrity was obtained in a number of ways. First, therapists met on a weekly basis with a licensed clinical psychologist with extensive background administering and training PCIT. During these meetings, therapists described 
previous session(s) and were provided an overview of the content outline for the upcoming session(s). The supervisor provided feedback in order to ensure proper treatment integrity. Also, therapists brought treatment integrity checklists to each session each giving a detailed item-by-item description of the session's procedure and checked off items as they were completed (see Appendix K). Last, one therapist observed and independently complete integrity checklists for $57 \%$ of the therapy sessions. Integrity rates were calculated by dividing the number of session items completed by the total number of session items and multiplying by 100 . Treatment integrity scores were averaged across all sessions for each client and ranged from $97 \%$ to $98.5 \%$.

\section{Reliability of the Observational Assessments}

Coder training. Two graduate students were trained to code parent-child observations using the DPICS-III, child compliance using the Compliance Test, and child imitation using the imitation of pretend play task. Training included a series of didactics, homework assignments, and evaluations. After the training, the raters coded live or videotaped interactions. Coders were considered reliable after attaining an agreement of .75 Kappa for each of the dependent variables on three consecutive observations.

Interobserver agreement. All DPICS-III, Compliance Test, and imitation of pretend play task observations were coded live with the exception of pre-treatment, posttreatment, and follow up sessions which were coded live and also videotaped. Inter-rater agreement was attained for $55 \%$ of the observations. Kappas were calculated for each DPICS-III code used as a dependent variable or a component of a dependent variable (i.e., Labeled Praise [LP], Behavioral Description [BD], Reflection [RF], Indirect Command [IC], Direct Command [DC], Questions [QU], Negative Talk [NT], Child 
Compliance [CCO], Child Noncompliance [NCO], No Opportunity to Comply [NOC], and Contingent Praise [CP]. Kappa's were averaged across participants and DPICS situation (i.e., CDI, PDI, cleanup) for each DPICS-III code. Average Kappas and the range for each code were the following: $\mathrm{LP}(M=.81$, range $=.77-.84), \mathrm{BD}(M=.79$, range $=.78-.80), \mathrm{RF}(M=.80$, range $=.73-.93), \mathrm{IC}(M=.91$, range $=.88-.97), \mathrm{DC}(M$ $=.92$, range $=.88-.97), \mathrm{QU}(M=.89$, range $=.84-.92), \mathrm{NT}(M=.96$, range $=.94-.98)$, $\mathrm{CCO}(M=.92$, range $=.90-.94), \mathrm{NCO}(M=.96$, range $=.94-.98), \mathrm{NOC}(M=.93$, range $=.93-.94), \mathrm{CP}(M=.96$, range $=.94=.98)$. A Kappa value for the Compliance Test was also obtained and averaged across participants $(M=.88$, range $=.86-.90)$ as well as for the imitation of pretend play task $(M=.77$, range $=.70-.90)$.

Results

\section{Primary Hypotheses}

\section{Child Compliance for Kenneth}

Compliance Test. Kenneth's compliance data are displayed in Figure 1.

Compliance rate across baseline sessions was relatively low ranging from $17 \%$ to $30 \%$ and a phase mean of $25.67 \%$. Although compliance rate remained low, there was a slight increase across the CDI phase with a phase mean of $36 \%$. During the PDI phase, there was a noticeable upward shift in compliance with rates ranging from $47 \%$ to $80 \%$ and phase mean of $60.88 \%$. Compliance rate at post-treatment was $77 \%$ and $100 \%$ at followup.

PDI observations. PDI compliance data are displayed in Figure 2. Child compliance data were gathered across all treatment sessions with PDI coding beginning at PDI session \#3. Pre-treatment score was $66 \%$ and PDI scores ranged from $25 \%$ to 
$100 \%$ with an average of $83.88 \%$. Compliance rate at post-treatment and follow-up was $100 \%$.

Clean up observations. Clean up compliance data are demonstrated in Figure 3. Child compliance rate during a 5-minute cleanup situation was gathered at pre-treatment, post-treatment, and follow-up and showed an increase across treatment phases with compliance rates of $40 \%, 100 \%$, and $100 \%$, respectively.

Compliance Probability Checklist. Compliance probability checklist data are exhibited in Figure 4. At pre-treatment, Kenneth's caretaker reported that Kenneth would "usually" or "almost always" comply with $53 \%$ of the items on the checklist. At posttreatment, the value increased to $80 \%$ and continued improvement at follow-up with a score of $86 \%$.

\section{Child Compliance for Adam}

Compliance Test. Compliance percentage data for Adam are depicted in Figure 1. Low levels of compliance were demonstrated during the baseline phase with an average percentage of .75\% across 5 sessions. During the CDI phase of treatment, compliance percentage increased considerably to a phase mean of $56 \%$. During PDI, compliance percentages were variable throughout the phase ranging from $7 \%$ to $93 \%$ with an overall phase mean of $51 \%$. Compliance rate at post-treatment was $60 \%$ and decreased at followup to $37 \%$.

PDI observations. Adam's PDI compliance rate data are demonstrated in Figure 2. Child compliance data were gathered at pre-treatment and across 5 PDI treatment sessions beginning at PDI session \#7. Pre-treatment percentage was $29 \%$ and PDI scores 
ranged from $60 \%$ to $100 \%$ with an average of $83 \%$. Compliance rate at post-treatment was $63 \%$ and $80 \%$ at follow-up.

Clean up observations. Clean up compliance data are demonstrated in Figure 3. Child compliance rate during 5-minute cleanup situation was gathered at pre-treatment, post-treatment, and follow-up and showed an increase across treatment phases with compliance rates of $11 \%, 58 \%$, and $100 \%$, respectively.

Compliance Probability Checklist. Compliance probability checklist data are exhibited in Figure 4. Adam's caretaker indicated at pre-treatment that Adam would "usually" (defined as 51\%-75\% of the time) or "almost always" (defined as 76\%-100\%) comply with $57 \%$ of the commands he was capable of performing. At post-treatment, this likelihood increased to $88 \%$ of requests with a slight increase to $90 \%$ at follow-up.

\section{Child Compliance for Christopher}

Compliance Test. Christopher's compliance data are displayed in Figure 1. There was a notable upward trend across the initial baseline sessions $(33 \%, 43 \%, 47 \%)$ with a subsequent downward trend across the next three sessions $(27 \%, 30 \%, 23 \%)$. The phase mean for the baseline sessions was $33.83 \%$. Compliance rates through CDI remained generally consistent with baseline with a range between $33 \%$ and $40 \%$ and a phase mean of $34.40 \%$. There was considerable variability in compliance during PDI with rates ranging from $3 \%$ to $43 \%$ and a phase mean of $15.78 \%$. Compliance rate at post-treatment was $17 \%$ with a considerable increase at follow-up to $70 \%$.

PDI observations. PDI compliance data are depicted in Figure 2. Child compliance data were gathered at pre-treatment and pre-treatment ad across 5 treatment sessions beginning at PDI session \#4. Pre-treatment percentage was 29\% with PDI scores 
ranging from $75 \%$ to $100 \%$ with an average of $95 \%$. Compliance rate at post-treatment and follow up was $63 \%$.

Clean up observations. Clean up compliance data are demonstrated in Figure 3. Child compliance rate during a 5-minute cleanup situation was gathered at pre-treatment, post-treatment, and follow up and showed an increase across treatment phases with compliance rates of $38 \%, 100 \%$, and $100 \%$, respectively.

Compliance Probability Checklist. Compliance probability checklist data are exhibited in Figure 4. At pre-treatment, Christopher's mother reported that he was likely to "usually" or "almost always" comply with $34 \%$ of requests depicted on the assessment that he was capable of performing. At post-treatment, the probability ratio increased to $68 \%$ with a continued upward trend at follow-up with a compliance likelihood of $73 \%$.

\section{Caregiver Behavior}

Kenneth's caregiver behavior is depicted in Figure 5. There were zero positive parenting behaviors (PPBs) observed at pre-treatment with an observable increase through CDI $(M=24.25)$ and PDI sessions $(M=28.57)$. PPBs maintained at both posttreatment (36) and follow-up (30).

There were 7 negative parenting behaviors (NPB's) observed at pre-treatment. There was a downward trend in NPB's through CDI with a mean phase of 3. A further reduction was seen throughout PDI with a mean phase of .53. Low levels of NPB were maintained at post-treatment (1) and follow-up (2).

Positive caregiver behavior for Adam is demonstrated in Figure 5. At pretreatment, Adam's caregiver did not exhibit PPB's. A noticeable increase in PPB was observed at the session following the CDI didactic (29 PPB) and remained generally 
stable throughout the CDI phase. The phase mean of PPB during CDI was 30.83 . The level of PPB decreased to 24.27 during PDI. There were 32 PPBs at post-treatment and 29 at follow-up.

At pre-treatment, 19 NPB's were observed. During CDI, there was an observable decrease in NPB with a mean of .86. During PDI, low levels of NPB maintained with a mean of .85. There were 2 NPBs at both post-treatment and follow-up.

Christopher's caregiver behavior is depicted in Figure 5. At pre-treatment, there were no PPB's observed. During CDI, there was an observable increase of PPB's with a phase mean of 31.60. PPB's continued to increase through PDI with a phase mean of 36.25 and maintained at post-treatment and follow-up with a score of 36.

There were 26 NPBs observed at pre-treatment. There was an observable reduction in NPB's when CDI began with a score of 9 and a continued downward trend across CDI sessions with a mean of 5.80. CNB declined further through PDI sessions with a mean of 1.88. CNB's maintained at post-treatment and follow-up with 1 and 2 CNB's observed, respectively.

\section{Secondary Hypotheses}

\section{Parent Report of Child Behavior}

$E C B I$. ECBI intensity scores are displayed in Figure 6 while problem scores are demonstrated in Figure 7. Kenneth’s ECBI intensity scores were below clinical significance at baseline session \#1 but trended upwards across sessions 2 and 3 . The baseline average for the phase was 131.33 and above clinical cutoff. After introduction of CDI, ECBI scores demonstrated a notable upward trend with an average phase mean of 154.75. Intensity scores remained at CDI level until PDI session \#4 at which point scores 
decreased between PDI sessions \#5 and \#8. Scores were below treatment completion criterion at PDI session \#8. Average intensity score for PDI phase was below clinical cutoff at 130.75. ECBI problems scores remained below clinical levels throughout treatment. Scores across baseline and CDI remained generally stable with an average of 11.71. Scores across PDI sessions gradually decreased across sessions with an average of 5.88. Problem scores dropped to 0 at post-treatment and follow-up.

Adam's ECBI intensity scores at baseline were well above clinical cutoff (i.e., 131) with no notable trend and an average of 181.40 . During CDI, intensity scores demonstrated a decrease but remained elevated with an average of 175.83. It is worth noting that there was a downward trend across the last $3 \mathrm{CDI}$ assessments with scores shifting from a mean of 184 to an average of 167.77. During PDI, scores continued to decrease and was 113 (below completion criterion score of 114) at PDI session 11 with an overall phase mean of 143.63. Scores remained below completion criterion at posttreatment (109) and follow-up (111). ECBI problem scores were above clinical cutoff (i.e., 15) and stable throughout baseline with a mean of 26.75. Problem scores maintained at baseline levels during CDI with an average of 24.40 and remained at this level through the first 5 PDI sessions. Beginning at PDI session 5, scores began to decrease gradually and dropped below clinical significance at PDI sessions 10 and 11. Scores maintained below clinical cutoff at post-treatment (6) and follow-up (8).

Christopher's ECBI intensity scores were above clinical cutoff during baseline with a notable increase between baseline session 1 and the remainder of baseline sessions. Phase mean for baseline sessions was 178.17. During CDI, intensity scores decreased considerably from baseline with an average of 137.40 thus remaining above 
clinical cutoff. After PDI was introduced, intensity scores continued to decline and dropped below completion criterion at PDI sessions 5, 7, and 8 . The overall phase mean for PDI was 116.86 and below clinical cutoff. Post-treatment scores remained low at 102 but demonstrated a considerable increase at follow-up with a score of 144 . Problem scores followed same pattern as intensity scores for this dyad. Baseline scores were clinically significant with an average of 27.67. After CDI implementation, scores demonstrated a downward trend but remained above clinical cutoff with an average of 19.6. Scores continued to decrease during PDI with an average score of 13.14. ECBI problem scores were below clinical significance at PDI sessions 5, 6, and 7. At posttreatment and follow-up, scores maintained at low levels at 6 and 11, respectively.

Child Behavior Checklist. Total score and scores for the externalizing, internalizing, and PDD subscales are demonstrated in Figure 8 (all scores in this section are $t$-scores). Kenneth's total CBCL score decreased across assessment points with each score falling below clinically significant range. Externalizing score decreased considerably from 71 at pre-treatment to 54 at post-treatment and 55 at follow-up. Internalizing scores remained below clinical cutoff throughout the study. On the PDD scale, scores decreased from 78 at pre-treatment to 71 at post-treatment. At follow-up, PDD score decreased to 66 and below clinical cutoff.

Adam's total CBCL score was 79 and above clinical cutoff (i.e., 70) at pretreatment. Both post-treatment and follow-up scores were below clinical significance at 58 and 67, respectively. Likewise, internalizing (i.e., emotionally reactive, anxious/depressed, somatic complaints, withdrawn) subscale decreased from a pretreatment score of 72 to a post-treatment score of 53 and follow-up score of 60. 
Externalizing (i.e., attention problems and aggressive behavior) subscale score decreased from pre-treatment (86) to post-treatment (70) and follow-up (71) but remained clinically elevated at each assessment point. PDD scores went from above (72) to below clinical cutoff at post-treatment (64) and follow-up (66).

Christopher's CBCL total scores remained above clinical cutoff across assessment points $(72,74,78)$ with internalizing behavior maintaining just above clinical significance $(71,71,74)$ and externalizing behavior maintaining just below clinical cutoff across assessment points $(64,68,69)$. PDD scores remained at clinically elevated levels across assessment periods. Report of Autistic Behavior

Autism Behavior Checklist. ABC data are displayed in Figure 9. Each participant's scores on the $\mathrm{ABC}$ demonstrated a downward trend across treatment phases with all scores remaining above clinical cutoff (i.e., 44). At pre-treatment, Kenneth's $\mathrm{ABC}$ score was 91 with a post-treatment score of 48 . At follow-up, the $\mathrm{ABC}$ score maintained at post-treatment level with a score of 47 . Subscale analysis revealed a downward trend across categories with marked decreased on several subscales. The Relating subscale scores descended from 16 at pre-treatment to 10 at post-treatment and 6 at follow-up. The Language subscale (e.g., follows simple commands, gests desired objects by gesturing, echolalia) score decreased from 17 (highest score of 31) at pretreatment to 4 at post-treatment and follow-up. Last, the Social and Self Help scores diminished from 20 at pre-treatment to 9 at post-treatment and follow-up.

Adam's ABC pre-treatment score was 85 with a noticeable reduction at posttreatment and a score of 62. At follow-up, Adam's score further declined to 49. A more 
detailed analysis of the measure demonstrated downward trends in score across several subscales. First, the Relating subscale (e.g., attending to social cues, avoids eye contact, "looks through people") scores reduced from 15 (highest score of 38) at pre-treatment to 9 at post-treatment and follow-up. Next, Body and Object Use (e.g., appropriate use of toys, destructive, whirls/spins self) decreased from 28 (highest score of 38) at pretreatment to 5 at post-treatment with a slight increase at follow-up with a score of 9. Last, Social and Self Help (e.g., severe or minor temper tantrums, attention to social cues, aggressiveness) decreased from 23 (highest score of 25) at pre-treatment to 21 at posttreatment and 17 at follow-up.

Christopher's ABC score at pre-treatment was 112. There was a slight downward trend at post-treatment with a score of 103 and a further decrease in follow-up with a score of 96. A more detailed analysis revealed a downward trend in the Relating subscale with scores decreasing from 31 (out of 38) at pre-treatment to 23 at post-treatment and 20 at follow-up. In addition, the Sensory subscale (e.g., seems not to hear, no visual reaction to "new" people, stares into space for long periods of time) reduced from 19 (highest score of 25) at pre-treatment to 15 at post-treatment and 12 at follow-up.

Childhood Autism Rating Scale. The CARS score represents the average scores of independent coders at each assessment point of the study (i.e., pre-treatment, posttreatment, and follow-up). CARS data are depicted in Figure 10.

Kenneth's pre-treatment score of 33 was in the mild-moderate range whereas post-treatment score of 26 and follow-up score of 24.5 were both in the non-autistic range. Detailed analysis demonstrated a score reduction for each subscale ranging from .5 to 1 with just less than half ( 7 of 15 ) of subscales reducing by 1 point. 
Adam's pre-treatment CARS score was a 41.5 placing him in the severely autistic range. At post-treatment, the average score was a 31 indicating mild-moderate autistic behavior with a follow-up score of 32 which is also in the mild-moderate range. Detailed analyses of the CARS scores demonstrated a 1-2 point score reduction across subscales with the exception of Verbal Communication which remained at a score of 2 (out of 4; mildly abnormal range). Largest score deficit was observed on the Adaptation to Change subscale with scores decreasing from 4 (severely abnormal) at pre-treatment to 2 (mildly abnormal) at post-treatment and follow-up.

Christopher's CARS remained fairly even with each score falling in the mildmoderate autistic range. Specifically, Adam's data demonstrated a pre-treatment score of 44, a post-treatment score of 42 , and follow-up score of 38 . Detailed score analysis revealed score changes ranging from .5 to 2 points across subscales with majority of subscales remaining at the same level or a lower score of .5. The largest score reduction was 2 points (pre-treatment score of 4 and post-treatment score of 2) for the Body Use subscale.

\section{Parenting Stress}

Parenting Stress Index-Short Form. PSI-SF data are exhibited in Figure 11. With the exception of Total Stress $\left(95^{\text {th }}\right.$ percentile) and Difficult Child $\left(90^{\text {th }}\right.$ percentile) pretreatment scores, Kenneth's scores were within normal limits across treatment phases.

Adam's caregiver reported clinical significant Total Stress scores at pre-treatment and post-treatment with scores below clinical cutoff at follow-up. Difficult Child subscale followed the same pattern as Total Stress with scores decreasing from clinically significant levels ( $>85^{\text {th }}$ percentile) at pre-treatment to scores below clinical significance 
$\left(80^{\text {th }}\right.$ percentile) at follow-up. Parent-Child Dysfunctional Interaction subscale decreased from the $90^{\text {th }}$ percentile (above clinical cutoff) at pre-treatment to the $70^{\text {th }}$ percentile (below clinical cutoff) at post-treatment. Scores at follow-up increased to the $80^{\text {th }}$ percentile though remained below clinical cutoff. The Parental Distress subscale followed a similar pattern though scores remained below clinical cutoff across treatment phases.

For Christopher, all of the PSI-SF scores generally follow the same pattern, with decreased from pre-treatment to post-treatment and increases from post-treatment to follow-up. All scores remained above clinical significant levels with the exception of Parent-Child Dysfunctional Interaction which dropped below the clinical cutoff at posttreatment $\left(80^{\text {th }}\right.$ percentile).

Receptive Language

Peabody Picture Vocabulary Test. PPVT data are displayed in Figure 12. Kenneth's pre-treatment standard score was above the mean at 107 with an age equivalence of 3 years, 5 months. Scores at post-treatment and follow-up improved and were above one standard deviation of the mean with 124 and 120, respectively.

Adam's receptive language abilities at pre-treatment were advanced with a standard score of 127 and age equivalence of 6 years, 3 months. At post-treatment, his receptive language ability remained elevated with a score of 122 . At follow-up the standard score remained over a standard deviation above the mean at 119 .

Christopher's pre-treatment receptive language abilities were in the low average to borderline range with a standard score of 82 and age equivalence of 2 years, 2 months. His post-treatment score remained at 82 . At follow-up, standard score dropped two standard deviations below the mean with a score of 70 . 


\section{Child Intelligence}

WPPSI-III. WPPSI data are demonstrated in Figure 13. Kenneth's IQ scores demonstrated an upward trend across treatment phases. Full IQ increased from 105 at pre-treatment to 120 at post-treatment and 130 at follow-up. Verbal IQ scores showed a similar pattern with scores of 107 at pre-treatment, 120 at post-treatment, and 127 at follow-up. Performance IQ scores showed a similar pattern with scores of 102 at pretreatment, 114 at post-treatment, and 125 at follow-up.

Adam's intelligence quotient (IQ) remained generally stable across assessments with scores of 107 at pre-treatment, 102 at post-treatment, and 105 at follow-up with each score in the average range. Similarly, his verbal IQ (VIQ) remained steady with a standard score of 106 at pre-treatment to 112 at post-treatment and a slight reduction to 108 at follow-up. His performance IQ (PIQ) was lower than verbal IQ across assessment points remaining at 90 across pre-treatment and post-treatment and increasing to 101 at follow-up. It is worth noting that Adam's processing speed score was not attained as he was not able to complete subtests requiring fine motor skills (e.g., manipulating a pencil). Therefore, full IQ score was prorated based on verbal and performance abilities as indicated in the WPPSI manual.

Christopher's IQ scores across assessment were stable and in the extremely low range. His full IQ was 58 at pre-treatment, 56 at post-treatment, and 56 at follow-up. His VIQ scores were 67 at pre-treatment and 64 at post-treatment and follow-up. PIQ score was 65 at pre-treatment and 63 at post-treatment and follow-up. It is worth nothing that Similar to Adam, Christopher's motor difficulties precluded him from completing processing speed subscales resulting in a prorated full IQ. 


\section{Adaptive Functioning}

Vineland Adaptive Behavior Scales-Interview Edition. Vineland data are displayed in Figure 14. Kenneth's adaptive functioning composite standard score at pretreatment was a 106 and in the adequate range. Composite scores at post-treatment increased to 116 and in the moderately high range whereas it dropped back to the adequate range at follow-up with a score of 99 . Scores increased across domains from pre-treatment to post-treatment remaining in the adequate range with the exception of the Communication and Motor Skills domains which increased to the moderately high range. All scores were in the adequate range at follow-up and generally consistent with pretreatment levels besides the Socialization domain score of 77 which fell in the moderately low range.

Adam's adaptive functioning composite (i.e., communication, daily living skills, socialization, motor skills) pre-treatment standard score was 79 and in the moderately low range (i.e., 71-85) and remained at this level at post-treatment and follow-up with standard scores of 78 and 75, respectively. Scores across domains followed a general pattern with an increase at post-treatment but still remaining in the moderately low range (with the exception of communication skills which was in the adequate range at posttreatment but decreased to moderately low range at follow-up with a score of 81).

Christopher's adaptive functioning composite at pre-treatment was a standard score of 73 and in the moderately low range. Likewise, post-treatment and follow-up scores remained in the moderately average range with scores of 85 and 72, respectively. All scores followed the same pattern of increasing at post-treatment and decreasing at follow-up. With the exception of the Socialization domain which decreased from the 
moderately low range (74) to the low range (66) and the Daily Living Skills domain which increased from the moderately low range (77) to the adequate (101) range at posttreatment, scores remained within the moderately low classification at each assessment point.

Imitation

Imitation data are demonstrated in Figure 15. Kenneth's imitation task score was 12 at pre-treatment and 20 at both post-treatment and follow-up. At pre-treatment, Adam scored a 6 (out of 20) on the imitation task. The post-treatment score increased to 13 while the follow-up score decreased to 8. Christopher's imitation scores followed a similar pattern with a pre-treatment score of 12 , a slight increase at post-treatment with a score of 15, and a subsequent decrease follow-up with a score of 10.

\section{Parent Report of Behavior Function}

Questions about Behavioral Functioning. Frequency scores for attention subscale was elevated throughout study with exception of Kenneth's follow-up score. Results for Kenneth showed a reduction across severity scores for each subscale with the exception of the escape subscale which remained at a score of 10. Results of the QABF for Adam revealed a steady decrease in the severity score for the attention, escape, and tangible subscales across assessment points. The physical subscale revealed a drop from pretreatment score of 8 to 6 at post-treatment but an increase at follow-up with a score of 11 . Frequency scores remained generally stable across assessment points.

Christopher's QABF severity scores followed a similar pattern as scores decreased from pre-treatment to post-treatment across subscales. At follow-up, however, 
scores increased to above pre-treatment levels for each subscale. This trend held for frequency score as well.

\section{Consumer Satisfaction}

Treatment Attitude Inventory. TAI scores for Kenneth's caregiver was a 46 at post-treatment with the following items rated a 4: learning techniques of discipline, learning techniques for teaching child new skills, relationship between caregiver and child, and confidence in ability to discipline child. At follow-up, the TAI score was 47 with same items rated a 4 as post-treatment with exception of confidence disciplining child which was rated a 5.

TAI results for Adam were lowest among caregivers with scores of 39 (out of 50) at post-treatment and 37 at follow-up. Adam's caregiver rated all items slightly lower (i.e., 4) than the optimal score (i.e., 5) for each item with the exception of the degree to which the program helped with other general personal problems not directly related to my child which was rated a 3 and defined as neither helped nor hindered. At follow-up, Adam's caregiver rated each item 4 with the exception of the degree to which the program helped with other general personal problems not directly related to my child rated 3-neither helped or hindered), learning techniques of discipline (rated 3-a few new techniques), and learning techniques for teaching my child new skills (rated 3-a few new techniques).

TAI score for Christopher's caregiver was a 49 at post-treatment with the item regarding the relationship between caregiver and child rated a 4 and defined as somewhat better than before. At follow-up TAI score was 46 with the following items rated 4: learning techniques for teaching child new skills, relationship between caregiver and 
child, improvement of major behavior problems child presented at home before the program started, and improvement of child's compliance to commands or requests following treatment.

\section{Discussion}

This study primarily sought to examine the efficacy of PCIT in reducing noncompliant behavior, increasing positive caregiver behavior, and decreasing negative parenting behavior for families with children on the autism spectrum. The findings of the study serve as preliminary evidence indicating efficacy of PCIT with this specialized population across a number of domains. Specifically, results showed improved noncompliance and a reduction in problem behaviors across all three dyads as well as improvement in caregiver communication. Satisfaction with the treatment was indicated by each caregiver suggesting that PCIT was a well-received intervention for each family who participated in the study. Results, clinical implications, and future directions are discussed below.

\section{Primary Hypotheses}

\section{Child Compliance}

It was proposed that child compliance on the Compliance Test would increase from baseline during the PDI phase of the intervention. For two families (Adam and Kenneth), the data supported the hypothesis showing a noticeable difference in mean compliance rates between baseline and PDI. On the other hand, Christopher's compliance rate decreased between baseline and PDI. A closer examination of Adam's and Christopher's data revealed substantial variability during the PDI phase each showing a downward trend in scores. Interestingly, for both participants, compliance on the measure 
decreased following the session (session \#6 for Adam, session \#3 for Christopher) in which parents began to implement the PDI procedure (e.g., contingent praise for compliance or warning/timeout sequence for noncompliance). In other words, compliance rates on the Compliance Test demonstrated a noticeable decrease in the session directly following the time when PDI was implemented by the parent (Compliance Test and PDI observation were conducted separately with Compliance Test being administered at each session and PDI observations taking place after parent learned PDI procedure). One explanation for this is the negative behavioral contrast effect which states there is a decrease in the rate of responding in one condition as a result of the increase of a contingency in another condition (Gross \& Drabman, 1981). In other words, as parents began to use PDI skills, there were contingencies for behavior (contingent praise, warning, timeout) as opposed to the Compliance Test which was void of response-based contingencies throughout the study. For example, it is feasible that Adam's Compliance Test performance decreased after the introduction of PDI skills as neither compliance nor noncompliance on the assessment was met with a contingency. In contrast, during PDI, he was praised for compliance or given a warning/timeout for noncompliance. Although it could be argued a true contrast effect may not have occurred given that the Compliance Test was introduced prior to PDI observations at each treatment session, it is important to note that parents were expected to practice PDI skills between sessions. Thus, contingencies were administered between sessions and not exclusively during treatment sessions. Another explanation for the decline in compliance rates on the Compliance Test is that of repeated testing. It is possible that, given the number of testing administrations, participants demonstrated test fatigue and scores are a 
reflection of this as opposed to a valid measurement of compliance. Alternatively, as each Compliance Test administration is identical in terms of content, order, and parent behavior (neutral with no additional verbalizations beyond command), the test itself or some portion of it may have served as a conditioned stimulus for frustration after repeated trials. For instance, Adam exhibited frustration during the last several Compliance Test administrations of PDI often verbally expressing discontent with the test. Additionally, the participant (Christopher) with the longest baseline and most Compliance Test administrations prior to PDI demonstrated the most difficulty with the task. It is also worth noting that behavioral observations revealed that Christopher exhibited perseverative behaviors with several items on the Compliance Test during the later PDI sessions. For example, Christopher consistently began rolling a school bus back and forth soon after the Compliance Test commenced and would engage in the behavior for the majority of the administration. It was not clear as to whether this behavior was sensory related or based on frustration though he had difficulty transitioning away from the object after administration was complete suggesting the former explanation.

Interestingly, mean compliance rates during CDI increased from baseline for each child possibly suggesting that relationship enhancement skills impacted child compliance. Specifically, it is possible that each child exerted more effort after receiving parental attention for prosocial behaviors outside of the task. It is worth noting the increase in Adam's compliance rate between CDI sessions \#2 and \#3 (6\% to 96\%). After becoming ill, Adam was hospitalized for a short period of time before CDI session \#4 with his mother subsequently assuming more of a caregiver role over the next several sessions. This change in the environment (increased time with mother) may have influenced 
Adam's behavior on the assessment (i.e., history as threat to internal validity) though it is difficulty to determine the length of time it impacted his behavior.

At follow-up, two of the three participants displayed their highest Compliance Test scores. One possibility for this increase is that the twelve weeks between posttreatment and follow-up made the Compliance Test novel again, such that it no longer served as a conditioned stimulus for frustration as it did when it was given more consistently (i.e., $\sim$ twice/week for many weeks in a row). Moreover, it is possible that the parents continued to use PCIT skills leading to an additional three months of positive learning, allowing the children's compliance rate to improve to levels greater than posttreatment. This is consistent with the ceiling effect on other observations of compliance as well as the increase in parent report of expected compliance from post treatment to follow-up.

In addition to the Compliance Test, this study included other measures of child compliance: behavioral observations during parent-led play (PDI), behavioral observations during clean-up situation, and parent report of expected child compliance across 122 tasks. Table 4 provides a comparison of the current study with other PCIT studies assessing compliance through PDI and clean-up observations. In addition, the table includes a study (Tarbox, Wallace, Penrod, \& Tarbox, 2007) examining the effects of three-step prompting (vocal prompt, model prompt, physical guidance with contingent praise following compliance after vocal or model prompt), an applied behavioral analytic technique, on compliance with a young child on the autism spectrum. The table illustrates that the current study resulted in larger improvements in compliance rates than is typically demonstrated in PCIT research and rates comparable to ABA findings. While 
compliance percentage varied across families for the Compliance Test, PDI observations demonstrated a notable increase in compliance between baseline and the PDI phase for all children. Additionally, compliance percentage for the clean-up task increased across phases of treatment demonstrating improvement in compliance for all three children on this particular task. Similarly, parent report of compliance probability for each dyad showed that parents of all three children expected their child would be more compliant across a variety of situations and settings immediately following treatment and at followup. Taken together, the various measures of child compliance were relatively consistent in demonstrating improved compliance rates for all three participants at post-treatment and follow up.

\section{Caregiver Behavior}

Each family showed a similar pattern of skill acquisition for positive parenting behaviors (PPB). Each caregiver did not exhibit positive parenting skills at baseline. As hypothesized, a notable increase across families was observed during CDI. During PDI, skills continued to improve for the two caregivers of Christopher and Kenneth and remained at mastery level at follow-up. Adam's mother demonstrated less use of CDI skills during PDI. This caregiver required more intensive coaching with CDI skills, particularly with labeled praise. With coaching, her skills improved as PDI progressed and were close to mastery at follow-up.

As hypothesized, each caregiver demonstrated less use of negative parenting behaviors (NPB) between baseline and CDI. Christopher's caregiver exhibited the highest amount of NPB's (26) at pre-treatment whereas Kenneth's father showed the least (7). Low levels of NPB were maintained at follow-up for each parent. 
Findings for parenting behaviors are consistent with an extensive body of literature showing that behavioral parent training programs are effective in changing parent-child communication for families of children with oppositional behavior (Herschell, Calzada, Eyberg, McNeil, 2002). Recent PCIT studies have extended prior findings showing similar results with children with mental retardation (Bagner and Eyberg, 2007). Fewer studies have investigated positive parenting changes for children with developmental delays though that literature suggests that findings are consistent with this group as well (Bagner \& Eyberg, 2007; Harrold, Lutzker, Campbell, \& Touchette, 2002). Research examining PCIT with children on the autism spectrum exhibited an increase in positive parenting affect (Solomon, Ono, Timmer, \& GoodlinJones, 2008). These findings further support the notion that BPT's can improve parentchild interaction within this specialized population though additional research is needed to understand the mechanisms of change given the different manner in which children with developmental delays relate to others.

\section{Secondary Hypotheses}

\section{Parent Report of Child Behavior}

Each participant presented with clinically significant behavioral difficulties during baseline as measured by the ECBI. Data supported the hypothesis that parents would report a reduction in behavior problems at post-treatment and follow-up. Findings are similar to prior studies demonstrating a reduction in parent-reported child problem behavior following behavioral parent training programs with this population (Hudson et al., 2003; Huynen, Lutzker, Bigelow, Touchette, \& Campbell, 1996; Jamison, 2008; Plant \& Sanders, 2007; Solomon, Ono, Timmer, \& Goodlin-Jones, 2008) and provide further 
support of this treatment approach. Adam's and Christopher's intensity scores demonstrated a gradual decrease across CDI and PDI. Kenneth's intensity score showed a gradual increase during CDI likely as a result of his caregiver better recognizing behavior problems. His scores continued to slightly increase into PDI before showing a gradual downward slope through follow-up. Christopher's intensity score increased at follow-up to clinically significant levels. It is important to note that new stressors developed for Christopher's family between post-treatment and follow-up. Specifically, his mother became ill warranting several lengthy medical tests. Her medical symptoms and treatment were not shared with the researchers but were significant enough to delay the follow-up appointment for several weeks. One possible explanation for the ECBI increase between post-treatment and follow-up is that Christopher's mother was unable to consistently employ her newly learned skills because of the high stress levels, leading to some deterioration in Christopher's improved behavior.

Scores for the ECBI problem subscale generally followed the same pattern as the intensity scores for each participant. Further supporting previous research examining PCIT and autism (Solomon, Ono, Timmer, \& Goodlin-Jones, 2008), problem scores were below clinical cutoff at post-treatment and follow up. It is worth noting that although his scores decreased throughout therapy, Kenneth's problem score was below clinical significance throughout the study. This may be a valid reflection of his father's perception that he could manage Kenneth's behavioral issues with little difficulty. Alternatively, the scores may be minimizing the challenges the behavior presented which is a less likely explanation given the score profile of the intensity subscale. Overall, low problem scores indicate that each caregiver developed a sense of greater control and 
mastery of managing their child's behavior. Although each child will likely continue to demonstrate some level of oppositional behavior, results show that the parents feel they have attained the necessary tools to adequately handle the behaviors as they manifest.

With respect to the CBCL scores, caregivers for Adam and Kenneth reported externalizing behaviors in the clinically elevated range prior to treatment. Following treatment, Kenneth's scores were below clinical cutoff whereas Adam's scores decreased though remained elevated at post-treatment and follow-up. Christopher's caregiver reported externalizing behavior at below clinical levels at each phase of the study.

\section{Child Autistic Behavior}

Supporting the hypothesis that autistic behavior would decrease at post-treatment and follow up, caregiver report and observational measures revealed a general reduction in overall autistic behaviors across assessment points for each participant. Although scores uniformly decreased, they generally remained above clinical significant levels for each participant. While PCIT focuses on increasing compliance and enhancing parentchild communication, it may not target all core autistic behaviors. A closer examination of the Autism Behavior Checklist data demonstrated patterns that would be expected after implementation of PCIT. In particular, results showed an even decrease in scores for the Relating subscale. As this construct is devised of behaviors focused on connectedness (e.g., attending to social cues, eye contact, relationship-enhancement, imitation), it may be that improved communication impacted these behaviors.

In addition to the Relating subscale, scores also demonstrated an overall decrease within the Social and Self Help domain. Given that the majority of these items targeted behavioral issues (e.g., temper tantrums, aggressive behavior, impulsivity), it is probable 
to attribute these findings to treatment effects. Also, compliance improvements may have contributed to increased self-help behaviors.

Behavioral observations of the CARS provided corroborating support of the parent-report measures showing similar patterns of results. Kenneth's CARS scores decreased from the autistic range at pre-treatment to the non-autistic range at posttreatment and follow-up. Adam's scores remained in the autistic range but reduced from the severely autistic to mildly autistic category. Christopher's scores decreased from pretreatment to post-treatment but remained in the severely autistic range at each assessment point. Evidence of this study provided further support of previous examinations showing moderate to strong convergent validity of the ABC and CARS (e.g., Eaves \& Milner, 1993).

Last, the PDD subscale of the CBCL revealed scores in the non-clinical range following treatment for two participants (Kenneth, Adam). Interestingly, for both participants, caregivers reported "sometimes true" at pre-treatment and "not true" following treatment for the following items: "seems unresponsive to affection" and "shows little affection toward people." It is possible that this finding is a byproduct of the increased positive parent communication or solely the parent's perception of child affection. It is also important to consider that the term "affection" is not operationally defined by the measure and is therefore subject to idiographic interpretation.

Overall, findings on the autism-specific assessments demonstrated modest reductions in the overall scores and within individual domains. Although PCIT may reduce some behaviors commonly seen in children on the autism spectrum (e.g., behavioral difficulties), these findings are aligned with the notion that PCIT was not 
designed to be an intervention that treats the core symptoms of autism but rather an intervention that may be helpful in increasing children's readiness skills for a more comprehensive treatment.

\section{Parenting Stress}

Results of the PSI-SF did not fully support the hypothesis that parents would report reductions in stress at post-treatment and follow-up. For two caregivers (Adam and Christopher), total stress remained at clinically significant levels at post-treatment. This finding is congruent with other studies showing that parents of children with pervasive developmental disorders report elevated levels of parenting stress (Epstein et al., 2008) compared to controls. It is interesting that Kenneth's male caregiver reported less overall stress at post-treatment as previous research has shown that parent gender may impact stress levels for families with children with developmental delays (Civick, 2008; Dyson \& Dyson, 1997; Rousey, Best, \& Blacher, 1992). However, as research is discrepant and conflicting in this area, further studies are needed to better understand the differential effects a child with developmental delays has on the family system.

Christopher's caregiver reported elevated levels of stress on the Parent Domain which examines stressors independent of child rearing with more focus on individual factors. It is likely this score is a reflection of the emotional difficulties Christopher's caregiver reportedly experienced prior to and throughout the treatment. It is possible that her stress levels impacted progress in treatment or influenced the manner in which she responded on the assessments. Prior research has shown that mother's with children with developmental delays exhibit higher levels of depressive symptoms (Blacher, Lopez, Shapiro, \& Fusco, 1997) though the directionality of this phenomenon needs further 
investigation. Interestingly, the caregivers with more than one child with developmental delays showed the highest level and least reduction of overall stress.

All caregivers reported elevated scores on the Difficult Child subscale at pretreatment with scores remaining above cutoff at post-treatment for two dyads. The behavioral presentation and chronic nature of autistic behavior combined with the item content of the subscale (e.g., easily upset over small things, strong reactions when something happens that child doesn't like, my child is more of a problem than I expected) are likely indicators for these scores. Also, this finding supports prior studies showing a positive correlation between parental stress and externalizing behaviors of children with autism spectrum disorders (Civick, 2008).

In terms of the parent-child dysfunctional interaction, scores dropped to below significant levels for two dyads at post-treatment with the other dyad reporting a low level at pre-treatment with scores maintaining at post-treatment and follow-up. This result is promising in that the subscale measures relationship-based constructs such as emotional and social reciprocity. Therefore, it is possible that the positive parenting skills taught in PCIT may result in qualitative improvements in parent-child relationships. Studies investigating the efficacy of the Floortime approach found similar results demonstrating increased levels of child emotional expressiveness, intimacy, and social reciprocity (Greenspan \& Wieder, 1997; Solomon, Necheles, Ferch, \& Bruckman, 2007). Further PCIT studies should explore this variable employing a combination of parent report and behavioral observation measures.

Receptive Language Capabilities 
Data for the PPVT did not fully support the hypothesis that receptive language capabilities would increase after treatment. Adam's scores were generally uniform across assessment points and remained a standard deviation above the mean. As Adam's score was in the above average range at pre-treatment, it is possible that there was a ceiling effect resulting in scores remaining at generally the same level at post-treatment and follow-up. Christopher's scores remained in the low average to average range at posttreatment. However, his follow-up score reduced to the borderline range. Behavioral observations during follow-up revealed that Christopher demonstrated difficulties focusing often becoming distracted and agitated. Thus, the follow-up score is more likely an artifact of behavior and less a valid indication of ability level. Kenneth's scores supported the hypothesis with an increase at post-treatment and follow-up from pretreatment. The score difference may be attributed to several possible factors. First, it is feasible that Kenneth's score improved as a result of practice effects given that test was administered several times over a few months. Second, Kenneth was oppositional during the pre-treatment administration often refusing to answer items without prompting. His behavior could have disallowed him from performing at his optimal level whereas his improvement in behavior following treatment resulted in a more valid assessment of his capabilities. Third, as a result of the treatment, Kenneth's improved behavior may have increased parent-child communication placing him in a position to enhance his vocabulary skill set over the course of several months.

\section{Child Intelligence/Child Adaptive Functioning}

The child intelligence data did not fully support the hypothesis that scores would increase at post-treatment and follow-up as compliance with testing would increase. For 
Adam and Christopher, scores remained even across evaluations. Adam's scores were consistently in the average range whereas Christopher's scores were in the deficient range. Given Christopher's low verbal abilities, it may have been more appropriate to administer a non-verbal IQ assessment as language impairment placed him at a disadvantage with scores possibly being an underestimate of his true ability. Kenneth's scores increased across evaluations. Potential reasons for the increase are similar to those noted above such as practice effects and improved compliance during testing. Scores on the adaptive functioning measure remained generally even for each participant across assessment points. Kenneth demonstrated the highest composite scores each within the adequate range. Adam and Christopher's scores were consistently within the low average range.

Prior research has shown that intensive behavioral treatment (IBT) has increased adaptive behavior and enhanced cognitive functioning (Cohen, Amerine-Dickens, \& Smith, 2006; Howard, Sparkman, Cohen, Green, \& Stanislaw, 2005; Lovaas \& Smith, 2003; Sallows \& Graupner, 2005) compared to wait-list controls and alternative treatments. Although PCIT does employ some techniques consistent with IBT (e.g., discrete trial learning), this study did not demonstrate such robust effects. The differences in findings are likely attributable to dosage effects as children receiving IBT received approximately 40 hours per week of 1:1 intervention across contexts over a prolonged period of time (e.g., 2-4 years). In contrast, children in this study received an average of 15 hours of treatment across 2-3 months. Further research is warranted to investigate the long-term effects of PCIT on these domains.

\section{Imitation}


Scores on the imitation task supported the hypothesis that rates would increase for each child after treatment. An increase in imitation across participants is an interesting finding as this behavior is typically considered a core feature of autism. It is possible that an increase in overall compliance influenced this task as part of the administration required the caregiver to ask the child what he could do with the object directly after demonstrating the action several times. In this way, the question is an indirect command directed to the child with the imitation serving as compliance with the command. A second hypothesis is that the CDI skills enhanced the parent-child relationship resulting in each child being more attuned to their caregiver's actions and increasing the likelihood that the child would be more interested in the actions of their caregiver. Also, as parents were coached to recognize and praise imitation during treatment sessions, it is possible that the social reinforcement led to increased behavior. Prior research employing a similar imitation task (from which the task in this study was derived) used contingent reinforcement and behavioral description for imitation and showed a similar increase in imitation of gestures (Ingersoll, Lewis, \& Kroman, 2006). Also, as parents were engaging in special play time on a consistent basis, it is possible that the greater time on task with toys combined with increased interaction with each parent resulted in enhanced constructive play skills following treatment. Last, given the young ages of the participants, it is possible that imitation skills further developed over the course of treatment via natural developmental maturation. Future investigations are needed to assess whether child imitation generalizes to other individuals and settings and maintains over time.

\section{Parent Report of Behavior Function}


Given the reliance on social reinforcement, it was recognized that PCIT may not be an effective treatment for all children with ASD. Thus, it was important to assess a child's capability to respond to social attention. The QABF served as an assessment tool to examine the function of noncompliant behavior. Each caretaker reported high scores on the attention subscale at pre-treatment indicating that PCIT was likely a suitable treatment match for this particular group of children and adding further evidence to prior studies (Fisher et al., 1996; Gena, 2006; Piazza et al., 1999) demonstrating that some behavior is reinforced by attention in children with autism. Scores on the attention subscale remained elevated across evaluations for each participant with the exception of Kenneth's follow-up score which reduced considerably. Although this may have been a result of the treatment, it is also possible that his caretaker adopted a response set while completing the assessment as scores for the majority of subscales decreased considerably. Further research should continue to assess behavioral function via parent report and behavioral observations in order to make a determination of the appropriateness of PCIT.

\section{Consumer Satisfaction}

Overall, caregiver responses indicated a moderate to high level of satisfaction with the treatment. Caregivers reported lowest scores on the item assessing whether treatment helped with more personal problems unrelated to their child. Consumer satisfaction was comparable with PCIT studies (Bagner \& Eyberg, 2007; Eisenstadt et al., 1993; Schuhmann, et al., 1998) suggesting the parents were as satisfied with the treatment as parents of children without autism. Although results on this measure are promising, they should be interpreted with some caution as it is possible that the 
caregivers provided positively biased responses given that the assessments were not completed in an anonymous fashion.

\section{Clinical Implications}

The findings of this study indicate that PCIT was effective in increasing child compliance, reducing problem behaviors, and improving parent communication with three children on the high end of the autism spectrum. Although results are preliminary, they demonstrate that PCIT could be a viable first-line treatment for children on the autism spectrum with co-occurring behavioral difficulties. Study results demonstrated behavioral changes similar to those of children without developmental delays who received PCIT (Eisenstadt et al., 1993; McNeil et al., 1991; Schuhmann et al., 1998; Ware et al., 2008). The study is promising given that cases of autism have typically been excluded from participation in PCIT despite the increase in referrals to PCIT clinics. Strengths of the study included the use of multiple forms of measurement to assess child behavior including behavior observation and parent report. Also, in terms of diagnostic validity, all participants were assessed by professionals with expertise in autism with two participants diagnosed at nationally recognized centers for the assessment and treatment of autism. Observational and parent report measures were also included to corroborate diagnoses.

The study findings supported previous research (e.g., Bagner \& Eyberg, 2007; Jamison, 2008; Solomon, Ono, Timmer, \& Goodlin-Jones, 2008) demonstrating that PCIT is efficacious in reducing behavior problems in children with developmental delays while still adhering to the core components of the treatment. Although manualized, PCIT offers flexibility that allows treatment to be tailored to the individual needs of the child 
and family. For instance, in order to increase language use, parents were taught to ignore inappropriate attempts to acquire objects (e.g., screaming, using parents' hand to attain object), prompt the use of words, and then praise the child for appropriate communication. Another parent was coached to direct her child away from selfstimulatory behavior by giving an incompatible command (e.g., "Please sit down next to me," "Please draw me a circle"). In giving the command, the parent was able to reduce the self-stimulatory behaviors and simultaneously teach the child more prosocial activities.

It is important to note that each family received a higher dose of PCIT sessions ( $M=18$, range 16-21) than is typically given for children without developmental delays. For example, participants in the Eisenstadt et al. (1993) study averaged 14 sessions, participants in the Schuhmann et al. (1998) study averaged 13 sessions, and participants in the Bagner and Eyberg (2007) investigation averaged 12 sessions. Families in the current study required more PDI sessions. It is possible that behavioral problems are more persistent in this population. Alternatively, one parent expressed some discomfort with the timeout procedure, requiring more sessions to increase confidence in implementing the technique. Further research is warranted in this area to examine appropriate dose of treatment or potential barriers that may interfere with successful implementation of the intervention.

A final consideration that warrants discussion is the diagnosis of high-functioning autism. Currently, this diagnosis is not recognized by the American Psychological Association's Diagnostic and Statistical Manual of Mental Disorders, Fourth Edition, Text Revision (2000) and research is inconclusive in discerning HFA from Asperger's 
syndrome and pervasive developmental disorder-not otherwise specified (PDD-NOS). Thus, it is difficult to define what characteristics comprise this diagnosis though some researchers have speculated that language and intelligence are critical elements to consider (Ghaziuddin \& Mountain-Kimchi, 2004; Klin, Volkmar, Sparrow, Cichetti, \& Rourke, 1995). Each participant in the study was diagnosed with Autism Disorder with high-functioning defined as receptive language capabilities above 2 years of age. Results demonstrated a range of intelligence levels as evidenced by the WPPSI. As prior PCIT research has shown success with reducing oppositional behaviors with children with mental retardation (Bagner \& Eyberg, 2007), it is possible that children defined as more low-functioning may also benefit from PCIT. Future PCIT research should assess whether the treatment is effective with children on various points of the autism spectrum.

\section{Limitations}

Although findings of the present study are encouraging, certain limitations must be considered when interpreting the results. First, the primary measure of the study (i.e., Compliance Test) was generally insensitive to treatment effects and a relatively unreliable measure of child compliance. Another limitation of the study is questionable generalizabilty of the findings given the level of resources used to implement the project. The study was conducted by two advanced clinical psychology doctoral students each receiving intensive supervision from a PCIT expert. Also, an undergraduate student assisted with the majority of sessions on several tasks including providing childcare for participant's siblings. The study was also conducted at participant's homes. Though research demonstrates this home-based treatment delivery model comes with its unique set of challenges (Masse \& McNeil, 2008), it is more convenient for families and greatly 
reduces the likelihood of attrition. Many mental health agencies do not have sufficient resources to conduct in-home treatment. Also, given the sample size and varied nature of the diagnosis, it is difficult to generalize findings of the study to all children with autism. Lastly, participation in the study was voluntary and based on self-referrals possibly indicating a stronger motivation and commitment to change.

In addition to issues of generalizability, other limitations are noted. As participants were paid $\$ 250$ to complete measures for the study, it is feasible that their responses on the questionnaires were influenced by the remuneration. Also, as therapists conducted treatment sessions in participants' home, there may have been a tendency to respond more favorably on the measures in an effort to please the experimenters. Given this possibility, the use of behavioral observations were important to corroborate parent report. Next, behavioral observations were conducted by study staff with familiarity of the families. These data would have been strengthened by independent coders blinded to the time of assessment (i..e., pre, post, follow-up). Also, teacher report would have provided information about generalized effects to the classroom setting as seen in previous PCIT studies (e.g., McNeil et al., 1991). In addition, a longer follow-up period with additional assessment points would have provided a more accurate depiction of long-term effects of the treatment. Prior research assessing behavioral parent training approaches with non-developmentally delayed children (Eisenstadt et al., 1993; Hood \& Eyberg, 2003; Nixon, Sweeney, Erickson \& Touyz, 2003; Querido \& Eyberg, 2001) as well as children with developmental disabilities (Plant \& Sanders, 2007) have shown persistent effects over time. Although encouraging, further research should be conducted examining the long-term impact of BPT on families with children on the autism spectrum 
given the chronic nature of the disorder and possibility that the presentation of behavioral challenges is likely to change over time.

Although prior research indicates that changes in child behavior can be attributed to increases in positive parenting behavior and decreases in negative parenting behavior (Bagner \& Eyberg, 2007), it is possible that child behavior change is related to a general increase in attention and not necessarily the specialized attention taught during PCIT. An analysis examining spoken words during CDI observations at pre-treatment and posttreatment revealed a substantial difference for two participants (one participant's pretreatment observations could not be played back due to problems with the recording). Kenneth's caregiver articulated 59 words at pre-treatment and 310 words at posttreatment while Adam's caregiver was observed to have spoken 123 words at pretreatment and 215 words at post-treatment. Interestingly, Kenneth spoke 19 words at pretreatment and 83 words at post-treatment while Adam spoke 14 words at pre-treatment and 30 words at post-treatment. These results show that level of parent-child verbal engagement increased for both dyads. Although much of the parent language consisted of skills taught during CDI, it is plausible that a general increase in attention or a combination of both factors influenced child behavior outcome. Further examination of this research question is warranted.

Finally, a limitation inherent in a nonconcurrent multiple baseline design is the threat of history effects influencing the dependent variable. By introducing treatment in a nonconcurrent fashion, there exists the possibility that outcomes were influenced by an extraneous event. Although possible, it is worth noting that there was a large amount of 
overlap in that more than one participant was receiving therapy simultaneously reducing the threat of historical factors influencing study results.

\section{Future Directions}

As this study is one of the first empirically-based research projects investigating PCIT and autism, replication is an important next step. The results of the study serve as a foundation of information that can be useful in guiding future studies. Given the complicated nature of the population, additional single-subject designs would be useful in gathering detailed information about particular client characteristics that respond favorably or poorly to the components of PCIT. In addition, a randomized-clinical trial examining the efficacy of PCIT would be the logical next step. Although results of the investigation are promising, future studies should proceed with care. As children on the autism spectrum present with a myriad of complex behaviors combined with the limited empirical evidence for PCIT and autism, it is important that preliminary studies are conducted by therapists with advanced training and experience with PCIT. If future research supports the use of PCIT with this population, then specialized programs should be developed to assist advanced PCIT therapists in adapting and tailoring the intervention to meet the needs of this population. Last, as PCIT requires a receptive language capability of at least 2 years of age, it is important to gather data on the proportion of children excluded from PCIT due to difficulties with receptive language. If a large amount of preschool children with ASD are excluded on account of this parameter, then it is important to consider the appropriateness of PCIT with this population.

One additional component to PCIT that warrants further investigation is whether the addition of a social skills training component focused on enhancing social and 
communicative repertoires in children on the autism spectrum would enhance the overall efficacy of PCIT with this population. Throughout PCIT, parents learn skills to prompt their child to answer questions, ask questions, use eye contact, and initiate/maintain conversations. The administration of social skills training at the end of therapy might allow the parent to effectively teach these skills, particularly considering that the child has become more receptive to social interactions and more likely to comply when prompted to speak through the standard PCIT protocol alone. Further investigation should examine the usefulness of this additional component. It is important to consider, however, that previous studies (Chaffin et. al, 2004) indicated that adjunctive components of PCIT may be less effective than PCIT alone. Future studies should continue to examine the traditional model of PCIT making modifications only as dictated by further research (Eyberg, 2005).

\section{Conclusion}

This study serves as an initial step in understanding the efficacy of PCIT and high-functioning autism. Results of the study provide preliminary, yet valuable, evidence suggesting that PCIT may be a viable intervention for increasing compliance, decreasing disruptive behavior, and improving parent-child interactions in families with children on the autism spectrum. Although the results of the current study are promising, more research is needed in this area to determine the efficacy of the treatment with this specialized population. If further research is favorable, effectiveness research would be important to determine the impact of PCIT with children on the autism spectrum in community-based settings. 
PCIT and Autism 93

\section{References}

Abidin, R. R. (1995). Parenting Stress Index (3rd ed.). Odessa, FL: Psychological Assessment Resources.

Achenbach, T. M., \& Edelbrock, C. S. (1981). Behavioral problems and competencies reported by parents of normal and disturbed children aged 4 through 16 . Monographs of the Society for Research in Child Development, 46(1), Serial No. 188).

Achenbach, T. M., \& Rescorla, L. A. (2000). Manual for ASEBA Preschool Forms \& Profiles. Burlington, VT: University of Vermont, Research Center for Children, Youth, \& Families.

Achenbach, T. M., \& Rescorla, L. A. (2001). Manual for ASEBA School-Age Forms \& Profiles. Burlington, VT: University of Vermont, Research Center for Children, Youth, \& Families.

Adenilis, J.D., Piazza, C., \& Goh, H. (2001). Treatment of multiply controlled destrcutive behavior with food reinforcement. Journal of Applied Behavior Analysis, 34(1), $97-100$.

American Psychiatric Association (2000). Diagnostic and Statistical Manual of Mental Disorders, Fourth Edition, Text Revision. Washington, DC.

Bagner, D.M., Fernandez, M.A., \& Eyberg, S.M. (2004). Parent-child interaction therapy and chronic illness: A case study. Journal of Clinical Psychology in Medical Settings, 11, 1-6. 
Bagner, D.M., \& Eyberg, S.M. (2007). Parent-child interaction therapy for disruptive behavior in children with mental retardation: A randomized controlled trial. Journal of Clinical Child and Adolescent Psychology, 36, 418-429.

Baumrind, D. (1971). Current patterns of parental authority. Development Psychology Monographs, 4, (1, Pt. 2), 1-103.

Bessmer, J., \& Eyberg, S. (1993, November). Dyadic Parent-child Interaction coding system-II (DPICS-II): Initial reliability and validity of the clinical version. Paper presented at the AABT Preconference on Social Learning and the Family, Atlanta, Georgia.

Bhavnagri, N. P. (1999). Low income African American mothers' parenting stress and instructional strategies to promote peer relationships in preschool children. Early Education and Development, 10, 551-571.

Blacher, J., Lopez, S., Shapiro, J., Fusco, J. (1997). Contributions to depression in Latina mothers with and without children with retardation: implications for caregiving. Family Relations, 46, 325-334.

Boggs, S. R., Eyberg, S. M., \& Reynolds, N. A. (1990). Concurrent validity of the Eyberg Child Behavior Inventory. Journal of Clinical Child Psychology, 19, 7578.

Borrego, J., Anhalt, K., Terao, S.Y., Vargas, E.C. \& Urquiza, A.J. (2006). Parent-Child Interaction Therapy with a Spanish speaking family. Cognitive and Behavioral Practice, 13, 121-133. 
Brestan, E.V., Eyberg, S.M., Boggs, S.R. \& Algina, J. (1997). Parent-child interaction therapy: Parents' perceptions of untreated siblings. Child and Family Behavior Therapy, 19, 13-28.

Brestan, E. V., Jacobs, J. R., Rayfield, A. D., \& Eyberg, S. M. (1999). A consumer satisfaction measure for parent-child treatments and its relation to measures of child behavior change. Behavior Therapy, 30, 17-30.

Brumfield, B.D. \& Roberts, M.W. (1998). A comparison of two measurements of child compliance with normal preschool children. Journal of Clinical Child Psychology, 27, 109-116.

Capage, L.C., Bennett, G.M., \& McNeil, C.B. (2001). A comparison between African American and Caucasian children referred for treatment of disruptive behavior disorders. Child \& Family Behavior Therapy, 23, 1-14.

Carr, E.G. (1994). Emerging themes in the functional analysis of problem behavior. Journal of Applied Behavior Analysis 27(2), 393-399.

Carr, E.G., Dunlap, G., Horner, R.H., Koegel, R.L., Turnbull, A.P., Sailor, W., et al. (2002). Positive behavior support: Evolution of an applied science. Journal of Positive Behavior Interventions, 4, 4-16.

Carr, .E.G., Horner, R.H., Turnbull, A., Marquis, J., McLaughlin, D.M., McAtee, M.L., et al. (1999). Positive behavior support as an approach for dealing with problem behavior in people with developmental disabilities: A research synthesis. Washington, DC: American Association on Mental Retardation Monograph. 
Cohen, H., Amerine-Dickens, M., \& Smith, T. (2006) Early intensive behavioral treatment: Replication of the UCLA model in a community setting. Journal of Developmental Behavioral Pediatrics, 27, S145-S155.

Chaffin, M., Silovsky, J. F., Funderburk, B., Valle, L. A., Brestan, E. V., \& Balachova, T. (2004). Parent-Child Interaction Therapy with physically abusive parents: Efficacy for reducing future abuse reports. Journal of Consulting and Clinical Psychology, 72, 500-510.

Civick, P. (2008). Maternal and paternal differences in parental distress levels and marital satisfaction levels in parents of children diagnosed with autism spectrum disorders. Dissertation Abstracts International: Section B: The Sciences and Engineering, 69, 2619.

Ducharme, J. M., Atkinson, L., \& Poulton, L. (2000). Success-based, non- coercive treatment of oppositional behavior in children from violent homes. Journal of the American Academy of Child and Adolescent Psychiatry, 39, 995-1003.

Ducharme, J.M., \& DiAdamo, C. (2005). An errorless approach to management of child noncompliance in a special education setting. School Psychology Review, 34, 107115.

Ducharme, J.M., Popynick, M., Pontes. E., \& Steele, S. (1996). Errorless compliance to parental requests III: Group parent training with parent observational data and long-term follow-up. Behavior Therapy, 27, 353-372.

Ducharme, J. M., Spencer, T., Davidson, A., \& Rushford, N. (2002). Errorless compliance training: Building a cooperative relationship between brain-injured 
parents at risk for maltreatment and their oppositional children. American Journal of Orthopsychiatry, 72, 585-595.

Dunlap, G., \& Fox, L. (1999). A demonstration of behavioral support for young children with autism. Journal of Positive Behavior Support, 1, 77-87.

Dunn, L.M. \& Dunn, L.M. (1997). Peabody Picture Vocabulary Test ( $3^{\text {rd }}$ ed.). Circle Pines, MN: American Guidance Service.

Durand, V.M., \& Carr, E.G. (1992). An analysis of maintenance following functional communication training. Journal of Applied Behavior Analysis, 25, 777-794.

Durand, V. M., \& Crimmins, D. B. (1988b). The Motivation Assessment Scale. Topeka: Monaco \& Associates.

Dyson, L. \& Dyson, L. (1997). Fathers and mothers of school-aged children with developmental disabilities: parental stress, family functioning, and social support. American Journal of Mental Retardation, 102, 267-279.

Eaves, R.C., \& Milner, B. (1993). The criterion-related validity of the Childhood Autism Rating Scale and the Autism Behavior Checklist. Journal of Abnormal Child Psychology, 21(5), 481-491.

Eisenstadt, T.H., Eyberg, S.M., McNeil, C.B., Newcomb, K., \& Funderburk, B. (1993). Parent-child interaction therapy with behavior problem children: Relative effectiveness of two stages and overall treatment outcome. Journal of Clinical Child Psychology, 22, 42-51.

Epstein, T., Saltzman-Benaiah, J., O’Hare, A., Goll, J.C., \& Tuck, S. (2008). Associated features of Asperger syndrome and their relationship to parenting stress. Care, Health, and Development, 34, 503-511. 
Eyberg, S. M. (1974). Therapy Attitude Inventory. (Available from Sheila Eyberg, PhD, Department of Clinical and Health Psychology, Box 100165 Health Science Center, University of Florida, Gainesville, FL 32610-0165).

Eyberg, S.M. (2005). Tailoring and adapting parent-child interaction therapy for new populations. Education and Treatment of Children, 28, 197-201.

Eyberg, S. M., Bessmer, J., Newcomb, K., Edwards, D., \& Robinson, E. (1994). Dyadic Parent-child Interaction Coding System-II: A manual. Social and Behavioral Sciences Documents (Ms. No. 2897).

Eyberg, S.M., Boggs, S., \& Algina, J. (1995). Parent-child interaction therapy: A psychosocial model for the treatment of young children with conduct problem behavior and their families. Psychopharmacology Bulletin, 31, 83-91.

Eyberg, S.M., Funderburk, B.W., Hembree-Kigin, T.L., McNeil, C.B., Querido, J.G., \& Hood, K. K. (2001). Parent-child interaction therapy with behavior problem children: One and two year maintenance of treatment effects in the family. Child and Family Behavior Therapy, 23, 1-20.

Eyberg, S. M., \& Johnson, S. M. (1974). Multiple assessment of behavior modification with families: Effects of contingency contrasting and order of treated problems. Journal of Consulting and Clinical Psychology, 42, 594-606.

Eyberg, S. M., \& Matarazzo, R. G. (1980). Training parents as therapists: A comparison between individual parent child interactions training and parent group didactic training. Journal of Clinical Psychology, 36, 492-499.

Eyberg, S.M., Nelson, M.M., Duke, M., \& Boggs, S.R. (2005). Manual for the Dyadic Parent-Child Interaction Coding System Third Edition. University of Florida. 
Eyberg, S. M., \& Pincus, D. (1999). Eyberg Child Behavior Inventory Sutter Student Behavior Inventory - Revised professional manual. Psychological Assessment Resources.

Eyberg, S. M., \& Robinson, E. A. (1982). Parent-child interaction training: Effects on family functioning. Journal of Clinical Child Psychology, 11, 130-137.

Eyberg, S. M. \& Ross, A. W. (1978). Assessment of child behavior problems: The validation of a new inventory. Journal of Clinical Child Psychology, 7, 113-116.

Fernandez, M.A., Butler, A., \& Eyberg, S.M. (2006). Race matters: Treatment outcome for African American families in parent-child interaction therapy. Manuscript submitted for publication.

Fisher, W.W., Ninness, H.A., Piazza, K.C., \& Owen-Deschryver, J.S. (1996). On the reinforcing effects on the content of verbal attention. Journal of Applied Behavior Analysis, 29, 235-238.

Freeman, K. A., Walker, M., \& Kaufman, J. (2007). Psychometric properties of the Questions about Behavioral Functioning scale in a child sample. Amerian Journal on Mental Retardation, 112(2), 122-129.

Gena, A. (2006). The effects of prompting and social reinforcement on establishing social interactions with peers during the inclusion of four children with autism in preschool. International Journal of Psychology, 41 (6), 541-554.

Ghaziuddin, G. \& Mountain-Kimchi, K. (2004). Defining the intellectual profile of Asperger Syndrome: Comparison with High-Functioning Autism. Journal of Autism and Developmental Disorders, 34, 279-284. 
Green, G. (1996). Early behavioral intervention for Autism: What does the research tell us? In C. Maurice, G. Green, \& S.C. Luce (Eds.), Behavioral Intervention for Young Children with Autism (pp. 29-44). Austin, TX: PRO-ED.

Greenspan, S.I. (1992). Infancy and early childhood: The practice of clinical assessment and intervention with emotional and developmental challenges. Madison, CT: International University Press.

Greenspan, S.I., \& Wieder, S. (1999). A functional developmental approach to autism spectrum disorders. Journal of the Association for Persons with Severe Handicaps, 24, 147-161.

Greenspan, S.I., \& Wieder, S. (1997). Developmental patterns and outcomes in infants and children with disorders in relating and communicating: a chart review of 200 cases of children with autism spectrum diagnoses. Journal of Developmental an Learning Disorders, 1, 87-141.

Greenspan, S.I., \& Wieder, S. (2006). Engaging autism: Using the Floortime approach to help children relate, communicate, and think. Cambridge, MA: DaCapo Press.

Gross, A.M., \& Drabman, R.S. (1981). Behavioral contrast and behavior therapy. Behavior Therapy, 12, 231-246.

Hanf, C. (1969). A two-stage program for modifying maternal controlling during mother-child $(M-C)$ interaction. Paper presented at the meeting of the Western Psychological Association, Vancouver, British Columbia, Canada. Hanley, G.P., Iwata, B.A., \& McCord, B.E. (2003). Functional Analysis of Behavior Problem: a review. Journal of Applied Behavior Analysis, 36, 147-185. 
Harrold, M., Lutzker, J.R., Campbell, R.V., \& Touchette, P.E. (1992). Improving parentchild interactions for families of children with developmental disabilities. Journal of Behavior Therapy and Experimental Psychiatry, 23, 89-100.

Haskett, M.E., Ahern, L.S., Ward, C.S., \& Allaire, J.C. (2006). Factor structure and validity of the parenting stress index-short form. Journal of Clinical Child and Adolescent Psychology, 35, 302-312.

Hembree-Kigin, T., \& McNeil, C. (1995). Parent-Child Interaction Therapy. New York: Plenum.

Herschell, A. D., Calzada, E. J., Eyberg, S. M., \& McNeil, C. B. (2002). Parent-child interaction therapy: New directions in research. Cognitive and Behavioral Practice, 9, 6-16.

Hood, K. K., \& Eyberg, S. M. (2003). Outcomes of Parent-Child Interaction Therapy: Mothers' reports of maintenance three to six years after treatment. Journal of Clinical Child and Adolescent Psychology, 32, 419-429.

Horner, R.H., Carr, E.G., Strain, P.S., Todd, A.W., \& Reed, H.K. (2002). Problem behavior interventions for young children with autism: A research synthesis. Journal of Autism and Developmental Disorders, 32, 423-446.

Howard, J.S., Sparkman, C.R., Cohen, H.G., Green, G., \& Stanislaw. (2005). A comparison of intensive behavior analytic and eclectic treatments for young children with autism. Research in Developmental Disabilities, 26, 359-383.

Hudson, A.M., Matthews, J.M., Gavidia-Payne, S.T., Cameron, C.A., Mildon, R.L., Radler, G.A., \& Nankervis, K.L. (2003). Evaluation of an intervention system for 
parents of children with intellectual disability and challenging behavior. Journal of Intellectual Disability Research, 47, 238-249.

Huynen, K.B., Lutzker, J.R., Bigelow, K.M., Touchette, P.E., Campbell, R.V. (1996). Planned activities training for mothers of children with developmental delays. Behavior Modification, 20, 406-427.

Ingersoll, B., Schreibman, L. \& Tran, Q.H. (2003). Effect of sensory feedback on immediate object imitation in children with autism. Journal of Autism and Developmental Disorders, 33, 673-683.

Ingersoll, B., Lewis, E., \& Kroman, E. (2006). Teaching the imitation and spontaneous use of descriptive gestures in young children with autism using a naturalistic behavioral intervention. Journal of Autism and Developmental Disorders, 37, $1446-1456$.

Iwata, B. A., Pace, G. M., Kalsher, M. J., Cowdery, G. E., \& Cataldo, M. F. (1990). Experimental analysis and extinction of self-injurious escape behavior. Journal of Applied Behavior Analysis, 23, 11-27.

Jamison, R.T. (2008). The effects of parent-child interaction therapy on problem behaviors in three children with autistic disorder. Dissertation Abstracts International: Section B: The Sciences and Engineering, Vol 68(7-B), p. 4828.

Kahng, S. Abt, K.A., \& Schonbachler, H.E. (2001). Assessment and treatment of low-rate high-intensity problem behavior. Journal of Applied Behavior Analysis, 34(2), $225-228$. 
Klin, A., Volkmar, F. R., Sparrow, S. S., Cichetti, D. V. \& Rourke, B. P. (1995). Validity and neuropsychological characterization of Asperger syndrome. Journal of Child Psychology and Psychiatry, 36, 1127-1140.

Koegel, R.L., Bimbela, A., \& Schreibman, L. (1996). Collateral effects of parent on family interaction. Journal of Autism and Developmental Disorders, 23, 347-359.

Koegel, R.L., Camarata, S., Koegel, L.K., Ben-Tall, A., \& Smith, A.E. (1998). Increasing speech intelligibility in children with autism. Journal of Autism and Developmental Disorders, 28, 241-251.

Koegel, L.K., Camarata, S.M., Valdez-Mechaca, M. \& Koegel, R.L. (1998). Setting generalization of question-asking by children with autism. American Journal on Mental Retardation, 102, 346-357.

Koegel, L.K., \& Koegel, R.L. (1995). Motivating communication in children with autism. In E. Schopler \& G. Mesibov (Eds.), Learning and cognition in autism: Current issues in autism. (pp. 73-87). New York, Plenum Press.

Koegel, R.L., Koegel, L.K., \& Brookman, L.I. (2003). Empirically supported pivotal response interventions for children with autism. In A.E. Kazdin \& J.R. Weisz (Eds), Evidence-based psychotherapies for children and adolescents (pp. 341357). New York: Guilford Press.

Koegel, L.K., Koegel, R.L., \& Dunlap, G. (1996). Positive behavioral support: Including people with difficult behavior in the community. Baltimore, MD: Paul H. Brookes Publishing. 
Koegel, L.K., Koegel, R.L., Harrower, J.K., \& Carter, C.M. (1999). Pivotal response intervention I: Overview of approach. Journal of the Association for Persons with Severe Handicaps, 24, 174-185.

Koegel, R.L., O’Dell, M.C., \& Koegel, L.K. (1987). A natural language teaching paradigm for nonverbal autistic children. Journal of Autism and Developmental Disorders, 17, 187-200.

Koegel, L.K., Stiebel, D., \& Koegel, R.L. (1998). Reducing aggression in children with autism toward infant or toddler siblings. Journal of the Association for Persons with Severe Handicaps, 23, 111-118.

Krug, D.A., Arick, J.R., \& Almond, P.J. (1980). Autism Behavior Checklist. Austin, TX: Pro-Ed.

Lovaas, O.L. (1987). Behavioral treatment and normal educational and intellectual functioning in young autistic children. Journal of Consulting and Clinical Psychology, 55, 3-9.

Lovaas, O.L., \& Smith, T. (2003). Early and intensive behavioral intervention in autism. In A.E. Kazdin \& J.R. Weisz, (Eds.), Evidence-based psychotherapies for children and adolescents (pp. 325-340). New York: Guilford Press.

Lucyshyn, J.M., Horner, R.H., Dunlap, G., Albin, R.W., \& Ben, K.R. (2002). Positive behavior support with families. In J.M. Lucyshyn, G. Dunlap, \& R.W. Albin (Eds.), Families and positive behavior support: Addressing problem behavior in family context (pp 3-43). Baltimore, MD: Paul H. Brookes Publishing.

Lyons, E., Rue, H., Luiselli, J. \& DiGennaro, F. (2007). Brief functional analysis and 
supplemental feeding for postmeal rumination in children with developmental disabilities. Journal of Applied Behavior Analysis, 40(4), 743-747.

Mandell, D.S., Walrath, C.M., Manteuffel, B., Sgro, G. \& Pinto-Martin, J. (2005).

Characteristics of children with autistic spectrum disorders served in comprehensive community-based mental health settings. Journal of Autism and Developmental Disorders, 35, 313-321.

Marcus, L.M., Lansing, M., Andrews, C.E., \& Schopler, E. (1978). Improvement of teaching effectiveness in parents of autistic children. Journal of the American Academy of Child Psychiatry, 17, 625-639.

Masse, J., \& McNeil, C. (2008). In-Home Parent-Child Interaction Therapy: Clinical Considerations, Child and Family Behavior Therapy, 30 (2), 99-126.

Matos, M., Torres, R., Santiago, R., Jurado, M., \& Rodriguez, I. (2006) Adaptation of Parent-Child Interaction Therapy for Puerto Rican Families: A preliminary study. Family Process, 45, 205-222.

Matson, J. L., \& Vollmer, T. R. (1995). User's guide: Questions about behavioral function $(Q A B F)$. Baton Rouge, LA: Scientific Publishers.

McCabe, K.M., Yeh, M., Garland, A.F., Lau, A.S., \& Chavez, G. (2005). The GANA program: A tailoring approach to adapting parent-child interaction therapy for Mexican Americans. Education and Treatment of Children, 28, 111-129.

McNeil, C.B., Capage, L.C, Bahl, A., \& Blanc, H. (1999). Importance of early intervention for disruptive behavior problems: Comparison of treatment and waitlist-control groups. Early Education and Development, 10, 445-454. 
McNeil, C.B., Eyberg, S., Eisenstadt, T.H., Newcomb, K., \& Funderburk, B. (1991). Parent-child interaction therapy with behavior problem children: Generalization of treatment effects to the school setting. Journal of Clinical Child Psychology, $20,140-151$.

Mesibov, G.B. (1983). Current perspectives and issues in autism and adolescence. In E. Schopler \& G.B. Mesibov (Eds.), Autism in adolescents and adults (pp. 37-53). New York: Plenum.

Mesibov, G.B. (1994). A comprehensive program for serving people with autism and their families: The TEACCH model. In J.L. Matson (Ed.), Autism in children and adults: Etiology, assessment, and intervention. Belmont, CA: Brooks/Cole.

Miller, E. M., \& Eyberg, S. M. (1991). Parent-Child Interaction Therapy with a diabetic child. Advances in Child Health Psychology: Abstracts. Gainesville, FL: Clinical and Health Psychology Publishing.

Mulick, J.A., \& Butter, E.M. (2005). Positive behavior support: A paternalistic utopian delusion. In J.W. Jacobson, R.M. Foxx, \& J.A. Mulick (Eds.), Controversial therapies for developmental disabilities: Fad, fashion, and science in professional practice (pp. 384-404). Mahwah, NJ: Erlbaum.

Newsom, C., \& Hovanitz, C.A. (2006). Autistic Spectrum Disorders. In E.J. Mash \& R.A. Barkley (Eds.), Treatment of childhood disorders ( $3^{\text {rd }}$ ed., pp. 455-511). New York: Guilford.

Newsom, C., \& Kroeger, K.A. (2005). Nonaversive treatment. In J.W. Jacobson, R.M. Foxx, \& J.A. Mulick (Eds.), Controversial therapies for developmental 
disabilities: Fad, fashion, and science in professional practice (pp. 405-422). Mahwah, NJ: Erlbaum.

Nixon, R. D. V., Sweeney, L., Erickson, D. B., \& Touyz, S. W. (2003). Parent-Child Interaction Therapy: A comparison of standard and abbreviated treatments for oppositional defiant preschoolers. Journal of Consulting and Clinical Psychology, $71,251-260$.

Ozonoff, S., \& Cathcart, K. (1998). Effectiveness of a home program intervention for young children with autism. Journal of Autism and Developmental Disorders, 28, $25-32$.

Piazza C.C, Bowman L.G, Contrucci S.A, Delia M.D, Adelinis J.D, Goh H. (1999). An evaluation of the properties of attention as reinforcement for destructive and appropriate behavior. Journal of Applied Behavior Analysis, 32, 437-449.

Perry, A., Condillac, R.A., Freeman, N.L., Dunn-Geier, J., \& Belair, J. (2005). Multi-site study of the Childhood Autism Rating Scale (CARS) in five clinical groups of young children. Journal of Autism and Developmental Disorders, 35, 625-634.

Pincus, D.B., Choate, M.L., Eyberg, S.M., \& Barlow, D.H. (2005). Treatment of young children with separation anxiety disorder using parent-child interaction therapy. Cognitive and Behavioral Practice, 12, 126-135.

Plant, K.M. \& Sanders, M.R. (2007). Reducing problem behavior during care-giving in families of preschool-aged children with developmental disabilities. Research in Developmental Disabilities, 28, 362-385.

Polirstok, S.R., \& Houghteling, L. (2006). Asperger Syndrome: A primer for behavioral intervention. Journal of Early and Intensive Behavior Intervention, 3, 187-195. 
Querido, J. G., \& Eyberg, S. M. (2001, June). Parent-Child Interaction Therapy with Head Start families. Poster session presented at the second annual PCIT meeting, Sacramento, CA.

Rayfield, A., \& Sobel, A. (2000). Effectiveness of "in-room" coaching of Parent-Child Interaction Therapy. Paper presented at the First Annual Parent-Child Interaction Therapy Conference, Sacramento, CA.

Reitman, D., Currier, R. O., \& Stickle, T. R. (2002). A critical evaluation of the Parenting Stress Index - Short Form (PSI-SF) in a Head Start population. Journal of Clinical Child and Adolescent Psychology, 31, 384-392.

Repp, A. (1994). Comments on functional analysis procedures for school-based behavioral problems. Journal of Applied Behavioral Analysis, 27, 409-411.

Roberts, M.W. \& Powers, S.W. (1988). The Compliance Test._Behavioral Assessment, 10, 375- 398.

Rogers, S., Bennetto, L., McEvoy, R., \& Pennington, B. (1996). Imitation and pantomime in high-functioning adolescents with autism spectrum disorders. Child Development, 67, 2060-2073.

Rousey, A., Best, S., \& Blacher, J. (1992). Mothers' and fathers' perception of stress and coping with children who have severe disabilities. American Journal on Mental Retardation, 97, 99-109.

Sallows, G.O., \& Graupner, T.D. (2005). Intensive behavioral treatment for children with autism: Four-year outcome and predictors. American Journal on Mental Retardation, 110, 417-438. 
Schopler, E. (1994). A statewide program for the treatment and education of autistic and related communication handicapped children (TEACCH). Psychoses and Pervasive Developmental Disorders, 3, 91-103.

Schopler, E., Brehm, S.S., Kinsbourne, M., \& Reichler, R.J. (1971). Effect of treatment structure on development in autistic children. Archives of General Psychiatry, 24, 416-421.

Schopler, E., Mesibov, G.B., \& Baker, A. (1982). Evaluation of treatment for autistic children and their parents. Journal of the American Academy of Child Psychiatry, $21,262-267$.

Schopler, E., \& Reichler, R.J. (1971). Parents as cotherapists in the treatment of psychotic children. Journal of Autism and Childhood Schizophrenia, 1, 87-102.

Schopler, E., Reichler, R.J., Bashford, A., Lansing, M.D., \& Marcus, L.M. (1990). Psychoeducational Profile-Revised (PEP-R). Austin, TX: Pro-Ed.

Schopler, E., Reichler, R.J., \& Renner, B.R. (1988). Child Autism Rating Scale. Los Angeles, CA: Western Psychological Services.

Schuhmann, E.M., Foote, R.C, Eyberg, S.M., Boggs, S.R., \& Algina, J. (1998). Efficacy of parent-child interaction therapy: Interim report of a randomized trial with short-term maintenance. Journal of Clinical Child Psychology, 27, 34-45.

Short, A.B. (1984). Short-term treatment outcome using parents as co-therapists for their own autistic children. Journal of Child Psychology and Psychiatry, 25, 443-458.

Sidman, M. (1989). Coercion and its fallout. Boston: Authors Cooperative. Skinner, B.F. (1953). Science and human behavior. New York: Macmillan. 
Smith, T. (1999). Outcome of early intervention for children with autism. Clinical Psychology: Science and Practice, 6, 33-49.

Smith, I., \& Bryson, S. (1994). Imitation and action in autism: A critical review. Psychological Bulletin, 116, 259-273.

Smith, T., Groen, A., \& Wynn, J.W. (2000). Randomized trial of intensive early intervention for children with pervasive developmental disorder. American Journal on Mental Retardation, 102, 228-237.

Solomon, M., Ono, M., Timmer, S., \& Goodlin-Jones. (2008). The effectiveness of parent-chile interaction therapy for families of children on the autism spectrum. Journal of Autism and Developmental Disorders, 38, 1767-1776.

Solomon, R., Necheles, J., Ferch, C., \& Bruckman, D. (2007). Pilot study of a parent training program for young children with autism: the PLAY project home consultation program. Autism 11(3), 205-224.

Sparrow, S.S., Balla, D.A., \& Cicchetti, D.V. (1984). Vineland Adaptive Behavior Scales-Interview Edition. Circle Pines, MN: American Guidance Service.

Stevens, S., Thompson, A., Masse, J., Burrell, T., Conley, M., \& McNeil, C. (2005, November). Parent-Child Interaction Therapy and Pervasive Developmental Disorder: A Case Study. Poster session presented at the Association for the Advancement of Behavior Therapy, Washington, D.C.

Stone, W., Ousley, O., \& Littleford, C. (1997). Motor imitation in young children with autism: What's the object? Journal of Abnormal Child Psychology, 25, 475-485. 
Sturmey, P., Matson, J.L., \& Sevin, J.A. (1992). Analysis of the internal consistency of three autism scales. Journal of Autism and Developmental Disorders, 22, 321328.

Tarbox, R.S, Wallace, M.D., Penrod, B., \& Tarbox, J. (2007). Effect of three-step prompting on compliance with caregiver requests. Journal of Applied Behavior Analysis, 40(4), 703-706.

Timmer, S.G., Urquiza, A.J., Zebell, N.M., McGrath, J.M. (2005). Parent-child interaction therapy: Application to maltreating parent-child dyads. Child Abuse \& Neglect, 29, 825-842.

Turnbull, H. (1986). Presidential address 1986: Public policy and professional behavior. Mental Retardation, 24, 265-275.

Urquiza, A. J., \& McNeil, C. B. (1996). Parent-Child Interaction Therapy: Potential applications for physically abusive families. Child Maltreatment, 1, 134-144.

Volkmar, F.R., Cicchetti, D.V., Dykens, E., Sparrow, S.S., Leckman, J.F., \& Cohen, D.J. (1988). An evaluation of the autism behavior checklist. Journal of Autism and Developmental Disorders, 18, 81-97.

Wadden, N.P.K., Bryson, S.E., \& Rodger, R.S. (1991). A closer look at the autism behavior checklist: discriminant validity and factor structure. Journal of Autism and Developmental Disorders, 21, 529-541.

Ware, L.M., McNeil, C.B., Masse, J.J., \& Stevens, S.B. (2008). Efficacy of in-home Parent-Child Interaction Therapy. Child and Family Behavior Therapy, 30 (2), 127-135. 
Wechsler, D. (2003). Wechsler Intelligence Scale for Children (4 ed.) San Antonio, TX: The Psychological Corporation.

Wechsler, D. (2002) Wechsler Preschool and Primary Scale of Intelligence ( ${ }^{\text {rd }}$ ed.). San Antonio, TX: The Psychological Corporation

Wieder, S., \& Greenspan, S.I. (2006). Infant and early childhood mental health: The DIR model. In G.M. Foley \& J.D. Hochman (Eds.), Mental health in early intervention: Achieving unity in principles and practice (pp. 175-189). Baltimore, MD: Paul H. Brookes. 
PCIT and Autism 113

\section{Appendix A}

Autism Behavior Checklist (ABC; Krug, Arick, \& Almond, 1980) 
PCIT and Autism 114

\section{Appendix B}

Childhood Autism Rating Scale (CARS; Schopler, Reichler, \& Renner, 1988). 
Appendix C

Child Behavior Checklist Checklist (CBCL; Achenbach \& Edelbrock, 1981) 
PCIT and Autism 116

\section{Appendix D}

The Compliance Probability Checklist (Ducharme, Popynick, Pontes, \& Steele,1996) 
PCIT and Autism 117

Appendix E

The Compliance Test (Roberts \& Powers, 1988 


\section{Coding Sheet}

Child's Initials:

\% Compliance:

Date:

Scorer's Initials:

Please begin each compliance test with the following: "(Name), I have some things for you to do now. It's important that you do these right away, just like when you pick up your toys at school or home.

1.) Please pick up this cow

2.) Please put this cow in the farm house

3.) Please get that book and bring it back

4.) Please pick up this red block

5.) Please put this red block in the school bus

6.) Please draw a straight line on this piece of paper

7.) Please pick up this person

8.) Please put this person in the Lego box

9.) Please open this book (leave it open if child CO)

10.) Please pick up this car

11.) Please put this car in the basket

12.) Please push out your chair

13.) Please push in your chair (ask even if \#11 is NC-rearrange chair if child is too close to the table after $\mathrm{CO}$ )

14.) Please turn the page in this book (need to open if \#9 is NC)

15.) Please pick up this crayon

$\mathrm{CO}$

$\mathrm{CO}$

$\mathrm{NC}$

16.) Please put this crayon in the farm house

$\mathrm{CO}$

$\mathrm{NC}$

17.) Please close this book

$\mathrm{CO}$

$\mathrm{NC}$

18.) Please pick up this dinosaur

$\mathrm{CO}$

$\mathrm{NC}$

19.) Please put this dinosaur in the school bus

$\mathrm{CO}$

$\mathrm{NC}$

$\mathrm{CO}$

$\mathrm{NC}$

$\mathrm{CO}$

$\mathrm{NC}$

$\mathrm{CO}$

$\mathrm{NC}$

$\mathrm{CO}$

$\mathrm{NC}$

$\mathrm{CO}$

$\mathrm{NC}$

$\mathrm{CO}$

$\mathrm{NC}$

$\mathrm{CO}$

$\mathrm{NC}$

20.) Please roll these dice

$\mathrm{CO}$

$\mathrm{NC}$

21.) Please point to the dump truck

22.) Please pick up this book

$\mathrm{CO}$

$\mathrm{NC}$

$\mathrm{CO}$

$\mathrm{NC}$

$\mathrm{CO}$

$\mathrm{NC}$

$\mathrm{CO}$

$\mathrm{NC}$

$\mathrm{CO}$

$\mathrm{NC}$

$\mathrm{CO}$

$\mathrm{NC}$

23.) Please put this book in the basket

$\mathrm{CO}$

$\mathrm{NC}$

24.) Please touch your nose

$\mathrm{CO}$

$\mathrm{NC}$

25.) Please pick up this yellow block

$\mathrm{CO}$

$\mathrm{NC}$

26.) Please put this yellow block in the farm house

$\mathrm{CO}$

$\mathrm{NC}$

$\mathrm{CO}$

$\mathrm{NC}$

27.) Please pass me the green block

$\mathrm{CO}$

$\mathrm{NC}$

28.) Please pick up this person

29.) Please put this person in the basket

$\mathrm{CO}$

$\mathrm{NC}$

$\mathrm{CO}$

$\mathrm{NC}$

30.) Please point to your mouth

$\mathrm{CO}$

$\mathrm{NC}$

$\mathrm{CO}$

$\mathrm{NC}$

$\mathrm{NC}$ 


\section{Scoring Key}

For the "pick up" commands (i.e., "please pick up this cow"): Score compliance $(\mathrm{CO})$ if the child initiates a continuous motor movement within 5 seconds that terminates in grasping the object or complying with the command. Score noncompliance (NC) if the child fails to initiate within $\mathbf{5}$ seconds or if the child initiates, but discontinues after 5-seconds without grasping the object or completing the command.

For the "put away" commands (i.e., "please put this cow in the farmhouse"): Score compliance $(\mathrm{CO})$ if the child initiates a continuous motor movement within 5 seconds that terminates in releasing the object in/on the correct container. Score noncompliance (NC) if the child fails to initiate within 5 seconds or if the child initiates, but discontinues after 5-seconds without releasing the object correctly.

For commands that do not require the child to pick up or put away an object (i.e., "please roll the dice"), Score compliance (CO) if the child initiates a continuous motor movement within $\mathbf{5}$ seconds that terminates in completing the task. Score noncompliance (NC) if the child fails to initiate within 5 seconds or if the child initiates, but discontinues after 5-seconds without completing the task. 
PCIT and Autism 120

Appendix F

Demographics Form 


\section{Demographics Form}

\section{Background Information}

Please complete the following information. Place an X next to the appropriate responses.

Child's Name Date

Child's Birth Date

Child's Gender: __ Male

Child's Ethnicity: __ Caucasian

African American

Asian/Pacific Islander

Hispanic

Multi-Ethnic

Other

Caregiver's Birth Date

Caregiver's Gender: ___ Male

Female

Caregiver's Ethnicity: __ Caucasian

African American

Asian/Pacific islander

Hispanic

Multi-Ethnic

Other

Please list your child's siblings and their ages below:

\begin{tabular}{|l|l|}
\hline Name & Age \\
\hline & \\
\hline & \\
\hline & \\
\hline & \\
\hline
\end{tabular}




\section{Demographics Form (Continued)}

Which best describes your relationship with your child:

Biological parent

Step-parent

Foster parent

Adoptive parent

Other relative guardian

Other

The child's primary caregivers are:

Married

Separated
Divorced
Single
Living Together
Widow/er

The following describes the child's primary caregivers employment status:

Caregiver:

Working part-time

Unemployed

Retired

Full-time foster parent

Job Title:
Caregiver:

Working full time

Unemployed

Retired

Full-time foster parent

Job Title:

The highest education level of the child's primary caregivers are:

Caregiver:

Caregiver:

Some High School

GED

High School Degree

Professional/Trade School Degree

Associate's Degree

Bachelor's Degree

Master's Degree

Advanced Degree (ex: Ph.D., M.D.)

Other Other
Some High School

GED

High School Degree

Professional/Trade School Degree

Associate's Degree

Bachelor's Degree

Master's Degree Advanced Degree (ex: Ph.D., M.D.)

Approximate family income per year:

$\$ 10,000$ or below

$\$ 10,001$ to $\$ 20,000$

$\$ 20,001$ to $\$ 30,000$

$\$ 30,001$ to $\$ 40,000$ 


\section{Psychosocial History}

$\$ 40,001$ to $\$ 50,000$

$\$ 50,001$ to $\$ 60,000$

$\$ 60,001$ or above

Diagnosis Child Has Received:

Date Child Received Assessment/Diagnosis:

Agency Where Child Obtained Diagnosis:

Types of Services Your Child Has Received or is Currently Receiving (please indicate dates):

Medications Your Child Has Taken or is Currently Taking (please indicate dates and dosage):

Family History of Medical and Psychiatric Illness

\section{Medical History}

Approximate date of last physical examination:

Does the child have any illnesses or conditions for which (s)he receives or should receive regular care (e.g., asthma, allergies, food allergies, diabetes, anemia, seizures, gastrointestinal difficulties): 
Significant Hospitalizations, Surgical, or Invasive Procedures:

Any specialized diet (e.g., gluten-free)?

\section{Developmental History}

Were there any complications during pregnancy, labor, and/or delivery? If yes, explain:

Drug and/or Alcohol use during pregnancy? If yes, explain:

Social Relatedness during infancy and early childhood? If no, explain:

Developmental milestones (e.g., walking, talking) within normal limits? If no, explain:

\section{School Adaptation and Social Relations}

1.) School: (a) does the child attend school, preschool, daycare, etc? (b) Does the teacher report any instances of bad behavior? 
2.) Peer Relations: (a) does the child have a best friend? (b) does the child have any social relationships (school, neighborhood, family friends, etc.?

3.) Family Relations: (a) what is the mother-child relationship like? (b) what is the fatherchild relationship like? (c) does the child get along with siblings?

4.) Other: (a) does the child have any particular interests/hobbies?

\section{Presenting Problems:}


PCIT and Autism 126

Appendix G

DPICS-III Situation Instructions 


\section{Instructions:}

OK, IN THIS SITUATION, TELL (CHILD'S NAME) THAT HE/SHE MAY

PLAY WITH WHATEVER HE/SHE CHOOSES. LET HIM/HER PICK ANY

ACTIVITY HE/SHE WANTS. YOU JUST FOLLOW HIS/HER LEAD AND

PLAY ALONG WITH HIM/HER.

\section{PDI Instructions:}

THAT WAS FINE. NOW WE'LL SWITCH TO ANOTHER SITUATION. TELL (CHILD'S NAME) THAT IT'S YOUR TURN TO PICK THE GAME. YOU CAN PICK ANY ACTIVITY. KEEP HIM/HER PLAYING WITH YOU ACCORDING TO YOUR RULES.

\section{Cleanup Instructions:}

THAT WAS FINE. NOW I'D LIKE YOU TO TELL (CHILD'S NAME) THAT IT IS TIME TO LEAVE AND THE TOYS MUST BE PUT AWAY. TELL HIM HER THAT YOU WANT HIM/HER TO PUT THE TOYS AWAY. MAKE SURE YOU HAVE HIM/HER PUT THEM AWAY WUTHOUT YOUR HELP. HAVE HIM/HER PUT THEM AWAY IN THE BIG TOYBOX. 
PCIT and Autism 128

Appendix $\mathrm{H}$

DPICS-III Coding Sheet 


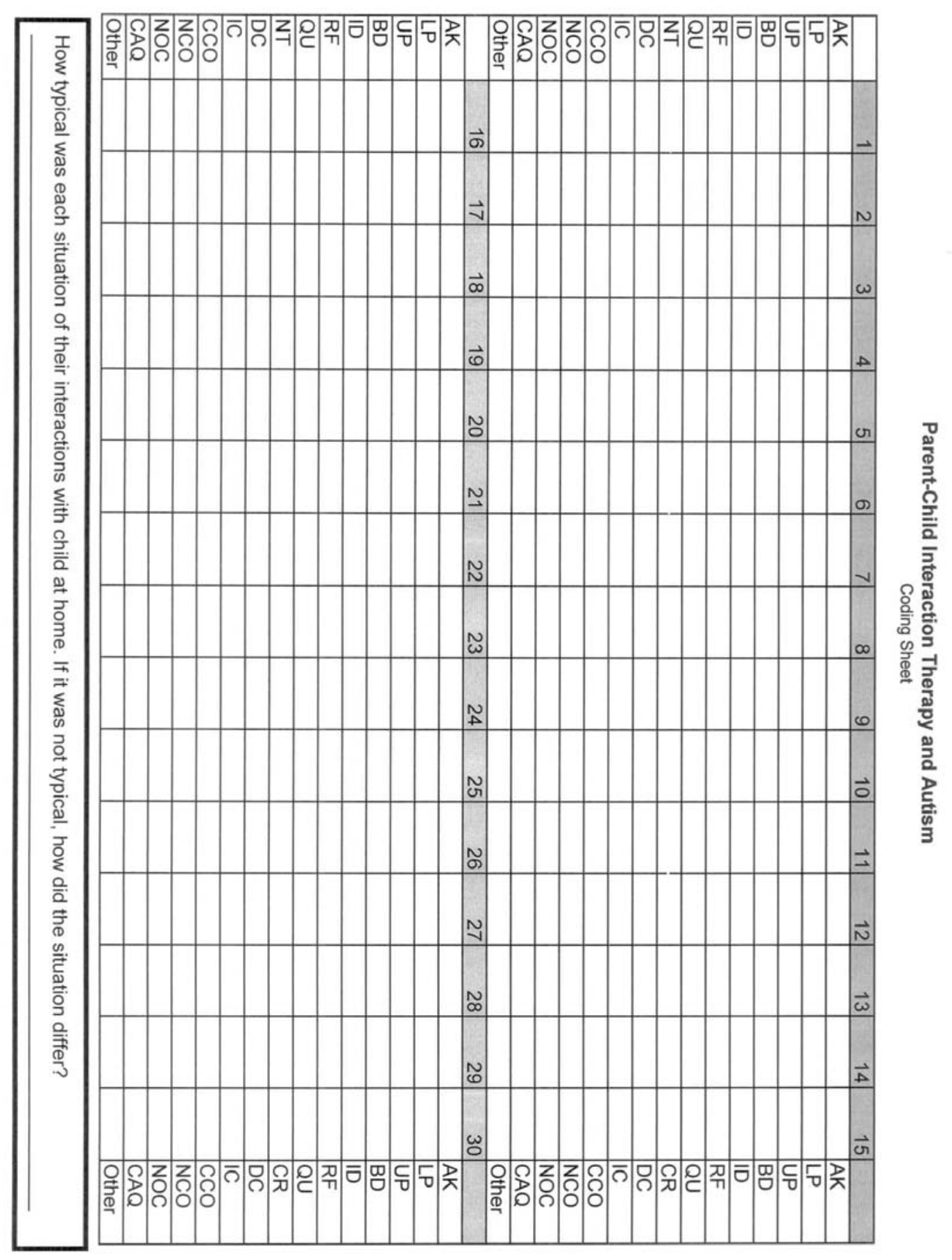


PCIT and Autism 130

\section{Appendix I}

Eyberg Child Behavior Inventory (ECBI; Eyberg \& Pincus, 1999; Eyberg \& Ross, 1978) 
Appendix J

Imitation of Pretend Play Task Coding/Instruction Sheet 
Appendix K

Integrity Checklist 


\section{FIRST CDI COACHING SESSION}

Date:

Therapist:

Child:

\section{Integrity Check? Y / N Rater:}

Materials to bring to this session (check after making sure each is in possession):

○ Participant's chart

- Toy box

- Clipboards

○ ECBI

ECBI Graph (in chart)

- Pencil for ECBI

- DPICS coding sheets (2 for each coder in chart)

- Interval audiotape, player, headphones

- Timer for coding

- Weekly Profile (in chart)

○ CDI homework sheet

○ Appointment card

Goals of this session:

○ Strengthen rapport with the family

- Continue to provide support

- Reinforce the caregiver(s) for their use of the skills and their progress (remember, this session should only focus on the positive).

\section{TREATMENT SESSION}

\section{Check in and set up}

Have therapist read ECBI to caregiver.

While caregiver completes the ECBI, talk with child briefly about therapy

- Why they are in therapy

- What therapy will be like

○ The room and the toys

- The in-room coaching rules (e.g., "I cannot look at you or talk with you when you are playing with your mom. You should pretend like I'm invisible. I will be whispering ideas to your mom to make her play with you even more fun. When our coaching time is over, then I can talk with you and play with you again.") 
Set up PCIT area - place the toys in the play area.

Let the child play at the table; sit with caregiver

Remind caregiver of the "Do" (i.e., PRIDE) and "Avoid" (i.e., commands, questions, criticisms) skills of CDI.

Review briefly, longer only if it seems you need to establish more credibility with the caregiver (i.e., if caregiver seems skeptical of treatment or of you as an expert).

Ask for homework sheets. Review homework for about 10 minutes (circle bullet which applies).

- If parents did not bring their homework sheets, or brought them back incompletely filled out, take their sheet (or new sheet) and fill in each day with them

- If parents have practiced every day, praise their conscientiousness and genuine efforts to help their child. Let them know you recognize the effort it takes to organize time and add a new event the routine.

- If the parents have not practiced every day, spend time teaching parents to problem-solve around this issue. Guide them to make a specific plan for when and where each day they will practice.

- When discussing homework activities on parents' sheets, note appropriateness of the activity/toys for CDI. Either praise their choices, or have them discuss how it worked to use that (inappropriate) activity. Then have them problemsolve until they achieve a solution.

- Comment on any notes parent wrote on homework sheet

Discuss one issue unrelated to the child's behavior or the caregiver's use of treatment skills or child management.

\section{Coding Compliance Test Observations}

Set up play area for the compliance test

Explain to the caregiver the purpose of the assessment: 
"Now we are going to observe you giving a series of commands to $\boldsymbol{N A M E}$. The purpose of this test is to get a better idea of $\boldsymbol{N A M E} \boldsymbol{S}$ ability to comply.

$\square$ Demonstrate/Practice (if needed) how the compliance test will be conducted. Show the parent the index cards with the commands/prompts and acclimate the parents to the marked toys. Be certain that the parent fully understands the test before administering it to the child.

Code compliance using the compliance coding sheet

\section{Coding and coaching}

$\square$ Note that today is the first session in which the new skills will be coded and coached. Describe the procedures.

Prepare interval audiotape and have therapists put on headphones.

$\square$ Get into your coaching position next to the caregiver (away from the child).

$\square$ Read CDI instructions for caregiver as follows:

"In this situation, tell $\boldsymbol{N A M E}$ that he/she may play with whatever he/she chooses. Let him/her choose any activity he/she wishes. Just follow his/her lead and play along with him/her."

Begin interval audiotape.

Set timer and code for exactly 5 minutes.

Coach parent with child for about 30 minutes.

a) First have caregiver tell child the rules of special playtime.

"Today we are going to have special playtime. You can play with any of the toys on the table, and I will play with you. There are two rules. You have to play gently with the toys and you have to stay in your chair. If you play roughly or get out of your chair, I will turn around like this and play all by myself. Then, when you play nicely or sit down, I will turn back around and play with you. You're playing nicely now, so we can play with anything on this table that you want to play with."

b) Give caregiver labeled praises for the best skills demonstrated during coding.

c) Focus coaching primarily on behavioral descriptions 
d) Give only positive feedback today; don't point out mistakes.

** See detailed coaching guidelines for this session in binder.

\section{Review}

$\square$ Review coding sheets with caregiver for about five minutes.

$\square$ Focus on their strengths and reassure them that they are doing fine.

\section{Wrap up}

$\square$ Give new CDI homework sheets and encourage caregiver to focus especially on decreasing questions and increasing reflections during their home practice.

(Unless these skills are already at criterion and another skill needs more emphasis).

$\square$ Confirm next appointment time with caregiver and give caregiver appointment card reminder.

$\square$ File integrity checklist(s), coding sheet(s), homework sheet, and ECBI in participant's file.

\section{Intermediate tasks}

Josh

- Enter DPICS data into Excel database and email to Josh, Cheryl within 24 hours of session.

- Examine data to determine if CDI criteria have been met.

- File participant chart.

Undergraduates

- Score ECBI

- Plot ECBI data on ECBI Graph (in chart).

- Plot DPICS data on Weekly Profile (in chart).

\section{Notes}

Please note anything unusual that happened during today's session (or any deviations from protocol) here: 


\section{Appendix L}

Parenting Stress Index—Short Form (PSI-SF); Abidin, 1995) 
PCIT and Autism 138

Appendix M

Peabody Picture Vocabulary Test-Third Edition (PPVT-III; Dunn \& Dunn, 1997) 


\section{Appendix N}

Questions about Behavioral Functioning (QABF; Mattson \& Vollmer, 1995). 
PCIT and Autism 140

\section{Appendix O}

Therapy Attitude Inventory (TAI; Eyberg, 1974). 


\section{Therapy Attitude Inventory}

(Please circle the response for each question which best expresses how you honestly feel.)

I. Regarding techniques of disciplining, I feel I have learned
1. nothing
2. very little
3. a few new
4. several useful techniques techniques
5. very many useful techniques

II. Regarding techniques for teaching my child new skills, I feel I have learned
1. nothing
2. very little
3. a few new
4. several useful techniques techniques
5 . very many useful techniques

III. Regarding the relationship between myself and my child, I feel we get along
1. much worse 2.
4. somewhat
5 . very much
than before
worse than as before
better than before
better than before
before
before

IV. Regarding my confidence in my ability to discipline my child, I feel
1. much less
2. somewhat 3. the same
4. somewhat
5. much more confident less confident more confident confident

$\mathrm{V}$. The major behavior problems that my child presented at home before the program started are at this time
1. consid
worse
somewhat 3. the same worse
4. somewhat improved
5. greatly improved

VI. I feel that my child's compliance to my commands or requests is at this time
1. considerably 2 . somewhat 3 . the same worse worse
4. somewhat 5. greatly improved improved

VII. Regarding the progress my child has made in his/her general behavior, I am
1. very
2. somewhat 3. neutral
4. somewhat 5. very dissatisfied dissatisfied satisfied satisfied

VIII. To what degree has the treatment program helped with other general personal or family problems not directly related to your child in the program
1. hindered
2. hindered
3. neither
4. helped
5. helped
much more slightly
helped nor somewhat
very much
than helped hindered

IX. I feel the type of program that was used to help me improve the behaviors of my child was
1 . very poor
2. poor
3. adequate
4. good
5. very good

$X$. My general feeling about the program I participate in, is
1. I disliked it 2. I disliked it 3. I feel
4. I liked it
5. I liked it
very much somewhat neutral
somewhat very much

Copyright (C1974 Sheila Eyberg, Ph.D 
Appendix $\mathrm{P}$

Vineland Adaptive Behavior Scales-Interview Edition (Sparrow, Balla, \& Cicchetti, 1984). 


\section{Appendix Q}

Wechsler Preschool and Primary Scale of Intelligence-Third Edition (WPPSI-III; Wechsler, 2002). 
Table 1

Dependent Variables, Measures, and Assessment Points

\begin{tabular}{|c|c|c|}
\hline Dependent Variable & Measure & Assessment Point(s) \\
\hline Child Compliance & $\begin{array}{l}\text { DPICS-III CDI observation } \\
\text { DPICS-III PDI observation } \\
\text { DPICS-III Clean Up observation } \\
\text { The Compliance Probability } \\
\text { Questionnaire (Parent Report) }\end{array}$ & $\begin{array}{l}\text { Pre-treatment } \\
\text { (videotaped) } \\
\text { Post-Treatment } \\
\text { (videotaped) } \\
\text { Follow up } \\
\text { (videotaped) }\end{array}$ \\
\hline Child Compliance & $\begin{array}{l}\text { The Compliance Test } \\
\text { DPICS-III PDI observation }\end{array}$ & $\begin{array}{l}\text { Prior to each session } \\
\text { PDI sessions only }\end{array}$ \\
\hline Child Imitation & Imitation of Pretend Play Task & $\begin{array}{l}\text { Pre-treatment } \\
\text { (videotaped) } \\
\text { Post-treatment } \\
\text { (videotaped) } \\
\text { Follow up } \\
\text { (videotaped) }\end{array}$ \\
\hline Caregiver positive behavior & DPICS-III CDI observation & $\begin{array}{l}\text { Pre-treatment } \\
\text { (videotaped) } \\
\text { Prior to each CDI }\end{array}$ \\
\hline
\end{tabular}


PCIT and Autism

\begin{tabular}{|c|c|c|}
\hline & & $\begin{array}{l}\text { treatment session } \\
\text { Post-treatment } \\
\text { (videotaped) } \\
\text { Follow up } \\
\text { (videotaped) }\end{array}$ \\
\hline Caregiver negative behavior & DPICS-III CDI observation & $\begin{array}{l}\text { Pre-treatment } \\
\text { (videotaped) } \\
\text { Prior to each CDI } \\
\text { treatment session } \\
\text { Post-treatment } \\
\text { (videotaped) } \\
\text { Follow up } \\
\text { (videotaped) }\end{array}$ \\
\hline $\begin{array}{l}\text { Caregiver report of child } \\
\text { behavior problems }\end{array}$ & $\begin{array}{l}\text { Child Behavior Checklist } \\
\text { Eyberg Child Behavior Inventory } \\
\text { (weekly) }\end{array}$ & $\begin{array}{l}\text { Pre-treatment } \\
\text { Post-treatment } \\
\text { Follow up }\end{array}$ \\
\hline Parenting stress & $\begin{array}{l}\text { Parenting Stress Index - Short } \\
\text { Form }\end{array}$ & $\begin{array}{l}\text { Pre-treatment } \\
\text { Post-treatment } \\
\text { Follow up }\end{array}$ \\
\hline
\end{tabular}


PCIT and Autism 146

\begin{tabular}{|c|c|c|}
\hline $\begin{array}{l}\text { Caregiver report of behavior } \\
\text { function }\end{array}$ & $\begin{array}{l}\text { Questions about Behavioral } \\
\text { Functioning }\end{array}$ & $\begin{array}{l}\text { Pre-treatment } \\
\text { Post-treatment } \\
\text { Follow up }\end{array}$ \\
\hline $\begin{array}{l}\text { Caregiver report of child } \\
\text { autistic behavior }\end{array}$ & Autism Behavior Checklist & $\begin{array}{l}\text { Pre-treatment } \\
\text { Post-treatment } \\
\text { Follow up }\end{array}$ \\
\hline $\begin{array}{l}\text { Observation of child autistic } \\
\text { behavior }\end{array}$ & Childhood Autism Rating Scale & $\begin{array}{l}\text { Pre-treatment } \\
\text { Post-treatment } \\
\text { Follow up }\end{array}$ \\
\hline $\begin{array}{l}\text { Child receptive language } \\
\text { abilities }\end{array}$ & Peabody Picture Vocabulary Test & $\begin{array}{l}\text { Pre-treatment } \\
\text { Post-treatment } \\
\text { Follow up }\end{array}$ \\
\hline $\begin{array}{l}\text { Child level of adaptive } \\
\text { functioning }\end{array}$ & $\begin{array}{l}\text { Vineland Adaptive Behavior } \\
\text { Scales-Interview }\end{array}$ & $\begin{array}{l}\text { Pre-treatment } \\
\text { Post-treatment } \\
\text { Follow up }\end{array}$ \\
\hline Child level of intelligence & $\begin{array}{l}\text { Wechsler Preschool and Primary } \\
\text { Scale of Intelligence-Third Edition }\end{array}$ & $\begin{array}{l}\text { Pre-treatment } \\
\text { Post-treatment }\end{array}$ \\
\hline
\end{tabular}


PCIT and Autism

\begin{tabular}{|l|l|l|}
\hline & & Follow up \\
\hline Consumer satisfaction & Therapy Attitude Inventory & Post-treatment \\
& & Follow up \\
\hline
\end{tabular}


Table 2

Definitions of DPICS-III Codes

\begin{tabular}{|c|c|}
\hline Code & Definition \\
\hline Acknowledgement & $\begin{array}{l}\text { Brief verbal or vocal response that indicate attention to } \\
\text { child but do not describe or evaluate. }\end{array}$ \\
\hline Behavioral Description & $\begin{array}{l}\text { Descriptive statements in which the subject of the } \\
\text { sentence is the child and the verb describes the child's } \\
\text { ongoing or immediately completed ( }<5 \text { seconds) } \\
\text { verbal or nonverbal observable behavior. }\end{array}$ \\
\hline Information Description & $\begin{array}{l}\text { Descriptive statements that introduce information } \\
\text { about people, objects, events, or activities, bo do not } \\
\text { clearly describe the child's current or immediately } \\
\text { completed behavior. }\end{array}$ \\
\hline Labeled Praise & $\begin{array}{l}\text { Labeled praise provides a positive evaluation of a } \\
\text { specific behavior, activity, or product of the child. }\end{array}$ \\
\hline Reflection & $\begin{array}{l}\text { A declarative phrase or statement that has the same } \\
\text { meaning as an immediately preceding child } \\
\text { verbalization. The reflection may paraphrase or } \\
\text { elaborate upon the child's verbalization but may not } \\
\text { change the meaning of the child's statement or } \\
\text { interpret unstated ideas. }\end{array}$ \\
\hline
\end{tabular}




\begin{tabular}{|c|c|}
\hline Unlabeled Praise & $\begin{array}{l}\text { A verbalization that contains positive evaluative words } \\
\text { or phrases but does not indicate the specific behavior, } \\
\text { activity, or product of the child being evaluated. }\end{array}$ \\
\hline Direct Command & $\begin{array}{l}\text { Declarative statements that contain an order or } \\
\text { direction for a vocal or motoric behavior to be } \\
\text { performed and indicate that the child is to perform this } \\
\text { behavior. }\end{array}$ \\
\hline Indirect Command & $\begin{array}{l}\text { Suggestion for a vocal or motoric behavior to be } \\
\text { performed that is implied or stated in question form. }\end{array}$ \\
\hline Negative Talk & $\begin{array}{l}\text { A verbal expression of disapproval for the child or the } \\
\text { child's attributes, products, or choices. Negative talk } \\
\text { also includes sassy, sarcastic, rude, or impudent } \\
\text { speech. }\end{array}$ \\
\hline Question & $\begin{array}{l}\text { A descriptive or reflective comment or } \\
\text { acknowledgement expressed in question form. }\end{array}$ \\
\hline Child Compliance & $\begin{array}{l}\text { Coded when the child obeys or begins to obey the } \\
\text { command within the } 5 \text {-second interval. }\end{array}$ \\
\hline Child Noncompliance & $\begin{array}{l}\text { Coded following a direct or indirect parental command } \\
\text { when the child does not obey, attempt to obey, or stops } \\
\text { attempting to complete the requested behavior within }\end{array}$ \\
\hline
\end{tabular}




\begin{tabular}{|l|l|}
\hline $\begin{array}{l}\text { Child No Opportunity for } \\
\text { Compliance }\end{array}$ & $\begin{array}{l}\text { the 5 second interval following the command. } \\
\text { to comply with a command. }\end{array}$ \\
\hline Child Answers Questions & $\begin{array}{l}\text { A verbal or nonverbal response to an information } \\
\text { question that provides or attempts to provide the } \\
\text { information requested in the question. }\end{array}$ \\
\hline Other & Coded when none of the other categories is applicable. \\
\hline
\end{tabular}


Table 3

Assessment Procedures

\begin{tabular}{|l|l|}
\hline \multicolumn{1}{|c|}{ Session } & \multicolumn{1}{c|}{ Description } \\
\hline Pre-treatment Assessment & $\begin{array}{l}\text { The Compliance Test } \\
\text { 5-minute DPICS-III CDI Observation } \\
5-\text {-minute DPICS-III PDI Observation } \\
5 \text {-minute DPICS-III Cleanup Observation } \\
\text { Autism Behavior Checklist } \\
\text { Childhood Autism Rating Scale } \\
\text { Child Behavior Checklist } \\
\text { Eyberg Child Behavior Inventory } \\
\text { Imitation of Pretend Play Task } \\
\text { Parenting Stress Index-Short Form } \\
\text { Peabody Picture Vocabulary Test } \\
\text { Questions about Behavioral Functioning } \\
\text { Vineland Adaptive Behavior Scales }\end{array}$ \\
\hline
\end{tabular}




\begin{tabular}{|c|c|}
\hline & $\begin{array}{l}\text { Wechsler Preschool and Primary Scale of Intelligence- } \\
\text { Third Edition }\end{array}$ \\
\hline Pre-CDI Baseline & $\begin{array}{l}\text { The Compliance Test conducted no more than once per } \\
\text { day and no less than once per week (at least } 3 \text { data } \\
\text { points) }\end{array}$ \\
\hline $\begin{array}{l}\text { CDI treatment sessions/Pre- } \\
\text { PDI Baseline }\end{array}$ & $\begin{array}{l}\text { 5-minute DPICS-III CDI observation } \\
\text { The Compliance Test } \\
\text { Eyberg Child Behavior Inventory (weekly) }\end{array}$ \\
\hline PDI treatment sessions & $\begin{array}{l}\text { 5-minute DPICS-III CDI observation } \\
\text { 5-minute DPICS-III PDI observation } \\
\text { Eyberg Child Behavior Inventory (weekly) }\end{array}$ \\
\hline Post-treatment Assessment & $\begin{array}{l}\text { The Compliance Test } \\
\text { The Compliance Probability Questionnaire } \\
\text { 5-minute DPICS-III CDI Observation } \\
\text { 5-minute DPICS-III PDI Observation } \\
\text { 5-minute DPICS-III Cleanup Observation } \\
\text { Autism Behavior Checklist }\end{array}$ \\
\hline
\end{tabular}




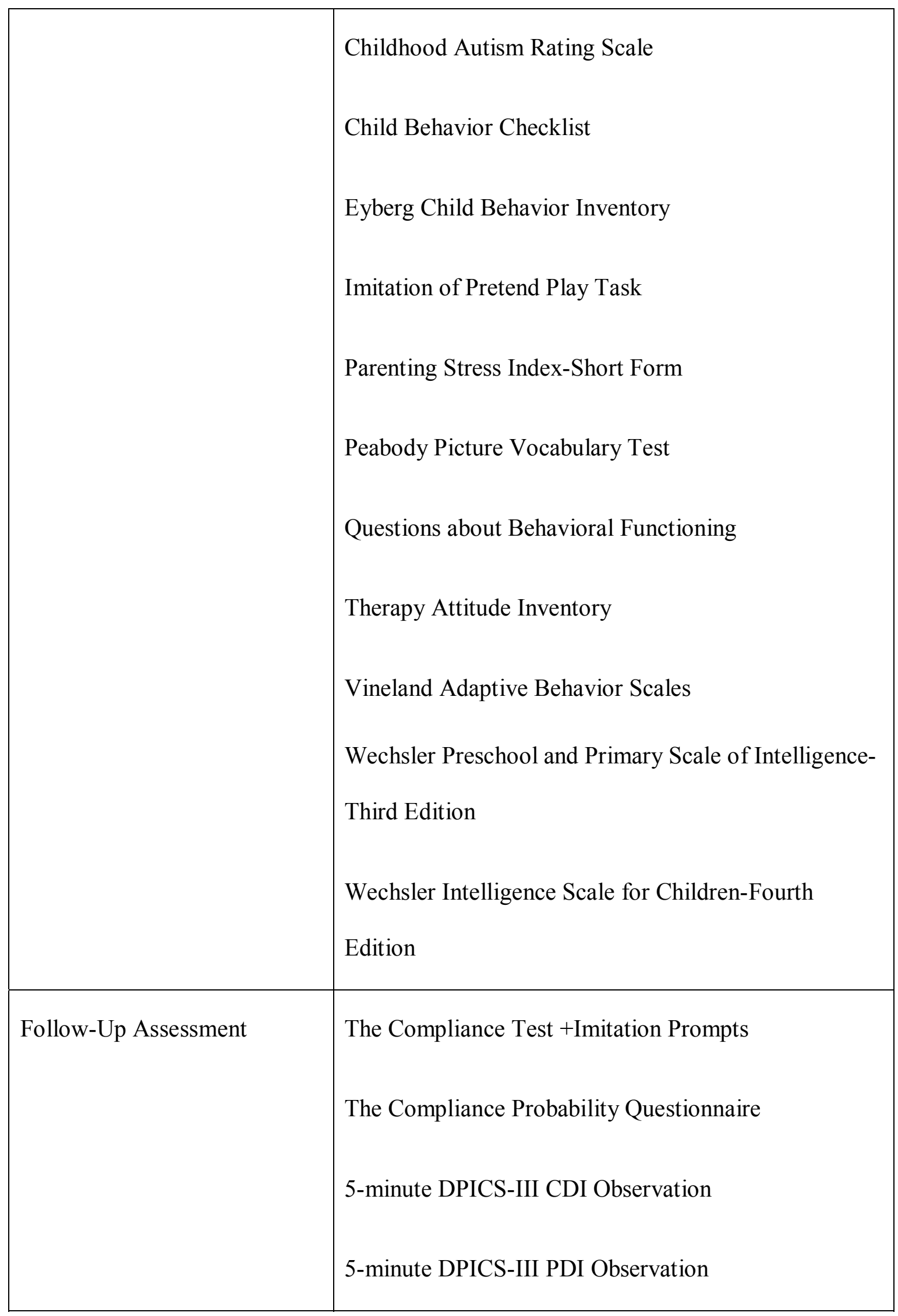


PCIT and Autism 154

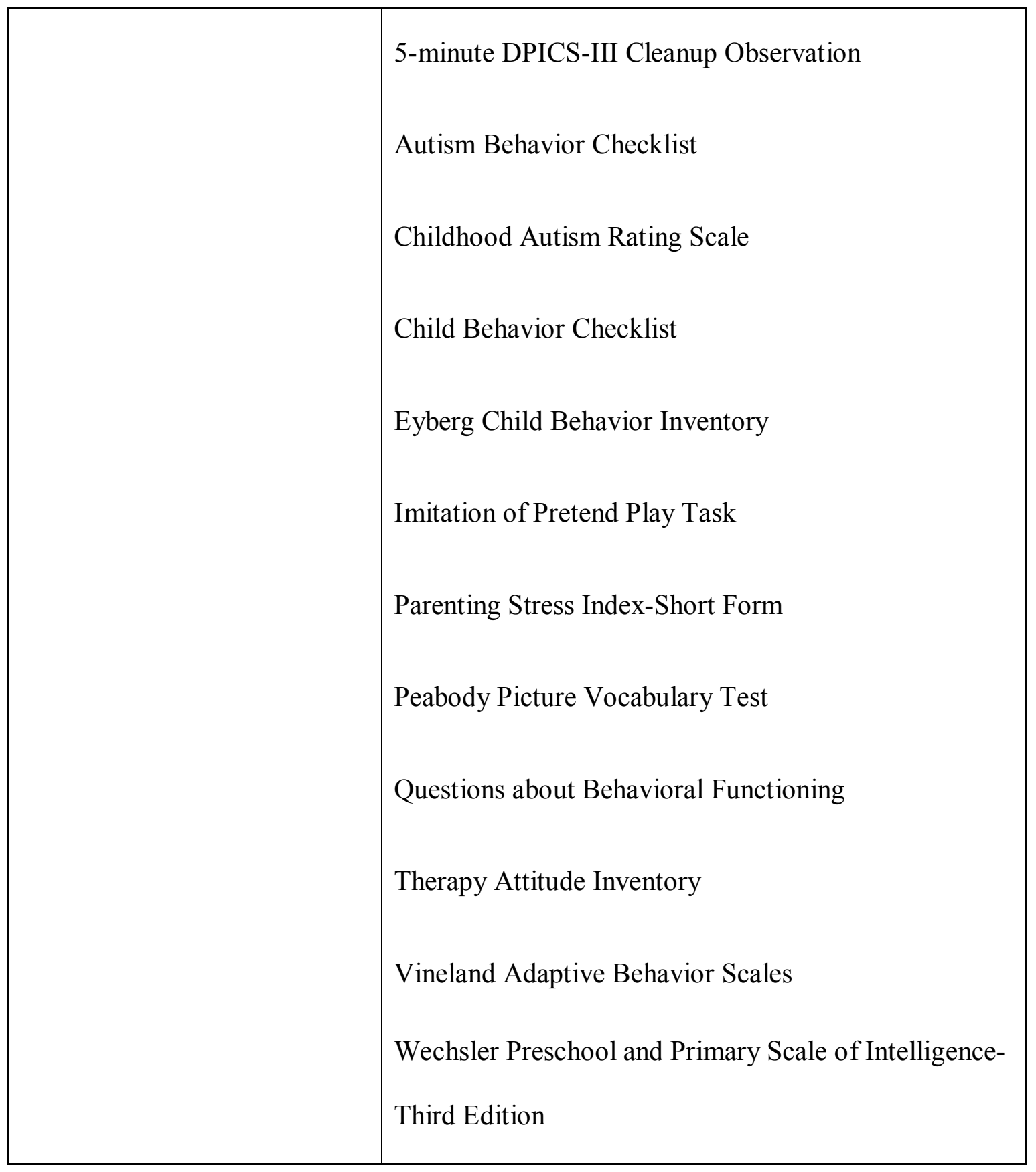


PCIT and Autism 155

Table 4

Comparison of child compliance rates to previous PCIT studies

Percent Child Compliance

\begin{tabular}{lccc}
\hline Study & Pre treatment & Post treatment & Follow up \\
& M (SD) & M (SD) & M (SD) \\
\hline Masse et al., 2009 & $35.5(18.1)$ & $80.7(21.3)$ & $90.5(15.7)$ \\
\hline Tarbox et al., 2007 & & & 100 \\
\hline Nixon et al., 2003 & 17 & $81(22)$ & $83(21)$ \\
\hline Schuhmann et al., 1998 & 25 & 46 & Not reported \\
\hline Eisenstadt et al., 1993 & $64(24)$ & $71.6(16.1)$ & Not reported \\
\hline McNeil et al., 1991 & $41.0(17.8)$ & $70.4(16.3)$ & Not conducted \\
\hline
\end{tabular}

$\mathrm{a}=$ PCIT study; $\mathrm{b}=$ ABA study 
PCIT and Autism 156
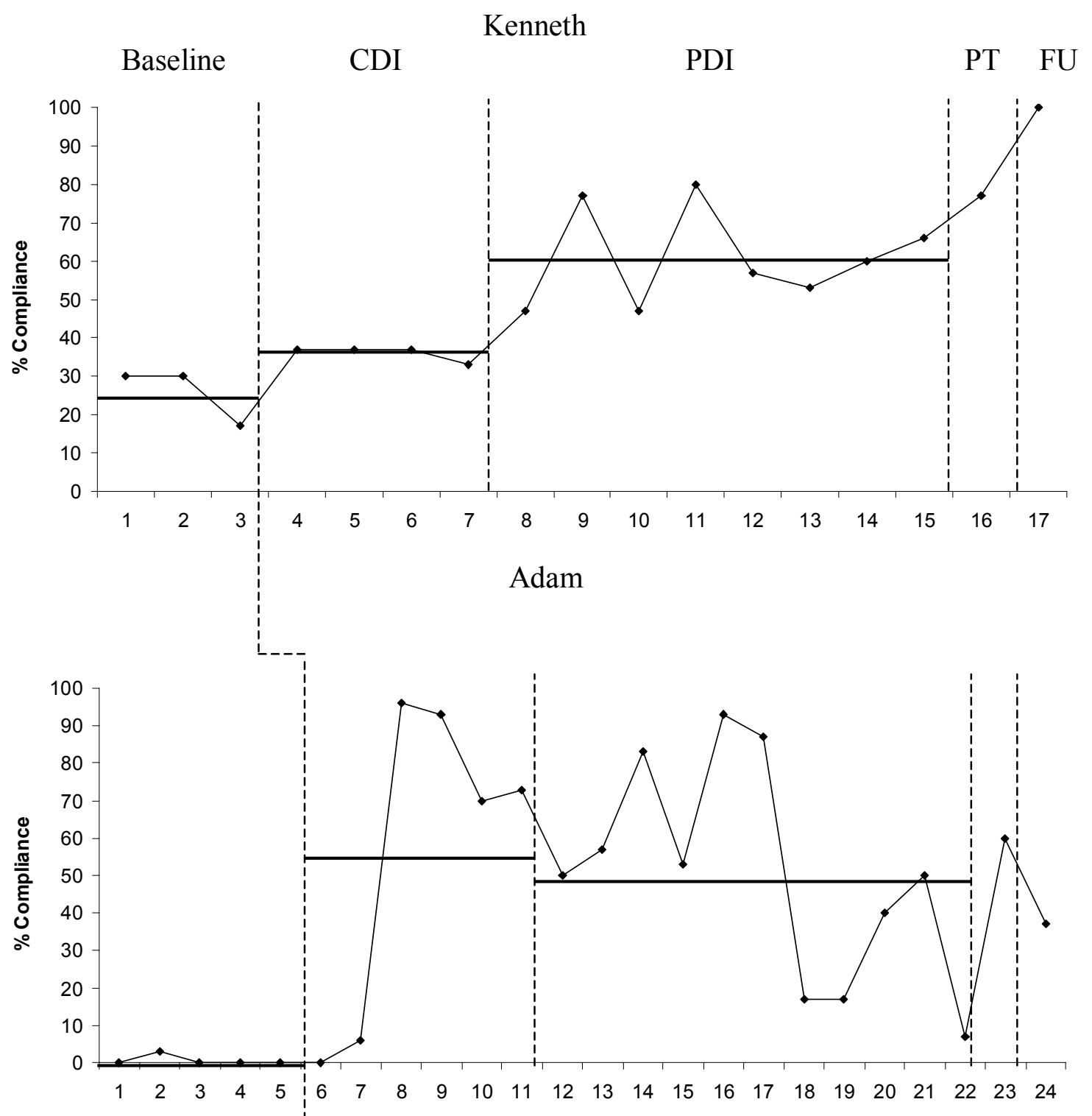

Christopher

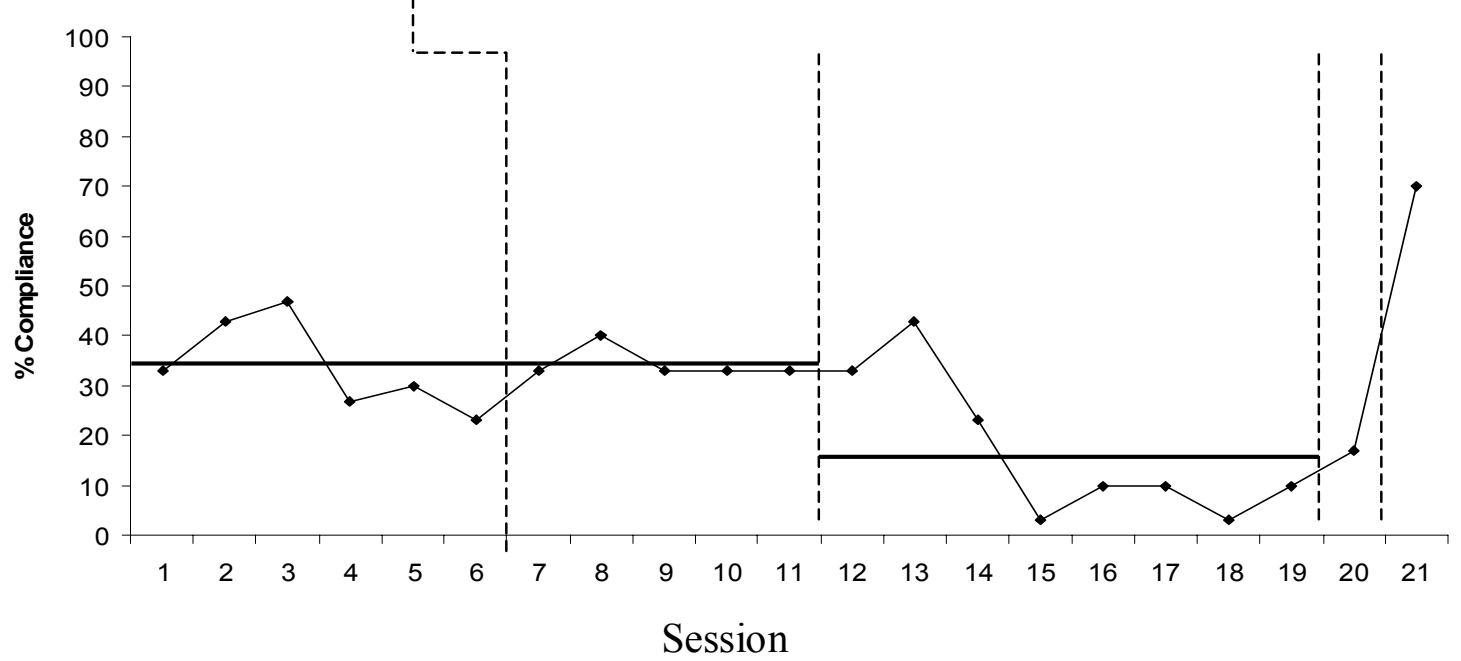

Figure 1. Compliance Test percentage exhibited by participants with horizontal lines indicating phase mean 


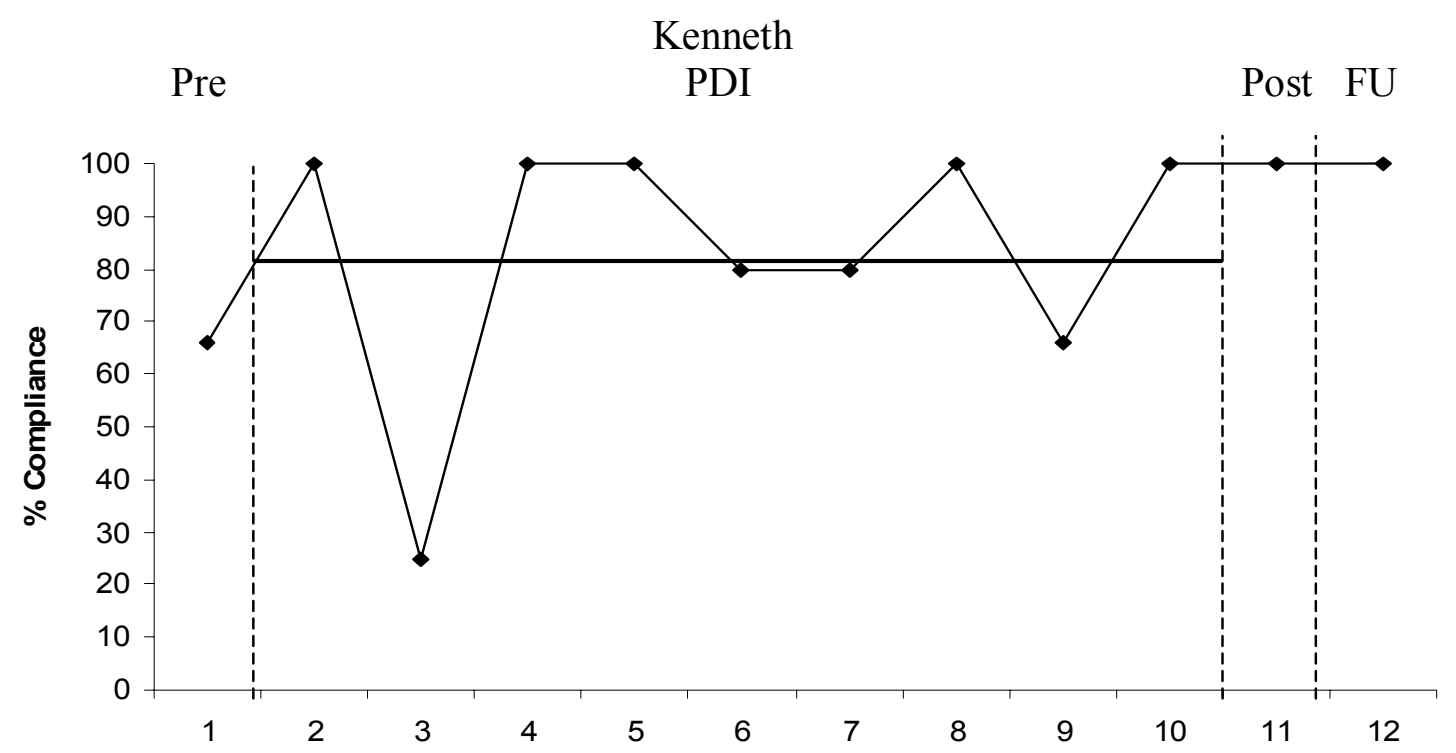

Adam

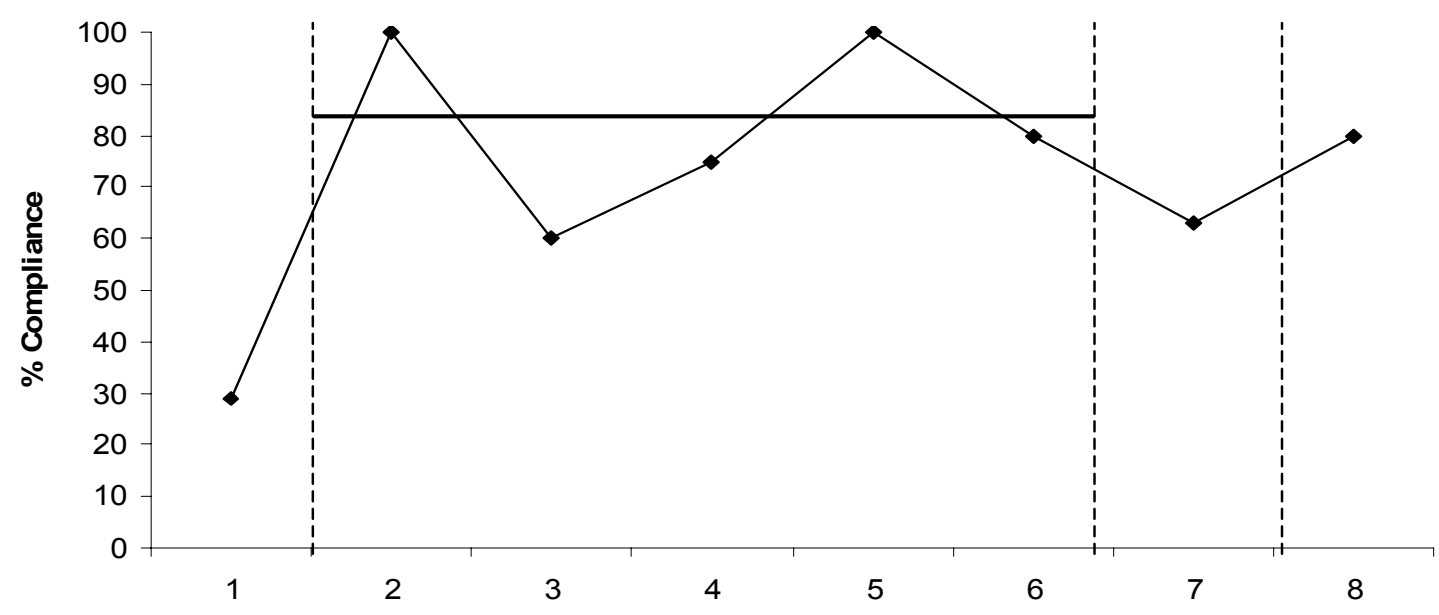

Christopher

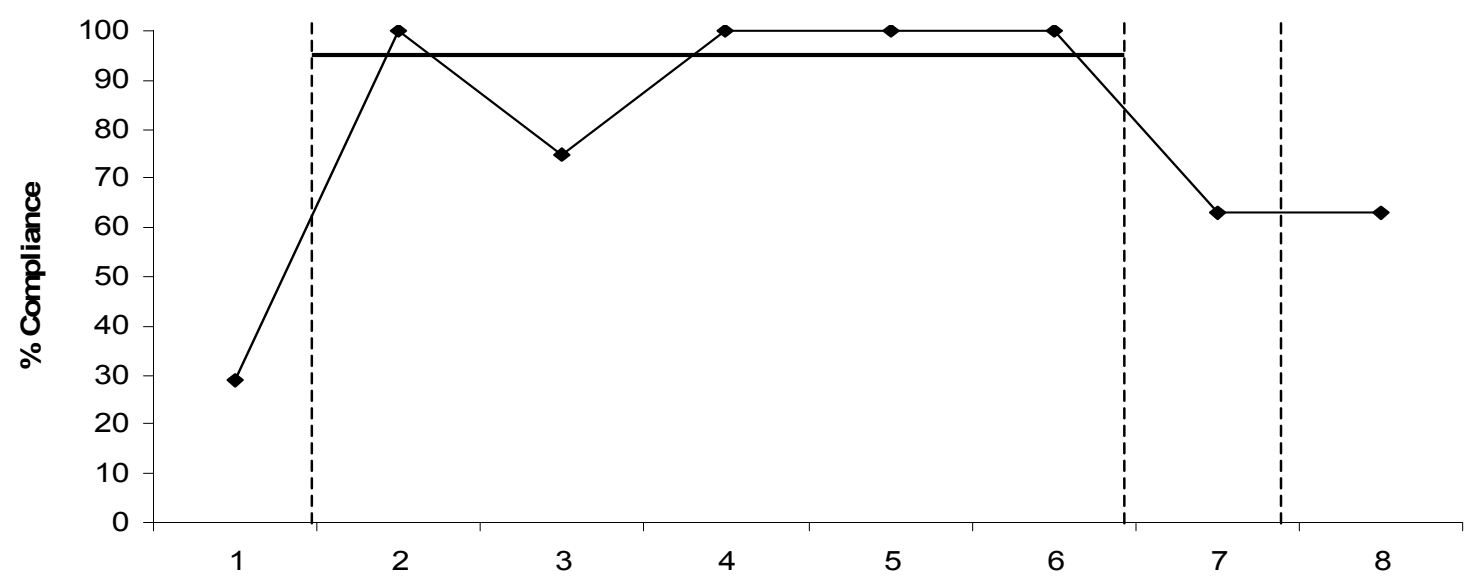

Session

Figure 2. PDI compliance percentage exhibited by participants with horizontal lines indicating phase mean. 
PCIT and Autism 158

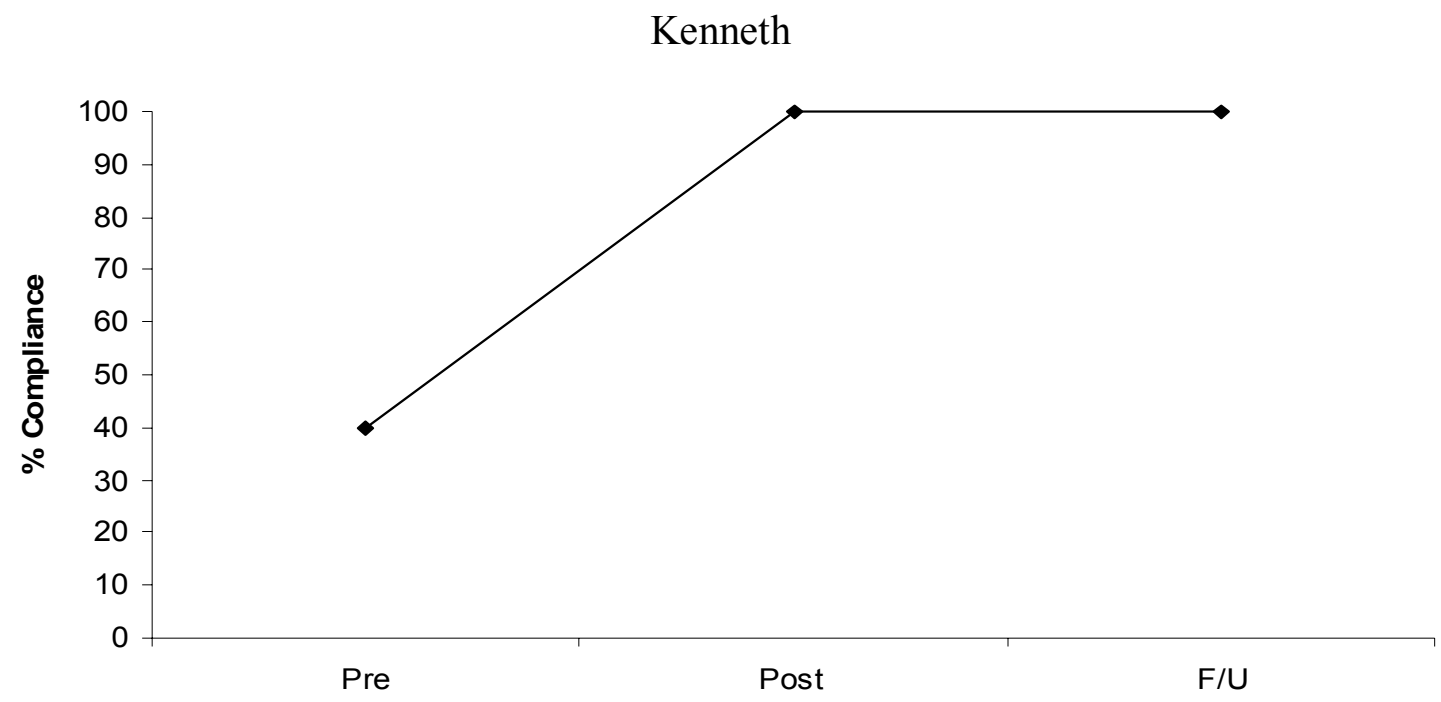

Adam

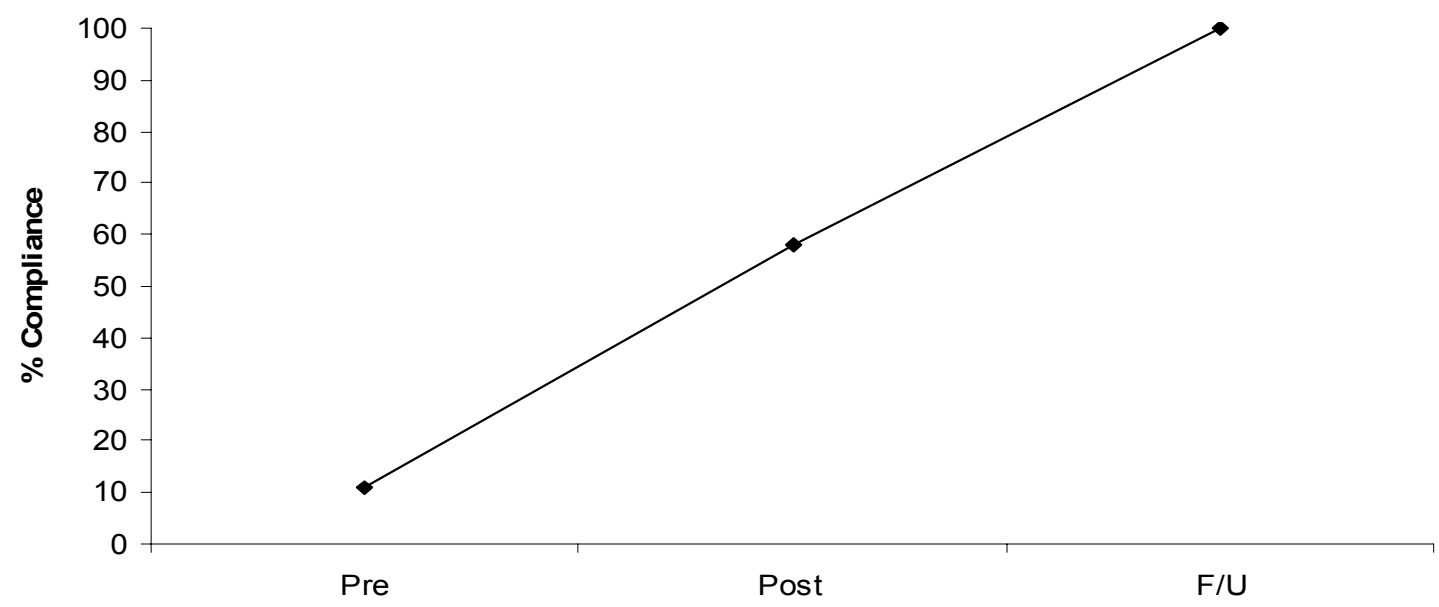

Christopher

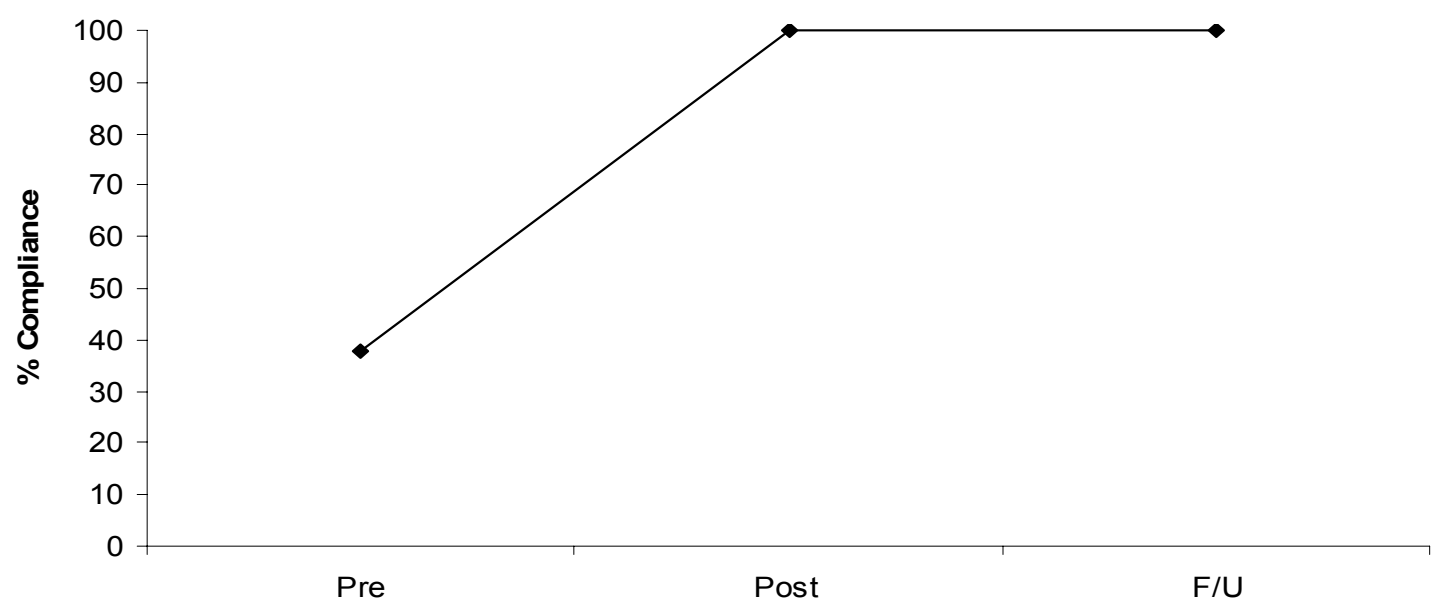

Figure 3. Clean-up task compliance percentage across participants. 


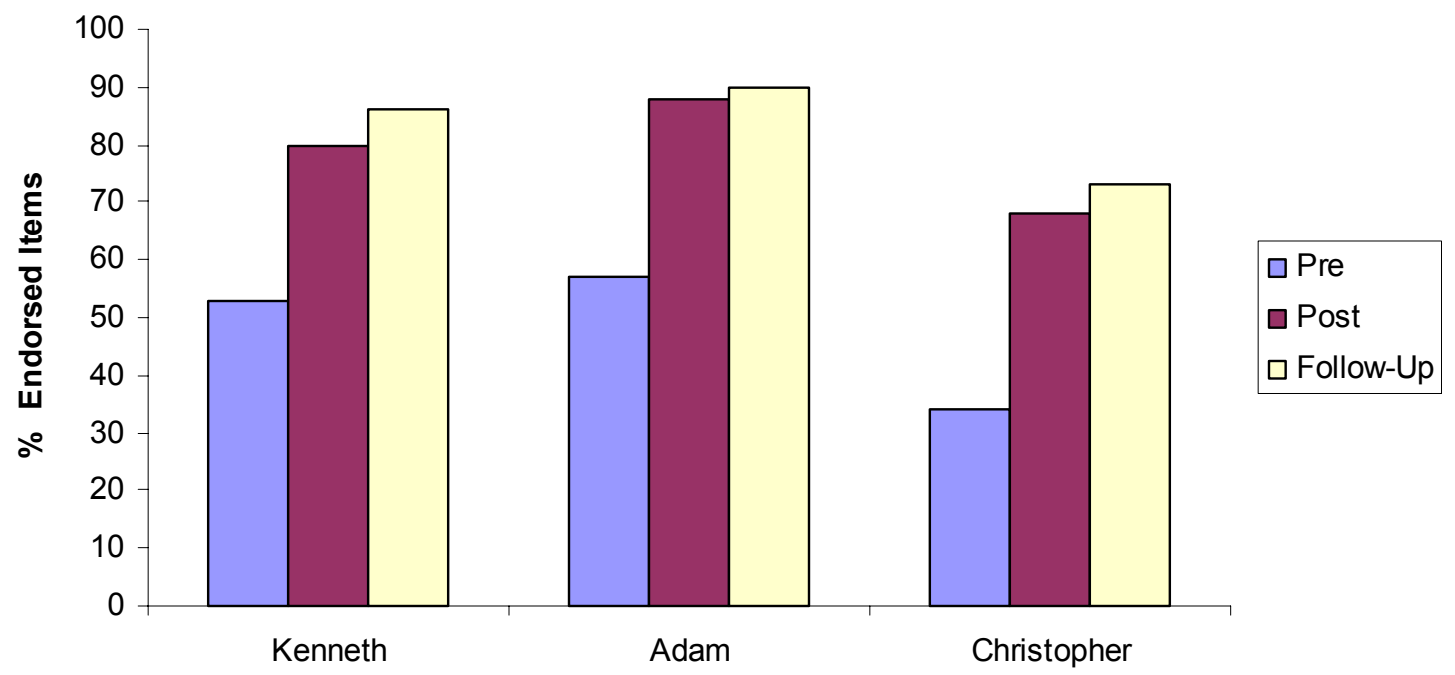

Figure 4. Parent report of percentage of measure items participants would "usually" or "almost always" comply with. 
PCIT and Autism 160
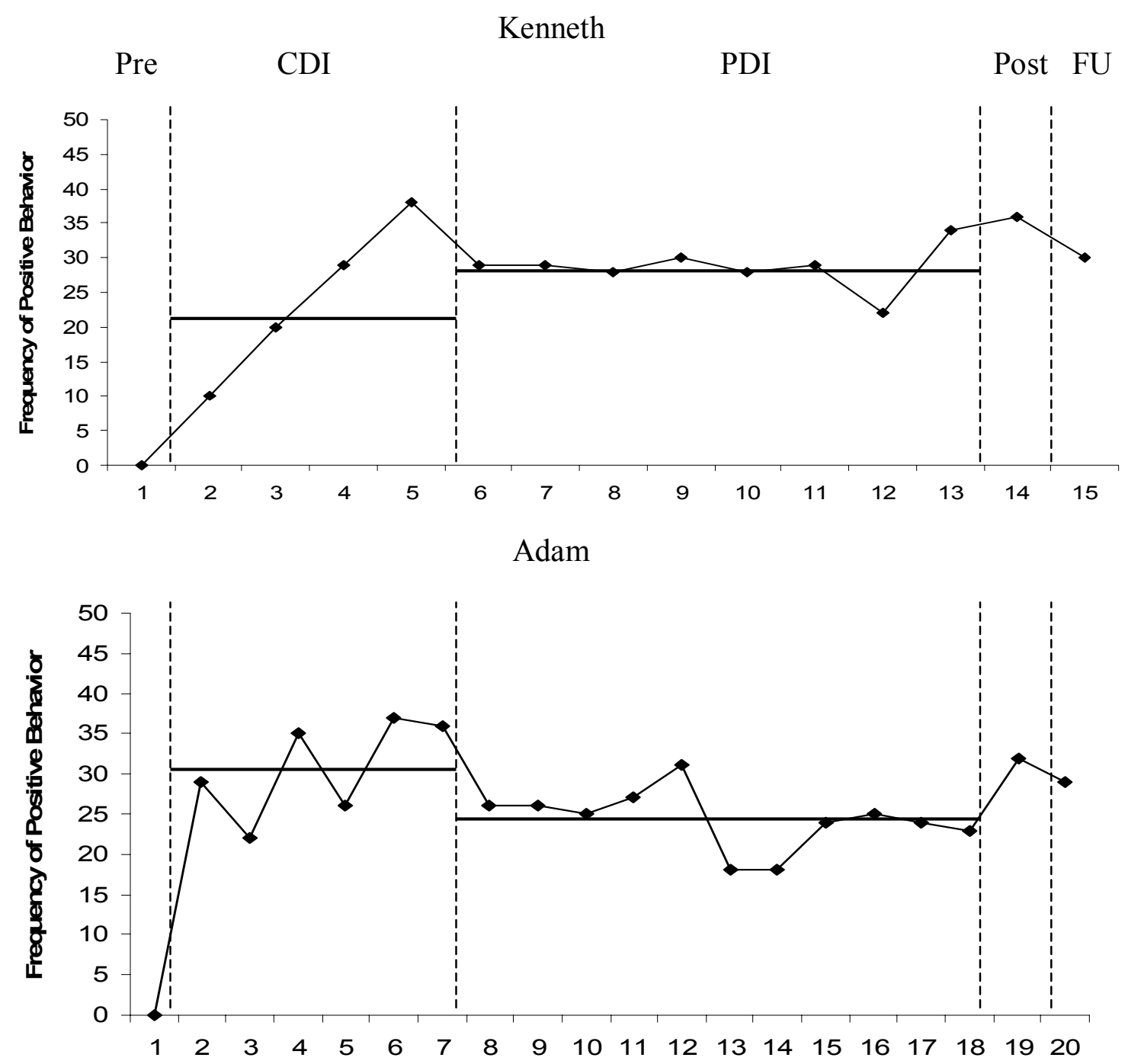

Christopher

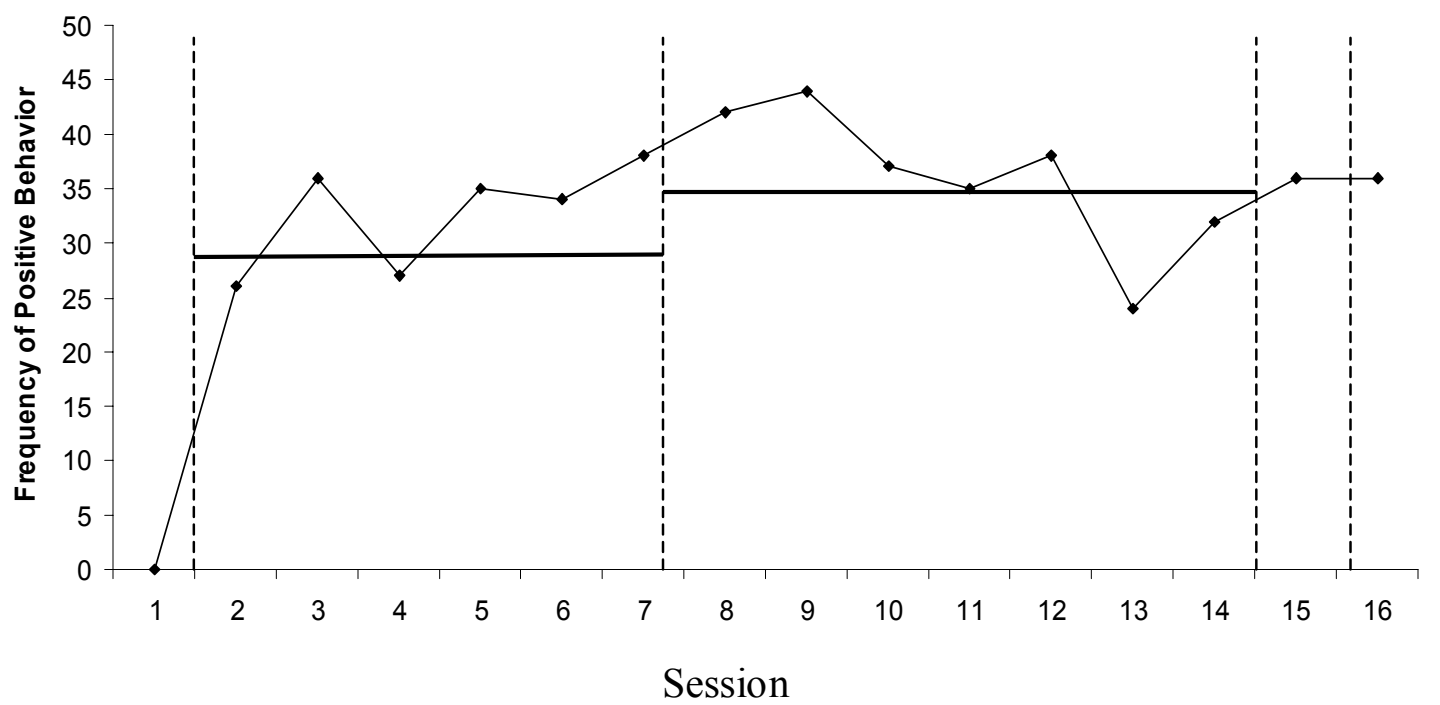

Figure 5. Positive parenting exhibited by caregivers with horizontal lines indicating phase mean. 

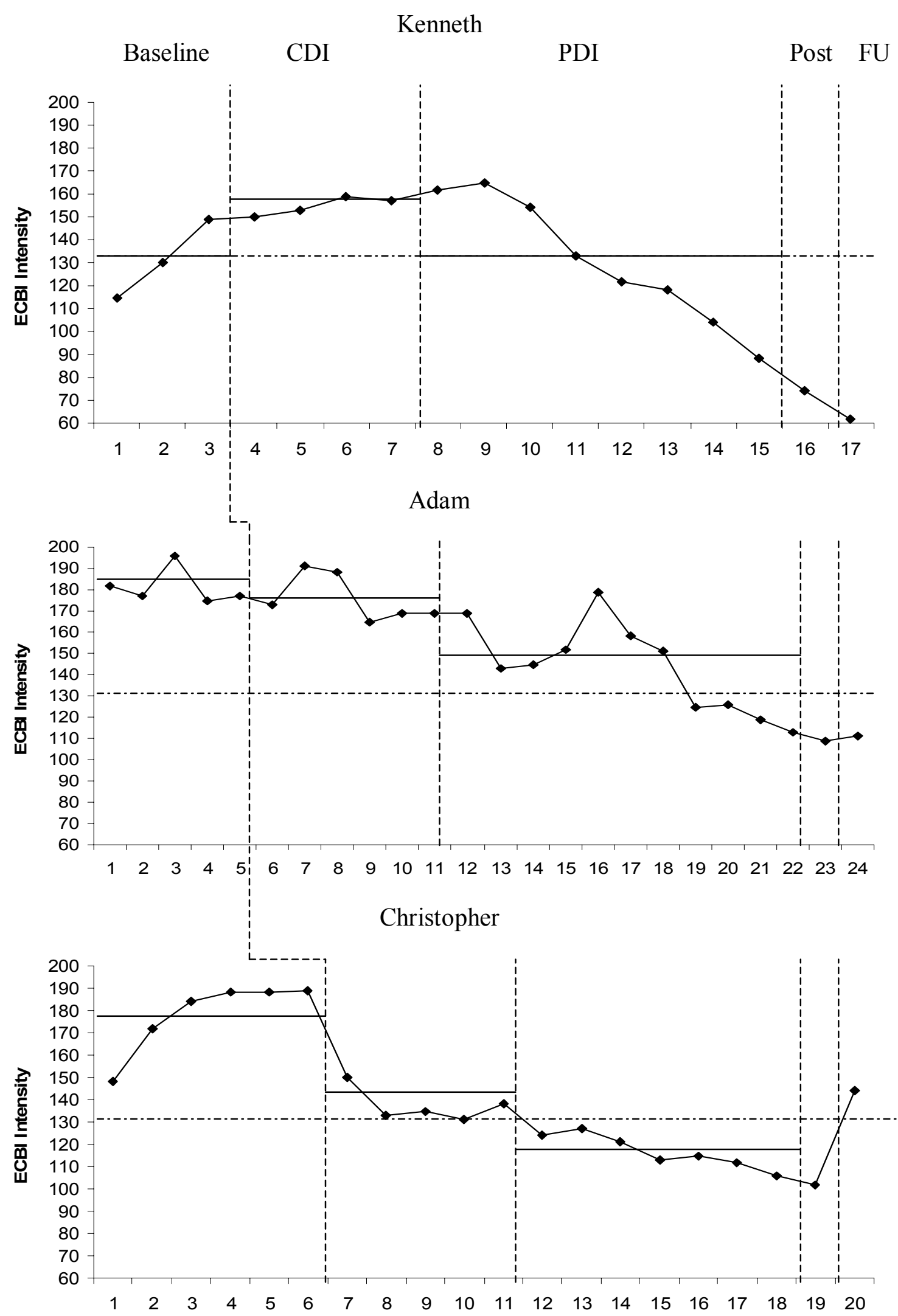

Session

Figure 6. ECBI intensity scores reported by caregivers with horizontal lines indicating phase mean and dashed horizontal line indicating clinical cutoff. 

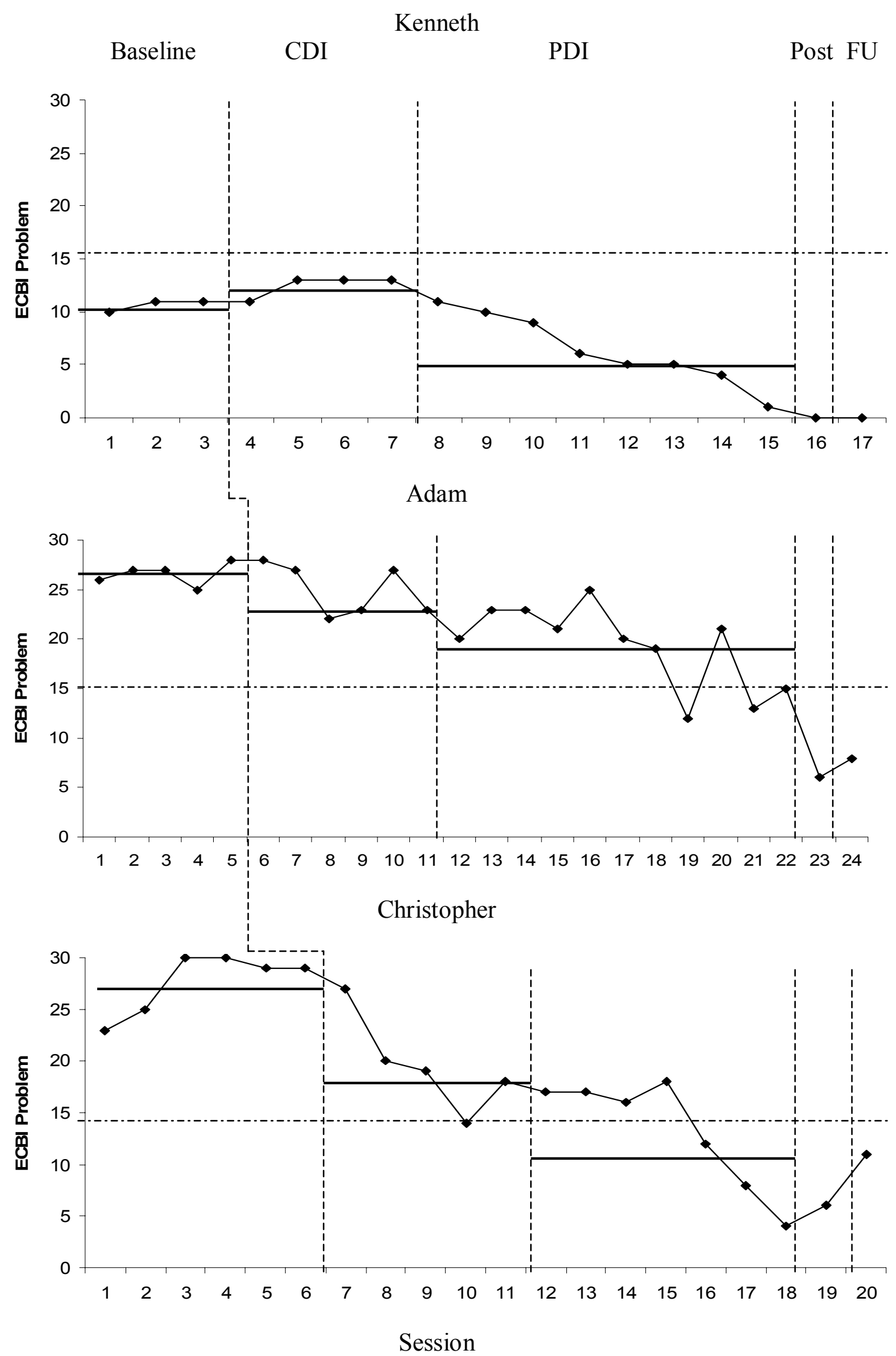

Figure 7. ECBI problem scores reported by caregivers with horizontal lines indicating phase mean and dashed horizontal line indicating clinical cutoff. 

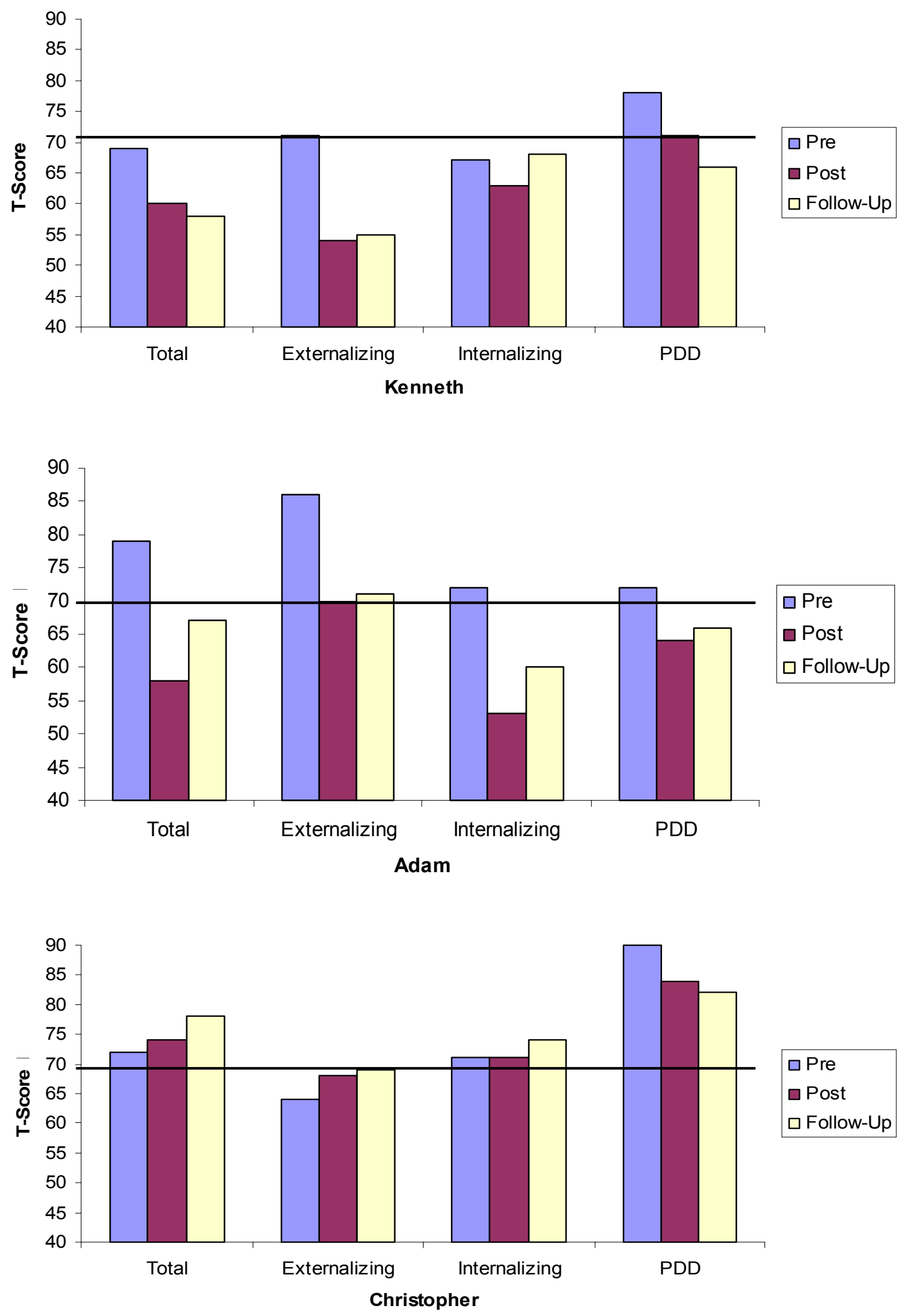

Figure 8. CBCL total score and subscales scores reported by caregivers with horizontal line indicating clinical cutoff. 


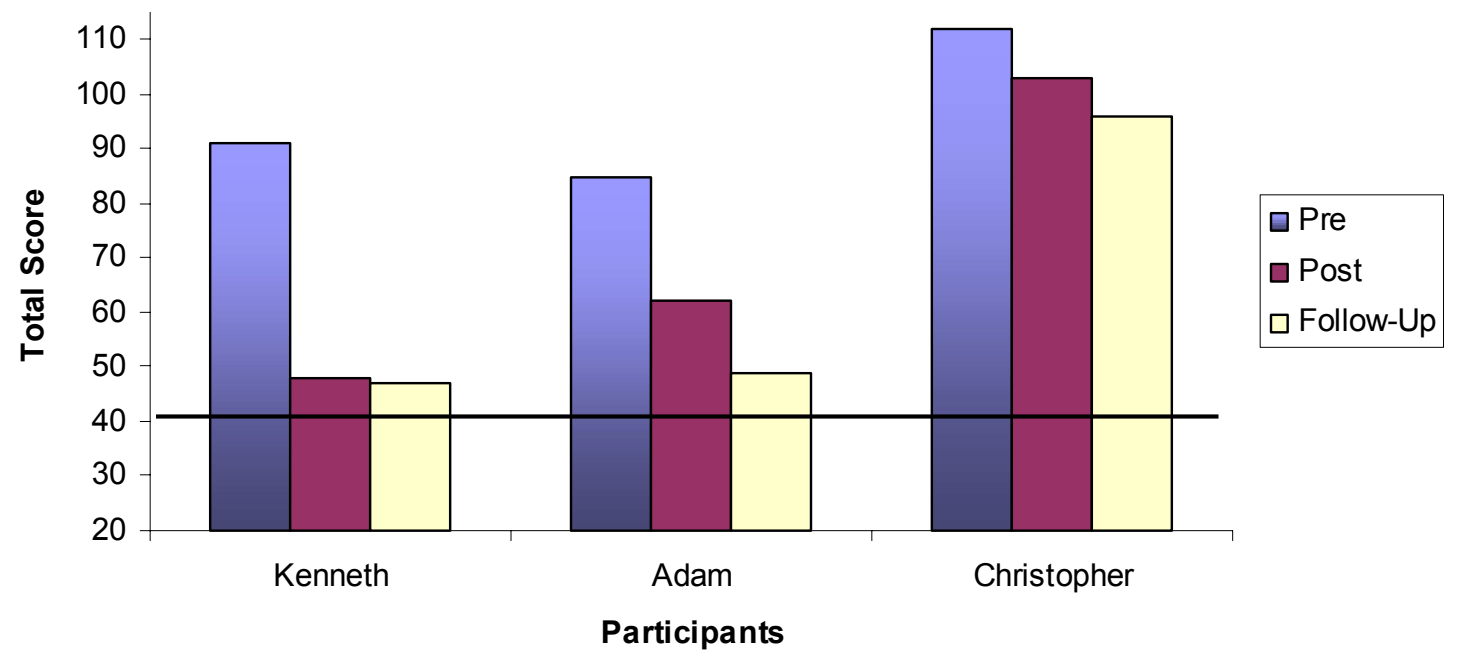

Figure 9. Autism Behavior Checklist total score reported by caregivers with horizontal line indicating clinical cutoff. 


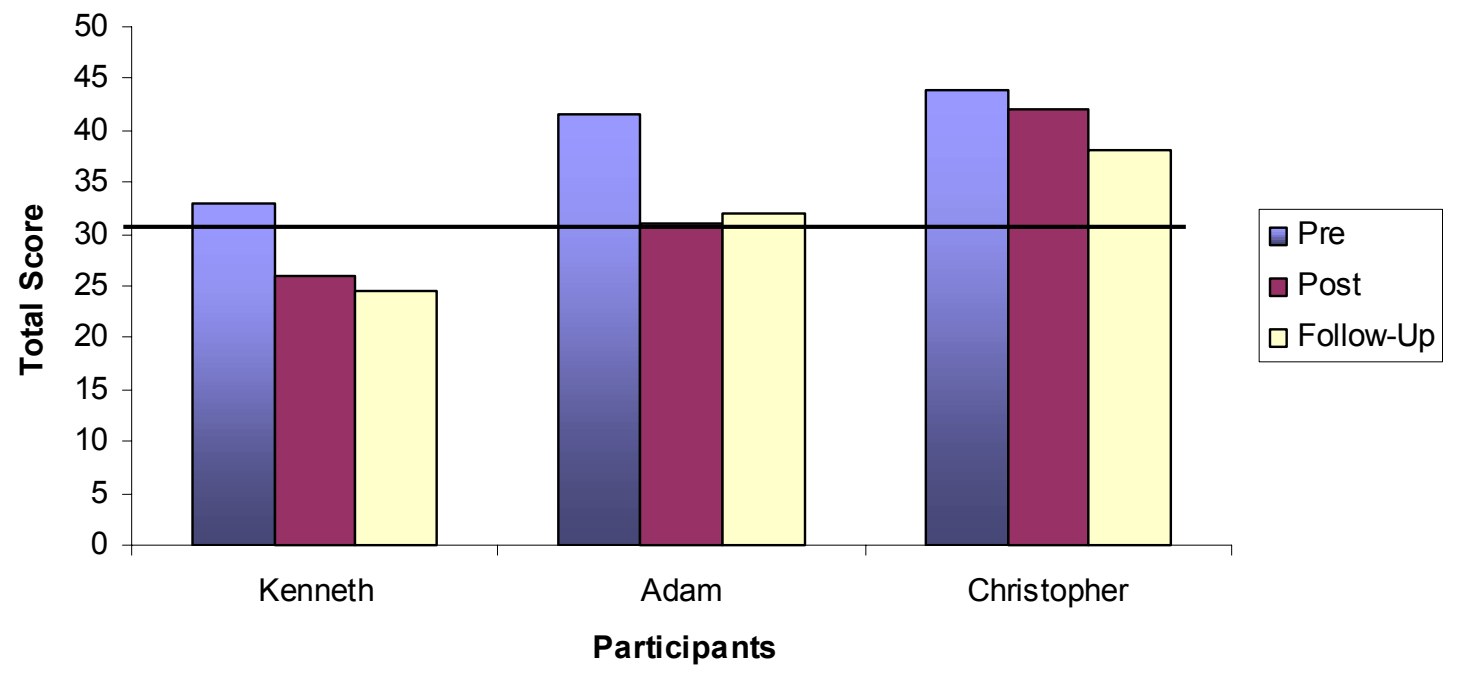

Figure 10. Childhood Autism Rating Scale total score across participants with horizontal line indicating clinical cutoff. 

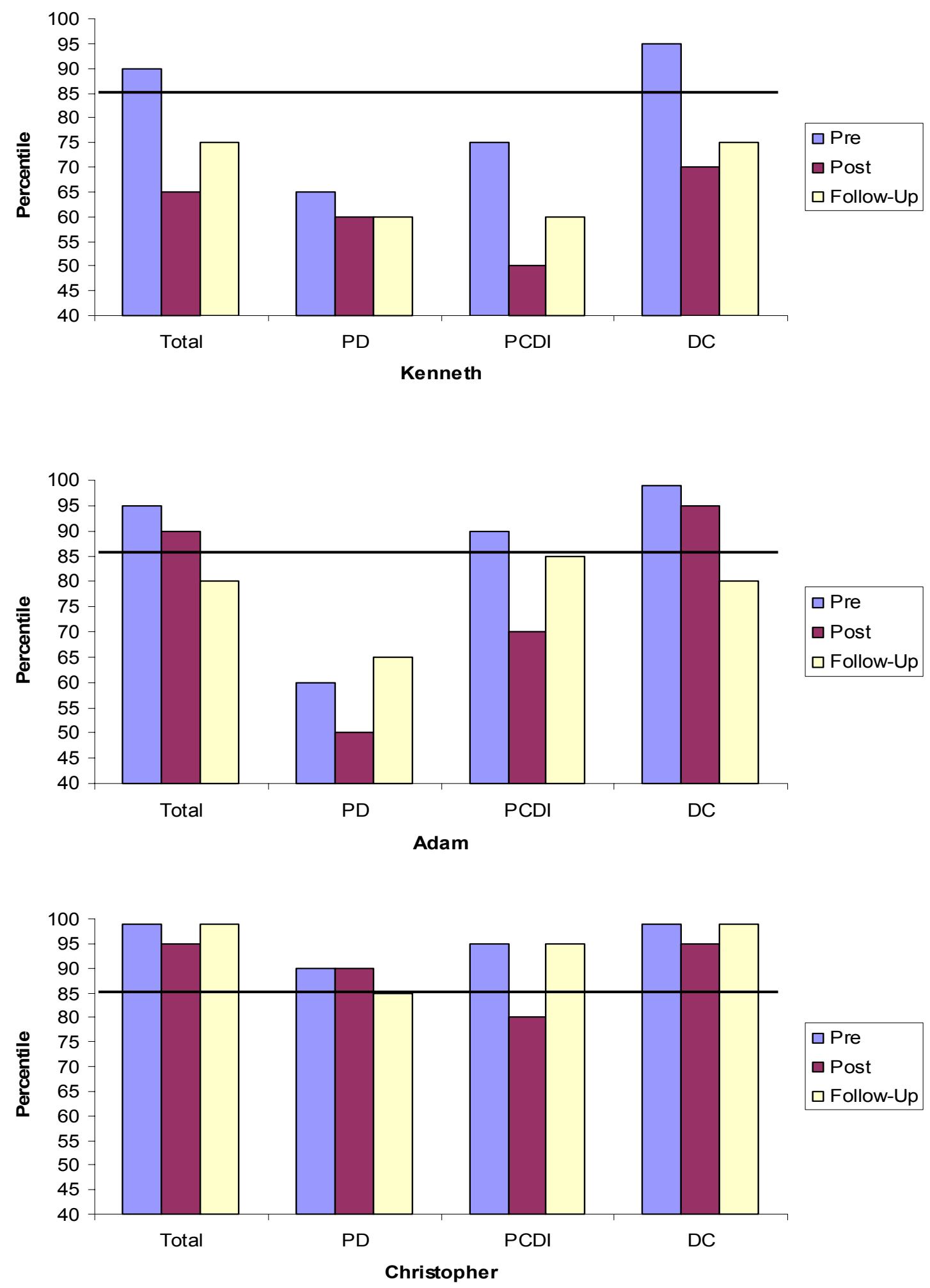

Figure 11. PSI total score and subscales scores reported by caregivers with horizontal line indicating clinical cutoff.

$*(\mathrm{PD}=$ Parental Distress, $\mathrm{PCDI}=$ Parent-Child Dysfunctional Interaction, $\mathrm{DC}=$ Difficult Child $)$ 


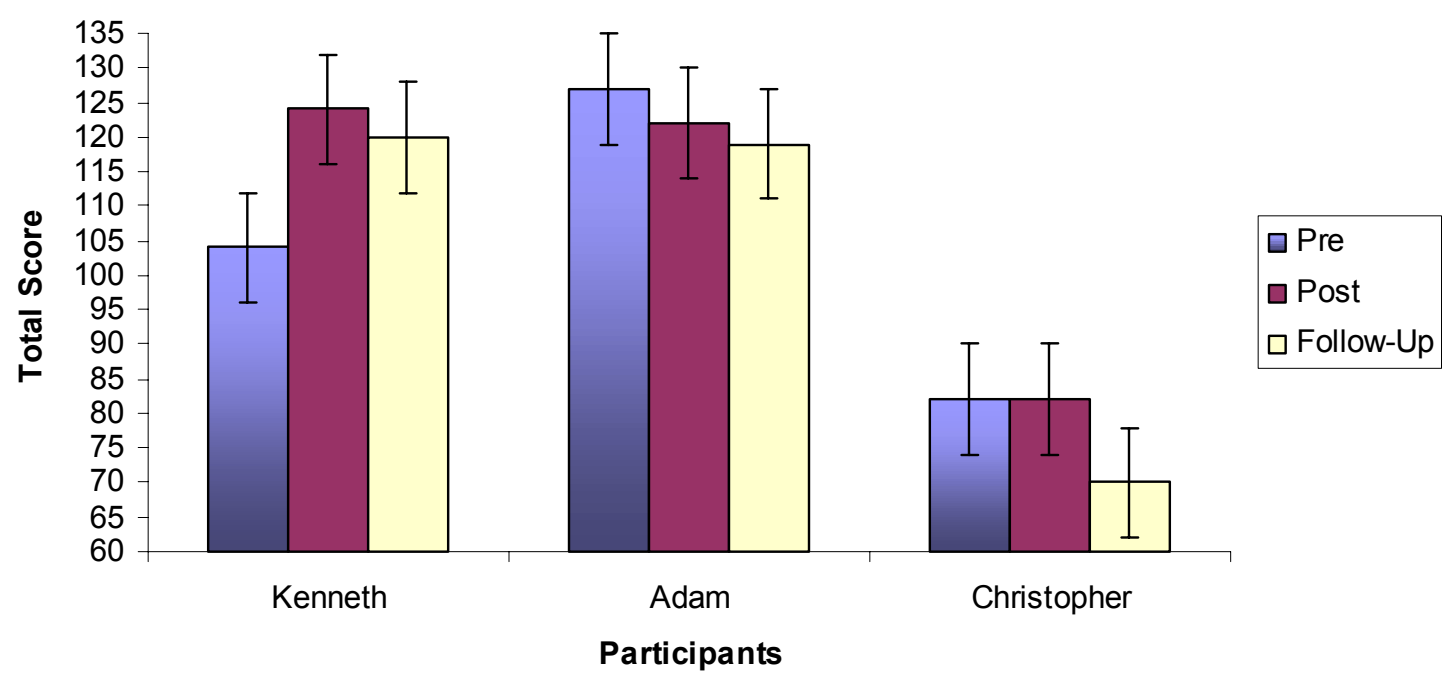

Figure 12. Peabody Picture Vocabulary Test score across participants. 

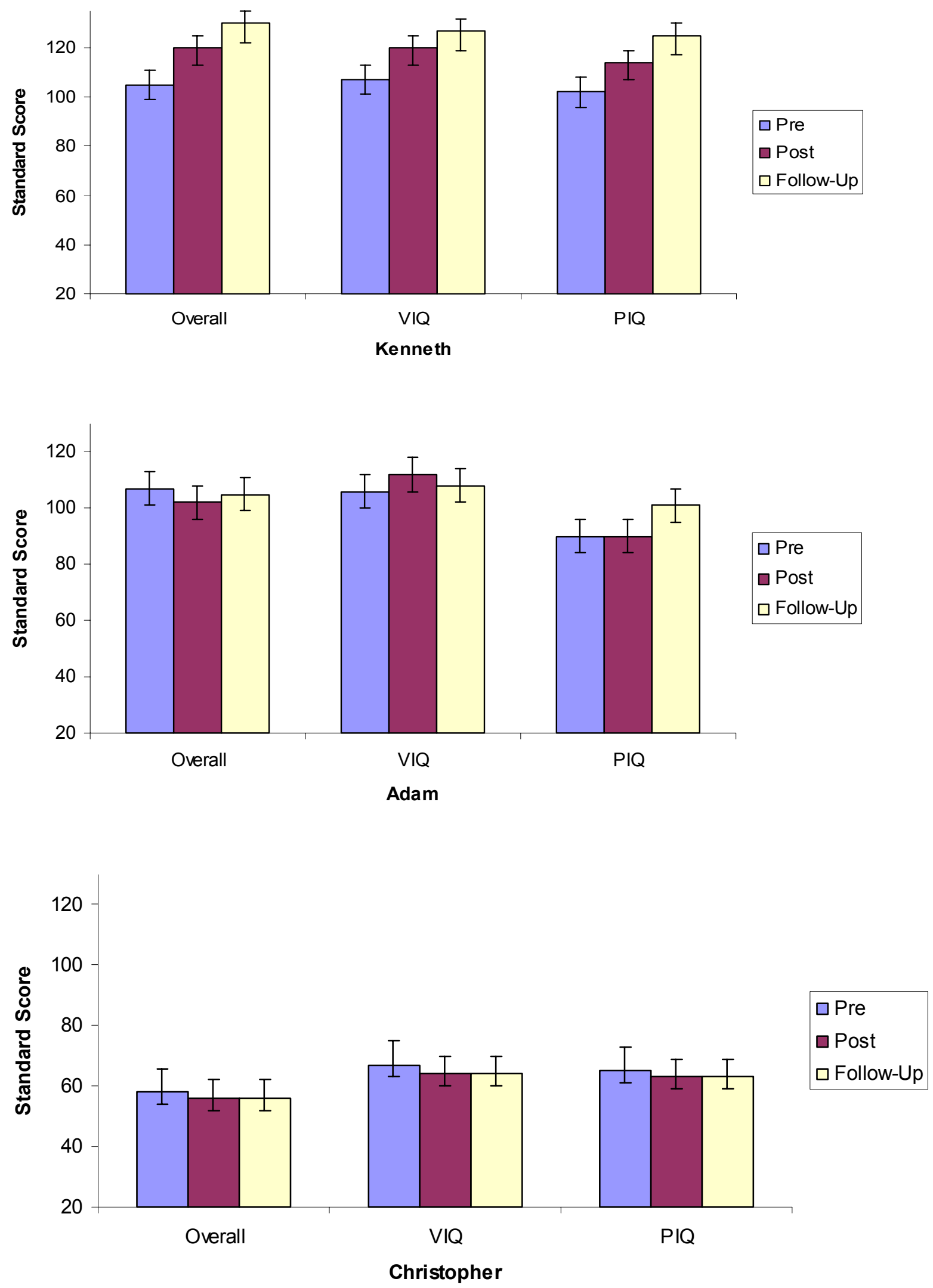

Figure 13. WPPSI overall score and subscale scores across participants. 


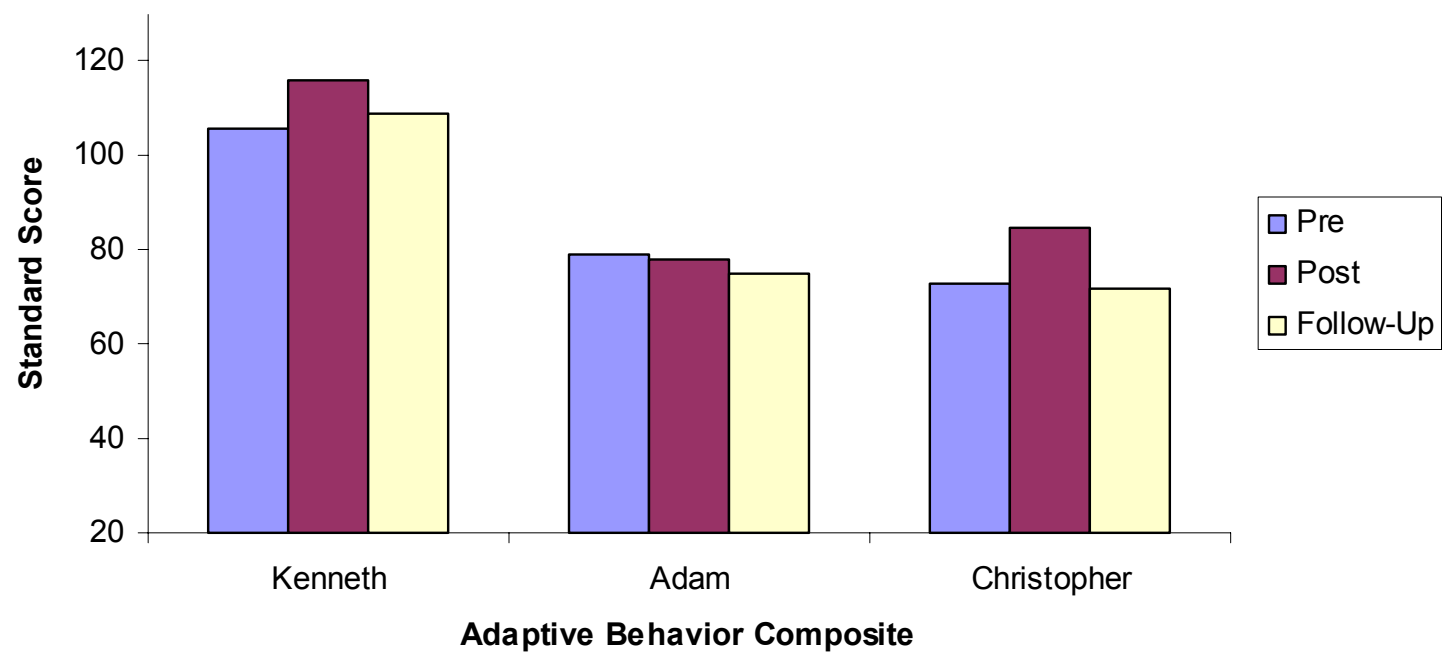

Figure 14. Vineland Adaptive Behavior Scale composite score across participants. 


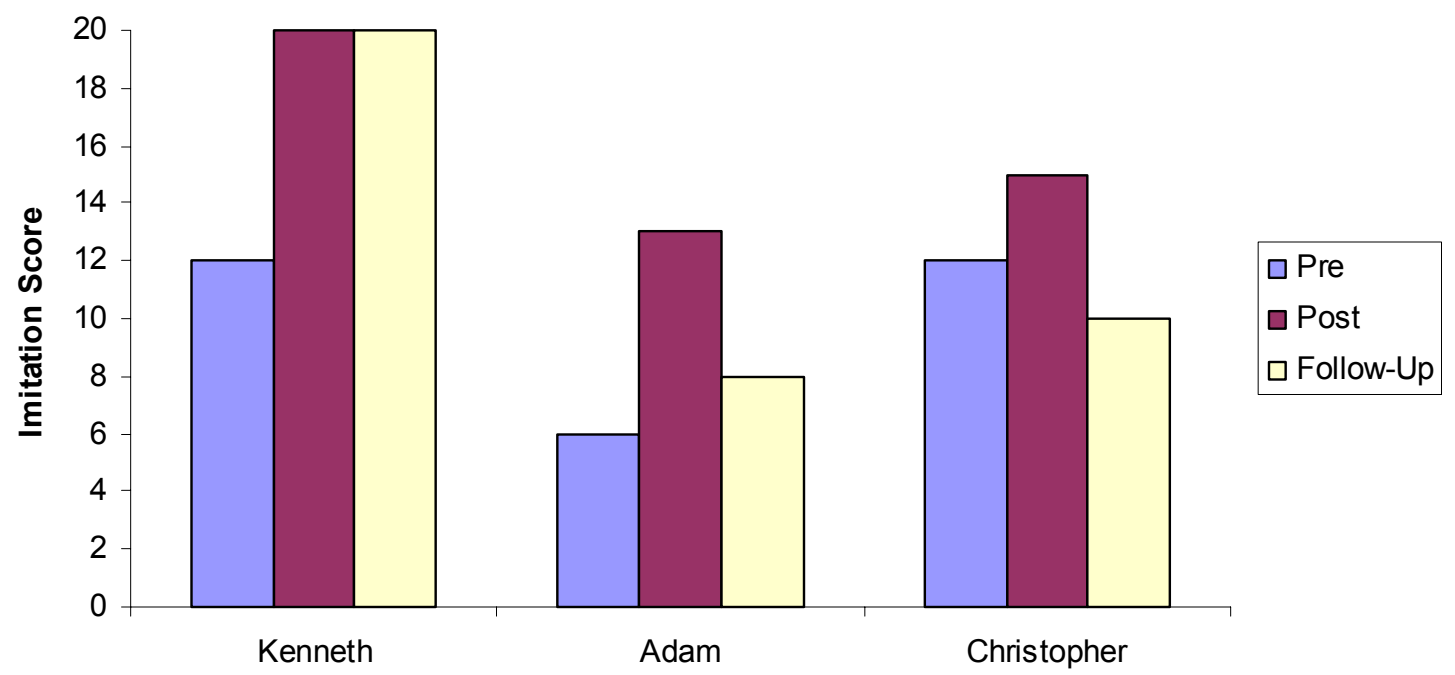

Figure 15. Imitation Task score across participants. 